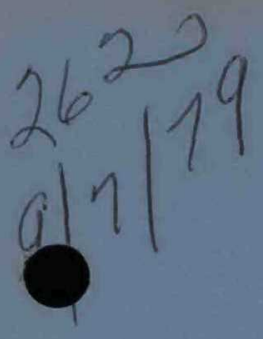

\title{
THE INFLUENCE OF HEAT TREATMENT ON THE MICROSTRUCTURE AND MECHANICAL PROPERTIES OF ALLOY 718 BASE METAL AND WELDMENTS
}

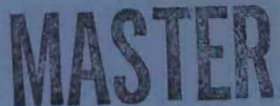

\section{Hanford Engineering Development Laboratory}




\section{DISCLAIMER}

This report was prepared as an account of work sponsored by an agency of the United States Government. Neither the United States Government nor any agency Thereof, nor any of their employees, makes any warranty, express or implied, or assumes any legal liability or responsibility for the accuracy, completeness, or usefulness of any information, apparatus, product, or process disclosed, or represents that its use would not infringe privately owned rights. Reference herein to any specific commercial product, process, or service by trade name, trademark, manufacturer, or otherwise does not necessarily constitute or imply its endorsement, recommendation, or favoring by the United States Government or any agency thereof. The views and opinions of authors expressed herein do not necessarily state or reflect those of the United States Government or any agency thereof. 


\section{DISCLAIMER}

Portions of this document may be illegible in electronic image products. Images are produced from the best available original document. 


\section{NOTICE}

This report was prepared as an account of work sponsored by the United States Government. Neither the United States nor the U.S. DOE, nor any of their employees, nor any of their contractors, subcontractors, or their employees, makes any warranty express or implied, or assumes any legal liability or responsibility for the accuracy, completeness or usefulness of any information, apparatus, product or process disclosed, or represents that its use would not infringe privately owned rights.

Printed in the United States of America

Available from

National Technical Information Service

U.S. Department of Commerce

5285 Port Royal Road

Springfield, Virginia 22161

Price: Printed Copy $\$ 6.50$; Microfiche $\$ 2.25$ 


\section{THE INFLUENCE OF HEAT TREATMENT ON THE MICROSTRUCTURE AND MECHANICAL PROPERTIES OF ALLOY 718 BASE METAL AND WELDMENTS}

\section{Hanford Engineering Development Laboratory}

W. J. Mills

June 1979

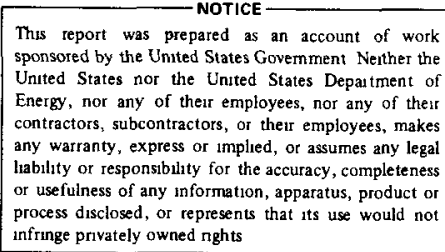

sroduct or

ifringe privately owned nghts 
-

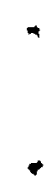


THE INFLUENCE OF HEAT TREATMENT ON THE MICROSTRUCTURE AND MECHANICAL PROPERTIES OF ALLOY 718 BASE METAL AND WELDMENTS

\author{
W. J. Mills
}

\title{
$\underline{\text { ABSTRACT }}$
}

The effect of heat treatment on the the metallurgical structure and tensile properties of three heats of Alloy 718 base metal and an Alloy 718 GTA weldment has been characterized. The two heat treatments employed were the "Conventional" (ASTM A637) precipitation treatment and a "modified" precipitation treatment designed to improve the toughness of Alloy 718 weldments. In addition, the GTA weldments were also characterized in the "as-welded" condition.

Light microscopy and thin foil and surface replica electron microscopy techniques revealed that the microstructure of this nickel-base superalloy was sensitive to heat treatment and heat-toheat variations. In general, the "modified" aging treatment resulted in a larger grain size and a more homogeneous microstructure than the "Conventional" treatments. Furthermore, the morphology of the primary strengthening $\gamma^{\prime \prime}$ phase was found to be finer and more closely spaced in the "conventionally" treated condition than in the "modified" condition.

Room temperature and elevated temperature tensile testing revealed that the strength of the "conventionally" treated Alloy 718 was generally superior to that of the "modified" material; however, the "conventional" aging treatment resulted in greater heatto-heat variations in tensile properties. This behavior was correlated with variations in the microstructure resulting from the two precipitation heat treatments.

The precipitate morphology of the Alloy 718 GTA weldments was also sensitive to heat treatment. The Laves phase was present in the interdendritic regions of both the "as-welded" and "conventionally" heat-treated welds. By contrast, the "modified" aging treatment significantly reduced the amount of Laves phase present in the weld zone. The room temperature and elevated temperature tensile properties of the precipitation hardened weldments were relatively insensitive to heat treatment, suggesting that reduction in Laves phase from the weld zone had essentially no effect on tensile properties. On the other hand, "as-welded" GTA weldments exhibited lower strength levels and higher ductility values than heat-treated ,welds. 
-

$x$

, 


\section{CONTENTS}

ABSTRACT

$\underline{\text { Page }}$

FIGURES

i i i

TABLES

vii

TABLES

$x i$

1. INTRODUCTIONS 1

1.1 OBJECTIVES AND SCOPE OF INVESTIGATION 1

1.2 ALLOY 718 METALLURGY 2

1.3 ALLOY 718 WELDMENTS METALLURGY 3

2. MATERIAL AND EXPERIMENTAL PROCEDURE 7

$\begin{array}{ll}2.1 \text { MATERIAL } & 7\end{array}$

2.2
METALLOGRAPHIC PROCEDURES

2.3 MECHANICAL PROPERTIES EVALUATION 14

3. RESULTS AND DISCUSSION - ALLOY 718 BASE METAL 17

3.1 MICROSTRUCTURE OF ALLOY 718 BASE METAL 17

3.1.1 Heat A (Heat No. 2180-1-9327) 17

3.1 .2 Heat B (Heat No. 52C9EK) 42

3.1.3 Heat $C$ (Heat No. H-673) 62

3.2 MECHANICAL PROPERTIES OF ALLOY $718 \quad 69$

4. RESULTS AND DISCUSSION - ALLOY 718 WELDMENTS 79

4.1 MICROSTRUCTURE OF ALLOY 718 WELDMENTS 79

4.2 MECHANICAL PROPERTIES OF ALLOY 718 WELDMENTS 84

$\begin{array}{ll}\text { 5. SUMMARY } & 99\end{array}$

$\begin{array}{ll}\text { REFERENCES } & 101\end{array}$

$\begin{aligned} \text { APPENDIX I - } & \text { IDENTIFICATION OF ELEMENTS CONTAINED IN THE LARGE } \\ & \text { MC-TYPE INCLUSIONS FOUND IN ALLOY } 718\end{aligned}$ 
-

. 


\section{FIGURES}

Figure $\quad$ Page

1. Tensile specimen geometry (dimensions in $\mathrm{mm}$ ). 16

2. Microstructure of Heat A. 20

3. Surface replica micrographs of Heat A given the "conventional" heat treatment.

4. Surface replica micrographs of Heat A given the "conventional" heat treatment.

5. Electron surface replica micrographs of Heat A given the "modified" precipitation treatment.

6. Thin foil micrographs of "conventionally" heat treated Alloy 718 (Heat $A$ ).

7. Thin foil micrographs of Heat A given the "conventional" heat treatment.

8. Thin foil micrographs of "modified" treated Heat $A$.

9. $\gamma^{\prime \prime}$ platelet size distribution for Heat A.

10. Microstructure of Heat B.

11. Electron micrographs of Heat B given the "conventional" treatment.

-12. Electron micrographs of Heat B. given the "modified" heat treatment.

13 Electron surface replica micrographs of the "modified" treated Heat $B$ grain boundary regions.

14. Thin foil micrographs of "conventionally" treated Alloy 718 (Heat B).

15. Thin foil micrographs of "conventionally" treated Heat B.

16. Thin foil micrographs of "modified" heat treated Alloy 718 (Heat B).

17. $\gamma^{\prime \prime}$ platelet size distribution for Heat $B$.

18. Microstructure of Heat $C$. 
FIGURES (cont'd)

$\underline{\text { Figures }}$

Page

19. Surface replica micrographs of Heat $C$ given the "conventional" heat treatment.

20. Electron surface replica micrographs of Heat $B$ given the "modified" precipitation heat treatment.

21. Surface replica micrographs of Heat $C$ given the "modified" heat treatment.

22 Effect of temperature on the tensile properties of precipitation heat treated A1loy 718 (Heat A).

23 Effect of temperature on the tensile properties of precipitation heat treated A1loy 718 (Heat B).

24. Effect of temperature on the tensile properties of precipitation heat treated A1loy 718 (Heat C).

25. Microstructure of the "as-welded" Alloy 718 GTA weldment.

26. Microstructure of the "conventional1y" treated A1loy 718 GTA we 1 dment.

27. Micrograph of "conventionally" heat treated A1loy 718

revealing that the Laves phase had completely transformed into needles.

28. Microstructure of the "modified" treated Alloy 718 GTA we 1 dment.

29. Effect of temperature on the yield strength of All oy 718 GTA we Idments.

30. Effect of temperature on the ultimate strength of Alloy 718 GTA we 1 dments.

31. Effect of temperature on the un if orm elongation of Alloy 718 GTA we ldments.

32. Effect of temperature on the reduction in area of Alloy 718 GTA we ldments.

33. Typical metallographic fracture profile of the "as-welded" A11 oy 718 GTA we ldment.

34. Typical metallographic fracture profile of the

"conventiona11y" heat treated Alloy 718 GTA weldment. 


\section{FIGURES (cont'd)}

Figures

Page

35. Typical metallographic fracture profile of the "modified" heat treated Alloy 718 GTA weldment.

A-1. "Conventionally" precipitation treated Heat $A$.

$A-2$

A-2. "Modified" precipitation treated Heat A.

$A-4$

A-3. "Conventionally" precipitation treated Heat C.

A-6 
•

7.

$\bullet$ 


\section{TABLES}

Table

I. Identification of Alloy 718 Heats 8

II. Chemical Composition (Percent By Weight). 9

III. Precipitation Heat Treatments for Alloy $718 \quad 10$

$\begin{array}{ll}\text { IV. Welding Procedures } & 11\end{array}$

V. List of Etchants 15

VI. Effect of Heat Treatment on the Grain Size of Precipitation
Heat Treated Alloy 718

VII. Y"Platelet Size $\quad 41$

VIII. Sumary of Mechanical Properties for Precipitation
Strengthened Alloy 718

IX. Summary of Diamond Pyramid Hardness Values for Precipitation
Strengthened Alloy 718

X. Sumary of Mechanical Properties of Alloy 718 Weldments 85

XI. Effect of Aging on the Room Temperature Hardness of As-Welded A1l oy 718 GTA Weldments 
THE INFLUENCE OF HEAT TREATMENT ON THE MICROSTRUCTURE AND MECHANICAL PROPERTIES OF ALLOY 718 BASE METAL AND WELDMENTS (FF125)

\section{INTRODUCTION}

\subsection{OBJECTIVES AND SCOPE OF INVESTIGATION}

Alloy $718^{*}$ is a high strength nickel-base superalloy that possesses excellent corrosion and oxidation resistance coupled with good tensile and creep properties at elevated temperatures. In addition, Alloy 718 exhibits excellent weldability in contrast to most nickel-base superalloys. As a result, Alloy 718 base metal and weldments have been employed in heat-res istant structural components in the nuclear industry.

Alloy 718 base metal and weldments are metallurgically complex, involving precipitation of several phases. Consequently, the precipitation reactions and mechanical properties of this superalloy and its weld can be altered significantly by heat treatment and heat-to-heat variation. This investigation was undertaken to characterize the effect of heat treatment and heatto-heat variations on the metallurgical structure and mechanical properties of Alloy 718 base metal and weldments.

This superalloy is generally used in the "conventional" heat treated condition (per ASTM A637); however, th is precipitation heat treatment results in poor toughness properties in Alloy 718 weldments. To improve toughness reponse with in the weld zone, a "modified" heat treatment was developed by Idaho National Engineering Laboratory. Both heat treatments were examined in th is study. The materials characterized herein are from the same heats of Alloy 718 being studied in a comparison fatigue and fracture program underway at HEDL. This investigation was designed to complement that work.

\footnotetext{
* The general specifications for this material may be found in ASME specification SA-637 Grade 718 for bar and forgings, and in SAE Specifications AMS-5596 and AMS-5597 for sheet, strip and plate.
} 


\subsection{ALLOY 718 METALLURGY}

Alloy 718 is a versatile precipitation-hardenable nickel-base superalloy developed for use at temperatures up to $700^{\circ} \mathrm{C}(1)$. It is employed in structural applications in the nuclear, aerospace, and petrochemical industr ies where high strength, creep res istance, and corrosion res is tance at elevated temperatures are important design considerations. Alloy 718 is also un ique in comparison to other nickel-base superalloys since it has excellent weldability, which is apparently associated with its sluggish precipitation kinetics.

The physical metallurgy of Alloy 718 was investigated previously in a number of studies $(1-10)$. These investigations revealed that Alloy 718,1 ike most nickel-base superalloys, is metallurgically complex, involving precipitation of several phases. On the other hand, the precipitation processes in Alloy 718 differ from those of most nickel-base alloys since Alloy 718 contains approximately 5 weight percent niobium. This high niobium content results in the formation of a coherent body-centered-tetragonal (bct) $\mathrm{Ni}_{3} \mathrm{Nb}$ precipitate ${ }^{(2-6)}$ referred to as gamma double prime $\left(\gamma^{\prime \prime}\right)$. The metastable $\gamma^{\prime \prime}$ phase, which forms as an ellipsoidal, disc-shaped particle lying on the $100 \mathrm{plane}^{(2)}$, is the principal source of strength ${ }^{(5,7)}$ in this exceptionally high-strength nickel-base superalloy. In addition to the $r$ " particles, a coherent face-centered-cubic ( $\mathrm{fCC}) \mathrm{Ni}_{3}(\mathrm{~A}, \mathrm{Ti})$ precipitate ${ }^{(2)}$ termed gamma prime $\left(\gamma^{\prime}\right)$ also forms, but in smaller quantities than the $\gamma^{\prime \prime}$ phase.

Alloy 718 is also susceptible to the formation of Widmanstätten $\delta$ phase, an ordered or thorhomb ic $\mathrm{Ni}_{3} \mathrm{Nb}$ precipitate, during process ing or heat treatment. In addition, the metastable $\gamma$ " phase can transform into the equilibrium $\delta$ phase upon prolonged exposure to elevated temperatures. These platelike $\delta$ particles are much less effective strengtheners than the finer $\gamma^{\prime \prime}$; hence, formation of excessive $\delta$ can reduce the strength of Alloy 718 by consuming a significant amount of $\mathrm{Nb}$. By contrast, a limited amount of globular $\delta$ along the grain boundary can optimize the stress-rupture ductility, since the presence of grain boundary particles impedes long-range grain boundary sliding. 
Carbides also represent an important class of phases present in Alloy 718 . Primary MC-type carbides form during solidification as coarse, irregular particles and their morphology remains unchanged during subsequent forging and heat treating operations. MC carbide films can also form along grain boundaries; however, such films should be avoided since they can result in severe embrittlement of the alloy. On the other $h$ and, the presense of globular or blocky grain boundary carbides is generally associated with good ductility as they tend to restrict grain boundary sliding.

Heat-resistant superalloys such as Alloy 718 are also prone to the formation of minor phases with abnormally short interatomic spacings, which have been termed topologically-close-packed (TCP) or $A_{2} B$ type precipitates. The TCP precipitates include $\sigma, \mu, X$ and Laves phases. Since these minor phases act as sources for localized crack initiation, they are detrimental to the rupture strength and ductility properties of Alloy 718 and should therefore be avoided through proper chemistry control and adequate hot working.

In summary, the large number of phases present in Alloy 718 make the physical nature of this nickel-base superalloy very complex. This situation is further complicated because this material is microstructurally dynamic at high temperatures (i.e., the phases are not stable). Consequently, the phases present and the resulting mechanical properties of the alloy are strongly influenced by heat treatment, processing history, melt practice, alloying variations, and other factors.

\subsection{ALLOY 718 WELDMENTS METALLURGY}

Most precipitation hardenable nickel-base alloys are susceptible to weldassociated cracking problems. Strain-age cracks tend to develop in heat affected zones during the initial heat treatment after the welding process $(13,14)$. These cracks result from very rapid formation of the primary strengthening $\gamma^{\prime}$ phase found in most nickel-base superalloys; hence, the heat affected zone is strengthened prematurely, thereby inh ib iting relaxation of residual stresses in the component. This strengthening of the 
matrix shifts the burden of stress relief to the grain boundary regions, which then results in intergranular fracture or strain-age cracking.

Alloy 718 is unique among nickel-base superalloys because of its superior weldability and resistance to strain-age cracking while maintaining high strength. The outstanding weldability characteristics of Alloy 718 are believed to be associated with the sluggish precipitation kinetics of the primary strengthening $\gamma^{\prime \prime}$ phase $(13,15)$. The sluggish age hardening response yields a relatively low-strength, high-ductility heat affected zone during the initial aging period. This permits additional relocation of residual stresses, thereby improving the post-weld strain-age cracking res istance of Alloy 718. Although the weldability characteristics of th is superalloy are very attractive, a number of problems in welding Alloy 718 have been reported by Gordine ${ }^{(16)}$ : poor root penetration, microfissuring in the heat-affected zone, and inferior impact and ductility properties in the weld fusion zone. These problems can be solved, however, by adequate control of welding parameters and selection of proper solution heat treatments ${ }^{(16)}$.

Poor root penetration during welding, a problem with most nickel-base alloys, is due to the poor fluidity of the molten metal. Gordine ${ }^{(16)}$ studied the effect of numerous welding parameters on the root penetration of Alloy 718 and found that variations in shielding gas and weld joint geometry could improve penetration. A helium shielding gas was found to be superior to argon due to helium's higher ionization potential, which produces a hotter arc. In addition, a U-groove geometry was found to yield better root penetration than a $V$-groove geometry since the former design concentrates the molten puddle at the bottom of the groove. However, the U-groove geometry has two significant drawbacks: (1) it is expensive to machine, and (2) since the walls of the U-groove are nearly vertical, the weld bead may not fuse in to the base plate.

The second problem associated with Alloy 718 welds is microfissuring, associated with the formation of fine cracks approximately 1 to 2 grains in length along partially melted grain boundaries of the parent metal in close 
proximity to the fusion zone. The extent of microfissuring has been found to be a function of prior solution treatment temperature ${ }^{(16)}$, weld heat input (16), grain size ${ }^{(13-17)}$ and type of trace elements present (17). Gordine ${ }^{(16)}$ reported that base material subjected to solution treatment temperatures above $1038^{\circ} \mathrm{C}$ prior to welding was susceptible to microfissuring, whereas material annealed below th is temperature exhibited no microfissuring. A low weld heat input and a coarse-grained microstucture (gra in size coarser than ASTM No. 2) were also found to increase the susceptibility of A1loy 718 to microfissuring. In addition, Morrison, et al., (17) reported that increased amounts of magnesium, manganese, and silicon enhanced the microfissure res istance of this superalloy, whereas additions of $r$ are earths, which are. beneficial to iron-base alloy weldability, resulted in the formation of numerous weld-associated fissures. It should be recognized, however, that low concentrations of microfissures have been found to cause only relatively small degradation in the tensile properties of Alloy 718.

Perhaps the most severe problem associated with Alloy 718 weldments is the poor ductility and toughness properties in the weld fusion zone. This reduced ductility is believed to be associated with the presence of Laves phase in the interdendritic regions of the weld metal. The "conventional" heat treatment for Alloy 718 (solution anneal temperature of $954^{\circ} \mathrm{C}$ ) does not dissolve the Laves phase in the weld zone; hence the ductility is dramatically reduced. On the other hand, Gordine ${ }^{(16)}$ found that solution treating at temperatures above $1066^{\circ} \mathrm{C}$ resulted in the dissolution of Laves phase coinciding with a substantial improvement in ductility and impact toughness. Unfortunately, al though the higher temperature solution anneal dramatically enhances the ductility of the Alloy 718 weld, it also tends to reduce the strength of the parent metal.

The low weld ductility contributed to a series of failures in postweld heat treated Alloy 718 weldments. For example, problems were encountered at Aerojet Nuclear Company in qualification testing of Alloy 718 welds for the Power Burst Facility in-pile tube, a cylindrical pressure vessel ${ }^{(18)}$. Localized regions with in the welds were embrittled by the presence of Laves 
phase and failed prematurely during bend testing. To solve this problem, welds were given a higher localized solution anneal $\left(1107^{\circ} \mathrm{C}\right)$, after which the entire assembly was given a standard solution anneal followed by a $42-$ hour duplex age in order to restore adequate strength in the parent metal.

An additional series of problems concerning Alloy 718 welds were encountered during fabrication of Power Burst Facility acoustic filter units $(19,20)$. In this case, cracks developed in welded components during the duplex age. The cause of failure was found to be a combination of thermal stresses quenched in to the component following the solution anneal, coupled with the low ductility of the welds. To overcome this problem without degrading the base metal strength, a "modified" heat treatment was developed utilizing a $1093^{\circ} \mathrm{C}$ solution anneal followed by a slow cool (approximately $55^{\circ} \mathrm{C} / \mathrm{hr}$ ) instead of the conventional air cool. The slower cooling rate tends to reduce thermal stresses, while the higher temperature anneal dissolves the Laves phase, thereby restoring adequate toughness in the weldments $(20,21)$. 


\section{MATERIAL AND EXPERIMENTAL PROCEDURE}

\subsection{MATERIAL}

The three heats of Alloy 718 utilized in this investigation are described in Tables I and II. Three different melt practices are represented: the vacuum-induction-melting, electro-flux remelting process* (VIM-EFR), the vacuum-induction-melting, electro-slag-remelting process* (VIM-ESR), and the vacuum-induction melting, vacuum-arc-remelting process (VIM-VAR). Product forms include $1.27-\mathrm{cm}$ thick plate and $1.59-\mathrm{cm}$ thick rectangular bar stock.

Each heat of Alloy 718 was given two heat treatments: the "conventional" heat treatment (per ASTM A637) and a "modified" heat treatment developed by Idaho National Engineering Laboratory $(20)$ to improve the toughness of Alloy 718 base metal and weldments. The steps involved in these heat treatments are listed in Table III.

Alloy 718 weldments studied in the investigation were produced by an automatic gas tungsten-arc welding process (GTAW) using rectangular bar stock (Heat $C$ ) as the parent metal. The composition of the weld filler wire is given in Table II. All weldments were of the U-groove geometry design for better weld penetration. The procedures used to weld the Alloy 718 are outlined in Table IV. The GTAW welds were examined and tested in both heat treatment conditions in addition to the "as-welded" condition.

\subsection{METALLOGRAPHIC PROCEDURES}

Light microscopy as well as thin foil and surface replica transmission electron microscopy techniques were used to characterize the effect of

The vacuum-induction-melting, electro-slag-remelting process (VIM-ESR) is essentially the same as the vacuum-induction-melting electro-flux-remelting process (VIM-EFR). 
TABLE I

IDENTIFICATION OF ALLOY 718 HEATS

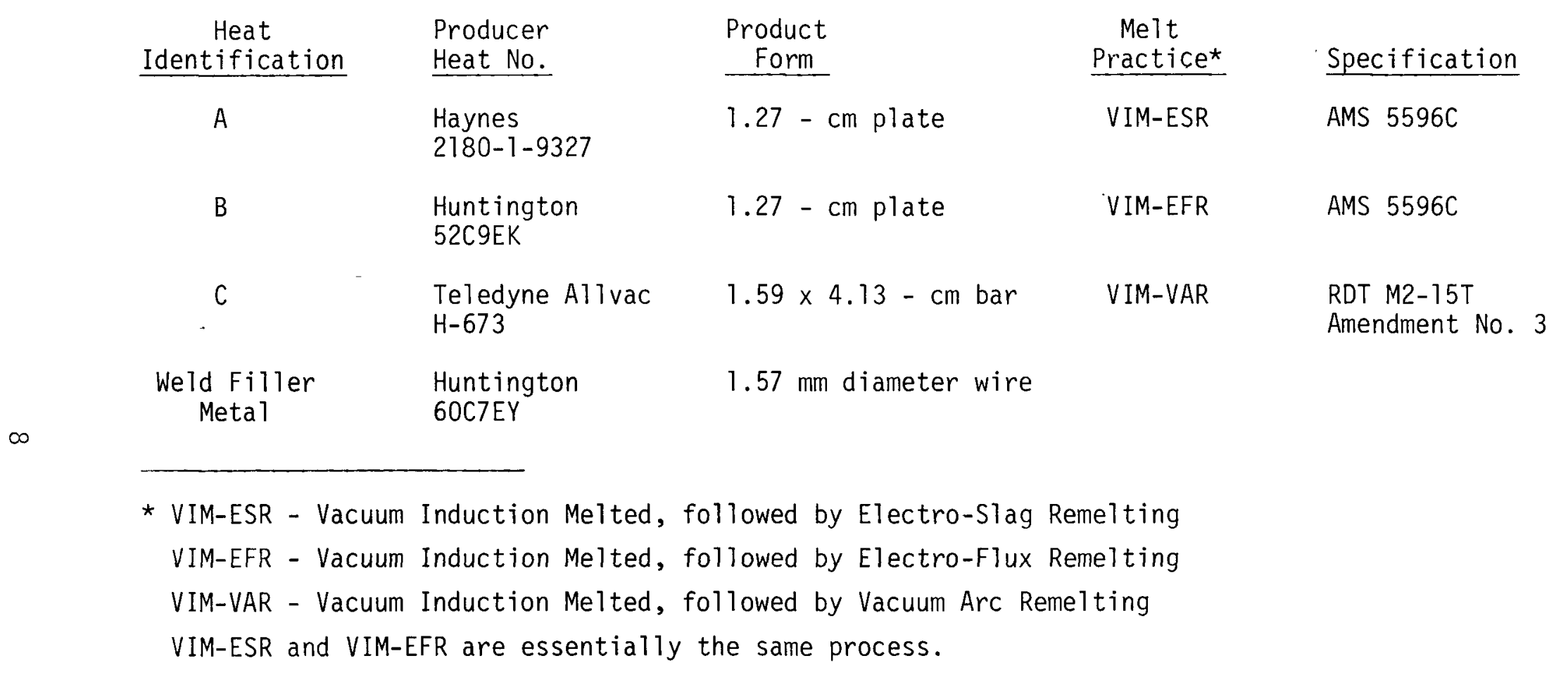


TABLE II

CHEMICAL COMPOSITION (Percent By Weight)

\begin{tabular}{|c|c|c|c|c|c|c|c|c|c|c|c|c|c|c|c|c|c|}
\hline Ident. & $\underline{C}$ & $\underline{M n}$ & $\mathrm{Fe}$ & $\underline{S}$ & $\underline{\mathrm{Si}}$ & $\underline{\mathrm{Cu}}$ & $\underline{\mathrm{Ni}}$ & $\underline{\mathrm{Cr}}$ & Al & $\underline{\mathrm{Ti}}$ & Co & $\underline{P}$ & $\underline{\text { Mo }}$ & $\underline{B}$ & $\mathrm{CB} \& \mathrm{Ta}$ & $\underline{\mathrm{Cb}}$ & Ta \\
\hline A & .04 & .08 & Bal. & $<.005$ & .07 & .02 & 51.60 & 18.30 & .52 & 1.01 & .12 & $<.005$ & 3.10 & .004 & 5.26 & * & * \\
\hline B & .07 & .08 & 18.19 & .007 & .17 & .11 & 53.44 & 18.11 & .49 & 1.08 & .03 & * & 3.00 & * & 5.10 & * & * \\
\hline C & .04 & .19 & Bal. & .002 & .10 & $<.01$ & 53.80 & 17.65 & .56 & 1.00 & .02 & .003 & 3.08 & .005 & 5.26 & 5.24 & .02 \\
\hline $\begin{array}{l}\text { Weld } \\
\text { Filler } \\
\text { Metal }\end{array}$ & .04 & .09 & 17.97 & .007 & .18 & .10 & 53.84 & 18.04 & .55 & 1.01 & .03 & .010 & 3.00 & .004 & 5.12 & 5.11 & .01 \\
\hline
\end{tabular}


"Conventiona1" Heat Treatment

Annealed at $954^{\circ} \mathrm{C}+8^{\circ} \mathrm{C}$, air cooled to room temperature

Aged 8 hours at $718^{\circ} \mathrm{C}+8^{\circ} \mathrm{C}$, furnace cooled to $621^{\circ} \mathrm{C}$ $+8^{\circ} \mathrm{C}$ and held at $621^{\circ} \mathrm{C}$ for a total aging time of 18 hours.

Air cooled to room temperature.

"Modified" Heat Treatment (developed by Idaho National

Engineering Laboratory)

Solution annealed 1 hour at $1093^{\circ} \mathrm{C} \pm 8^{\circ} \mathrm{C}$, cooled to $718^{\circ} \mathrm{C}$ $\pm 8^{\circ} \mathrm{C}$ at $55^{\circ} \mathrm{C} /$ hour $\pm 28^{\circ} \mathrm{C} /$ hour .

Aged 4 hours at $718^{\circ} \mathrm{C}$, cooled to $621^{\circ} \mathrm{C} \pm 8^{\circ} \mathrm{C}$ at $55^{\circ} \mathrm{C} /$ hour $\pm 28^{\circ} \mathrm{C} /$ hour .

Aged 16 hours at $621^{\circ} \mathrm{C}$, air cooled to room temperature. 


\section{TABLE IV}

\section{WELDING PROCEDURES}

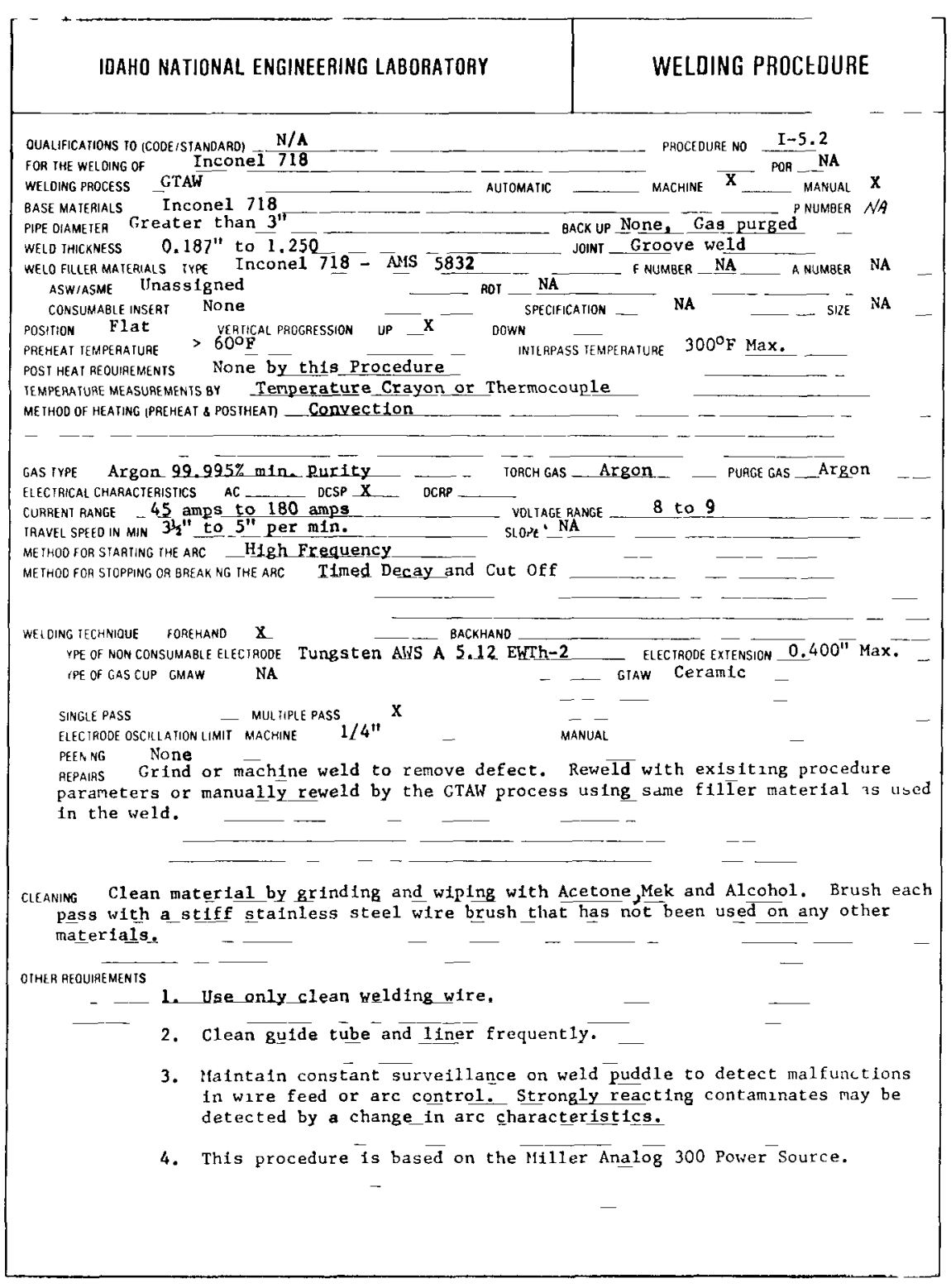


TABLE IV (Continued)

WELDING PROCEDURES

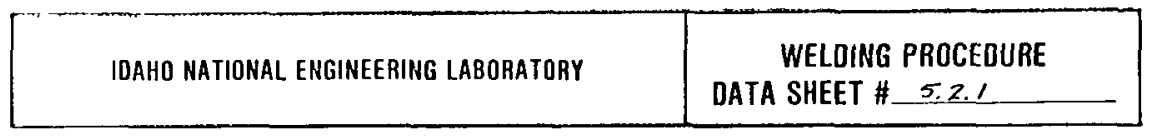

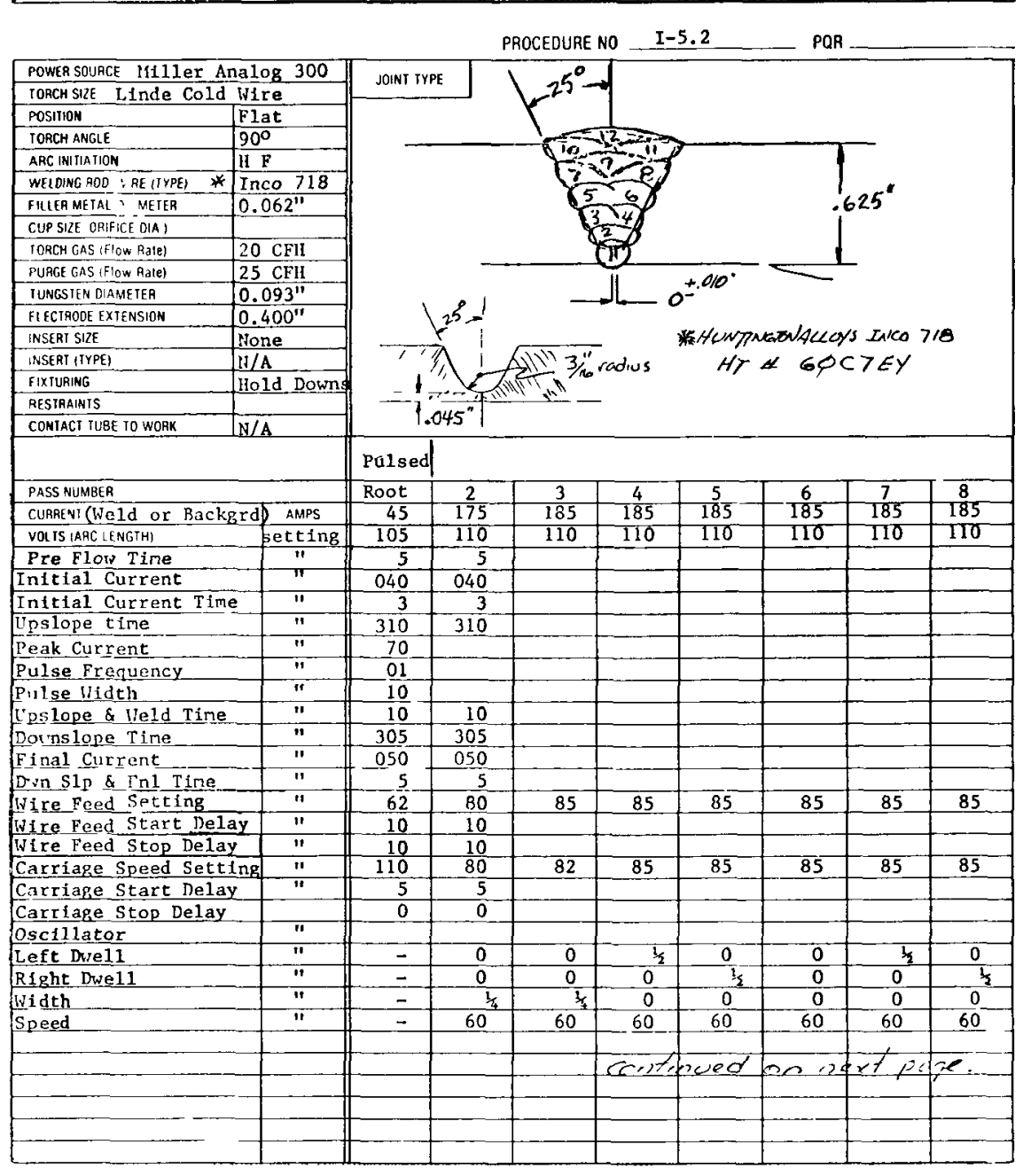


TABLE IV (Continued)

WELDING PROCEDURES

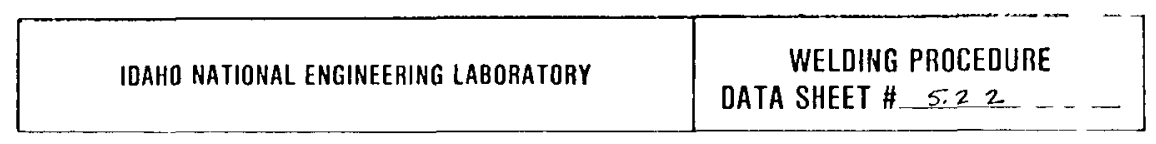

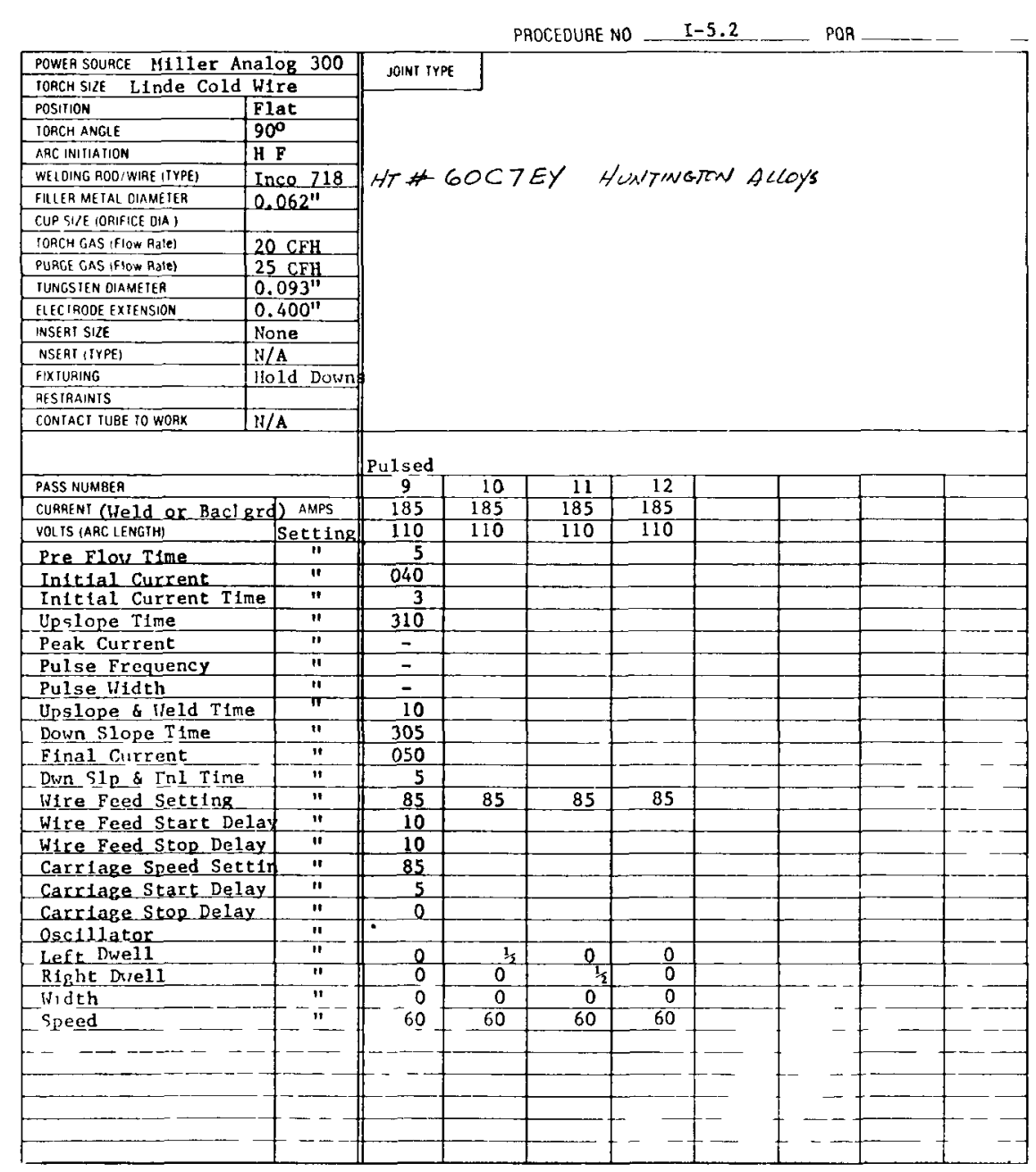


heat treatment on the microstructure of A1loy 718 base metal and weldments. Metallographic specimens were prepared for optical microscopic examination by standard metallographic procedures. Etchants used to reveal the general microstructure of the base metal and welds are listed in Table $V$.

Surface replicas and thin foils were prepared for transmission electron microscopy in order to examine the precipitate morphology of heat treated Alloy 718 in more detail. Standard two-stage surface replicas with Pt-Pd-C shadowing material were made from metallographic specimens that were mechanically polished and immersion-etched in Tucker's reagent (etchant No. 3 in Table V). Thin foils were prepared from thin wafers of the heat treated material to characterize the effect of that treatment on the morphology of the _" primary strengthening phase. Disks $3 \mathrm{~mm}$ in diameter were punched from these wafers. These disks were then thinned on a Fischione twin jet electropolisher until small holes appeared within the disk. Both thin foils and surface replicas were examined on a Philips EM200 electron microscope equipped with a double tilting goniometer stage.

\subsection{MECHANICAL PROPERTIES EVALUATION}

Tensile tests were performed on miniature buttonhead tensile specimens (Figure 1) fabricated with the specimen axis parallel to the longitudinal forming direction (or welding direction). The gage length of specimens taken from the Alloy 718 GTA weldment contained only weld metal. Tests were performed on an Instron Tensile Machine at a nominal strain rate of $1.78 \times 10^{-3} \mathrm{~min}^{-1}$ at temperatures ranging from room temperature to $649 \mathrm{C}$.

To investigate the effect of heat treatment on the mechanical response of selected microstructural features within the Alloy 718 base metal and weldment, micro-hardness testing was performed on polished samples. Diamond Pyramid Hardness numbers were obtained from each sample on a Tukon MicroHardness Tester by employing a 136 Diamond Pyramid Indenter and a 500-gram 
TABLE $V$

LIST OF ETCHANTS

Etchant 1 (for 1ight microscopy of Alloy 718 base metal)

Immersion etched in: $\quad 92-\mathrm{ml}$ hydrochloric acid ( $\mathrm{HCl}$ )

3-ml nitric acid $\left(\mathrm{HNO}_{3}\right)$

$5-\mathrm{ml}$ sulfuric acid $\left(\mathrm{H}_{2}^{3} \mathrm{SO}_{4}\right)$

Rinsed in:

90-m1 nitric acid $\left(\mathrm{HNO}_{3}\right)$

45-drops hydrofluoric acid (HF)

Etchant 2 (for light microscopy of Alloy 718 weldments)

Electrolytically etched in a $10 \%$

10-g oxalic acid

oxalic acid solution:

$100-\mathrm{ml}$ water

Etchant 3 (for surface replicas of Alloy 718 base metal)

Immersion etched in Tucker's reagent: 45-ml hydrochloric acid ( $\mathrm{HCl}$ )

15-mi nitric acid $\left(\mathrm{HNO}_{3}\right)$

15-ml hydrofluoric acid (HF)

25-ml water 


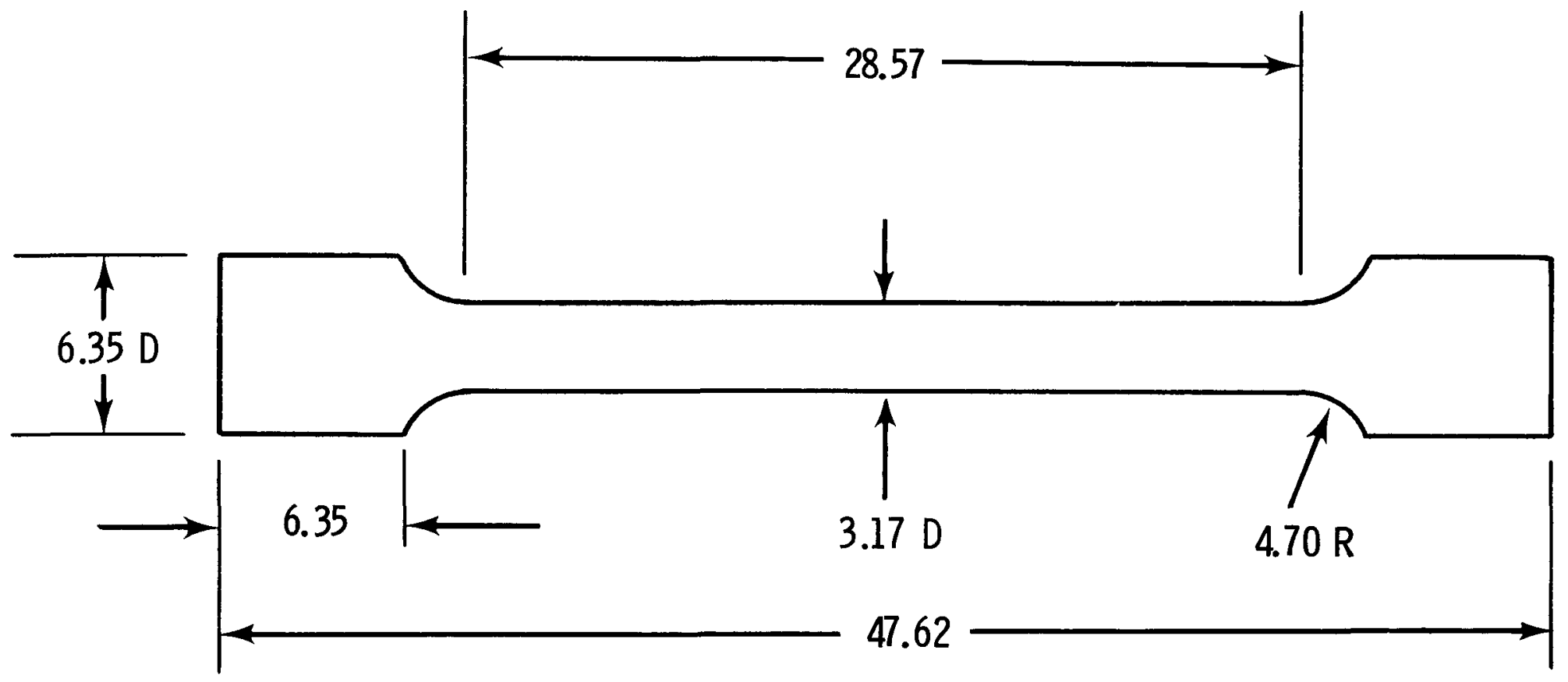

Figure 1. Tensile specimen geometry (dimensions in $\mathrm{mm}$ ). 
load in accordance with ASTM Specification E384-73(22). Both diagonals of each identation were measured, averaged, and substituted into the following equation to yield the Diamond Pyramid Hardness:

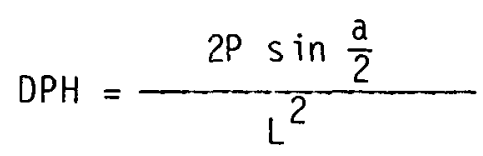

where $D P H=$ Diamond Pyramid Hardness

$$
\begin{aligned}
& P=\text { applied load, } \mathrm{kg} \\
& L=\text { average length of diagonals, mm } \\
& a=136^{\circ} \text { apex angle }
\end{aligned}
$$

Reported DPH values represent an average of three microhardness determinations.

Rockwell C hardness tests were performed on 1/2-inch thick transverse sections of Alloy 718 GTA weldments. Hardness values reported herein were averaged from nine hardness determinations. 
• 


\section{RESULTS AND DISCUSSION - ALLOY 718 BASE METAL}

\subsection{MICROSTRUCTURE OF ALLOY 718 BASE METAL}

\section{1 .1 Heat A (Heat No. 2180-1-9327)}

The microstructure of Alloy 718 was found to be very dependent on heat treatment. Typical microstructures for Heat A given the "conventional" and "modified" heat treatments are illustrated in Figures $2 \mathrm{a}$ and $2 \mathrm{~b}$, respectively. It is immediately obvious from these figures that the "modified" treatment resulted in a larger grain size; the "conventionally" treated Alloy 718 had an ASTM grain size of 8-1/2, whereas material given the "modified" heat treatment had a grain size of 2-1/2 (Table VI). It is apparent, therefore, that considerable grain growth occurred during the higher temperature solution anneal employed in the "modified" heat treatment. Figure 2 also illustrates numerous annealing twins and coarse MC-type carbide particles with in the grain interiors regardless of heat treatment. The large carbide inclusions have been identified by electron microprobe analys is as ( $\mathrm{Nb}, \mathrm{Ti}) \mathrm{C}$ (see Appendix I).

The "conventional" material also exhibited a duplex microstructure (Figure 2a) with light-etching regions preferentially oriented in the rolling direction. These elongated regionr, which contained slightly larger grains in comparison to those observed in the surrounding matrix, could have resulted from abnormal grain growth ${ }^{(23)}$, where some larger grains tend to grow rapidly by consuming smaller ones. This abnormal growth behavior $h$ as been reported in other nickel-base alloys (24-26).

Surface replication of the "conventionally" treated material revealed the presence of a coarse lenticular $\delta$ phase network coupled with a few MC carbides along grain boundaries (Figure 3 ). The $\delta$ precifitates initiated at the grain boundary and grew into the grain interior. Inside the elongated 


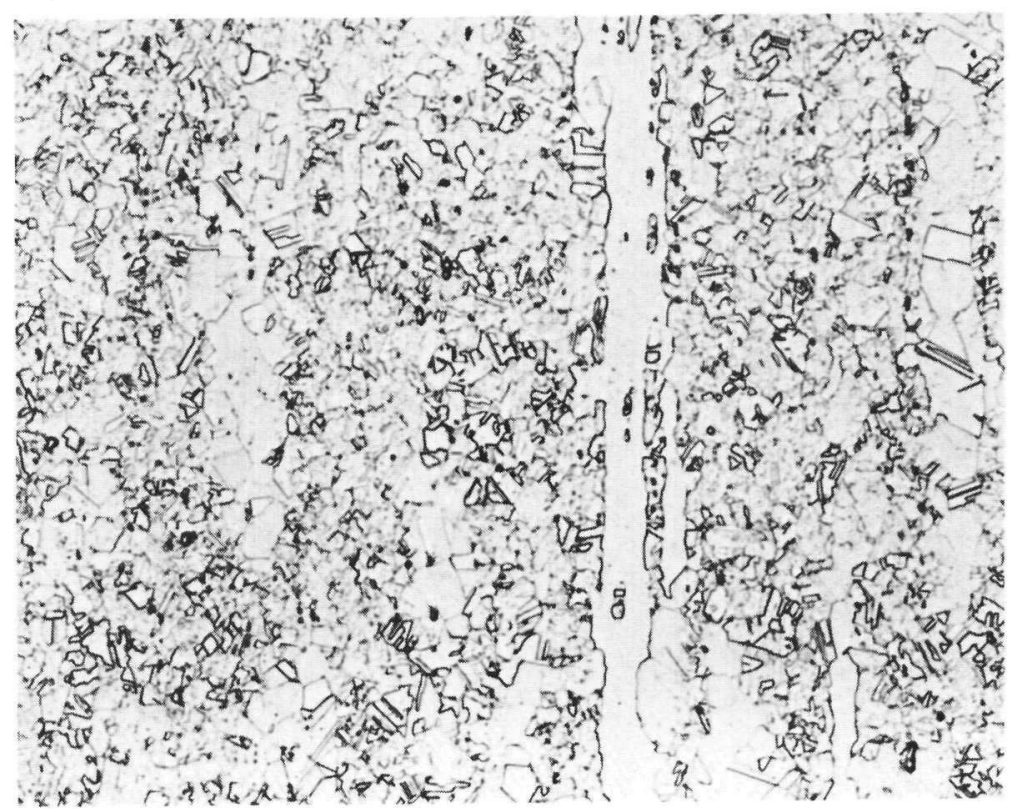

(a)

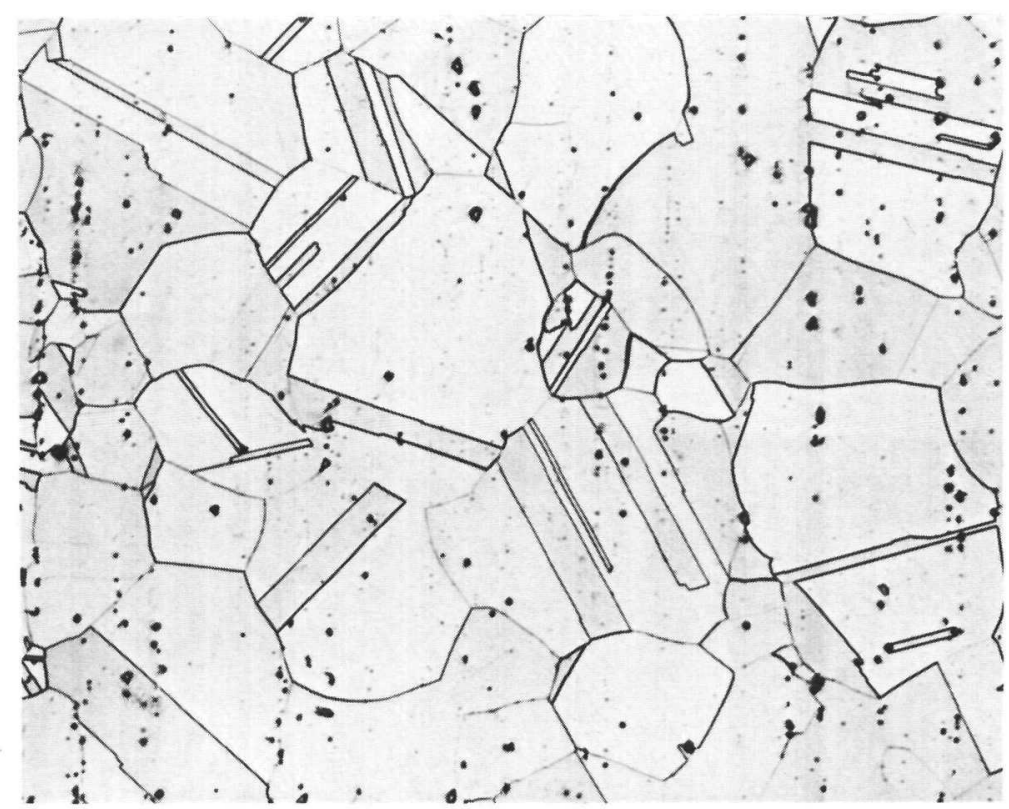

(b)

Figure 2. Microstructure of Heat $A$.

(a) "Conventional" heat treatment (100X).

(b) "Modified" heat treatment (100X). 
TABLE VI

EFFECT OF HEAT TREATMENT ON THE GRAIN SIZE

OF PRECIPITATION HEAT TREATED ALLOY 718

Material

Identification

A

B

C
ASTM GRAIN SIZE NO.

"Conventional"

"Modified"

$8-1 / 2 \quad 2-1 / 2$

5

$2-1 / 2$

$11-1 / 2$

4 


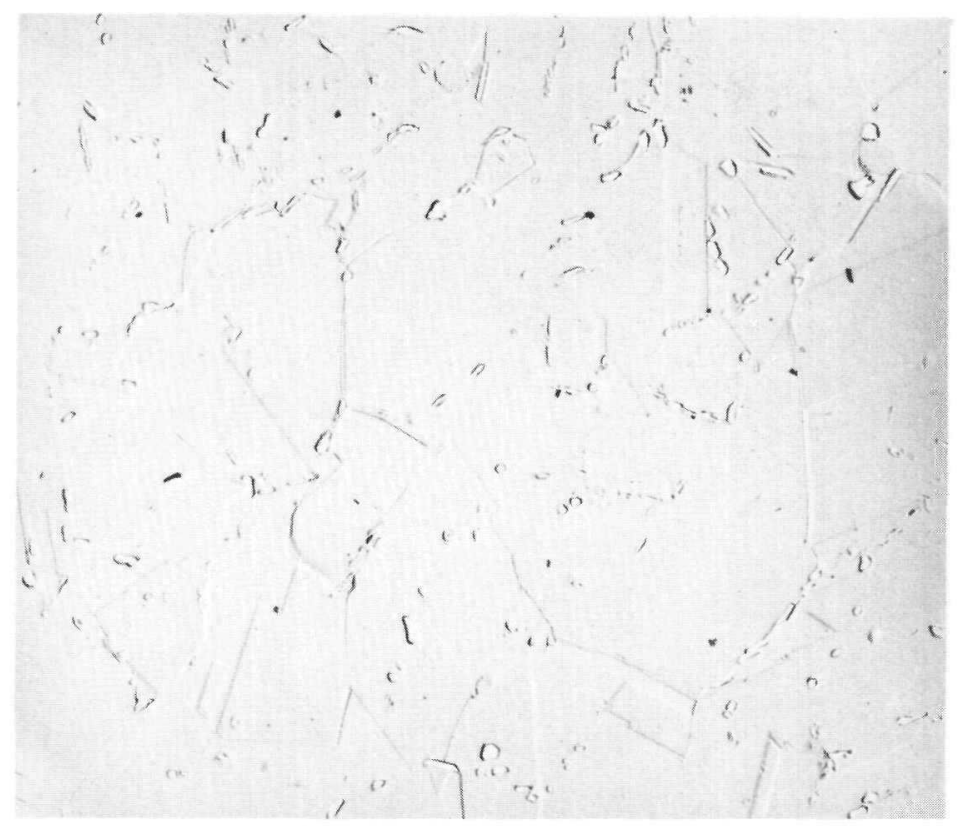

(a)

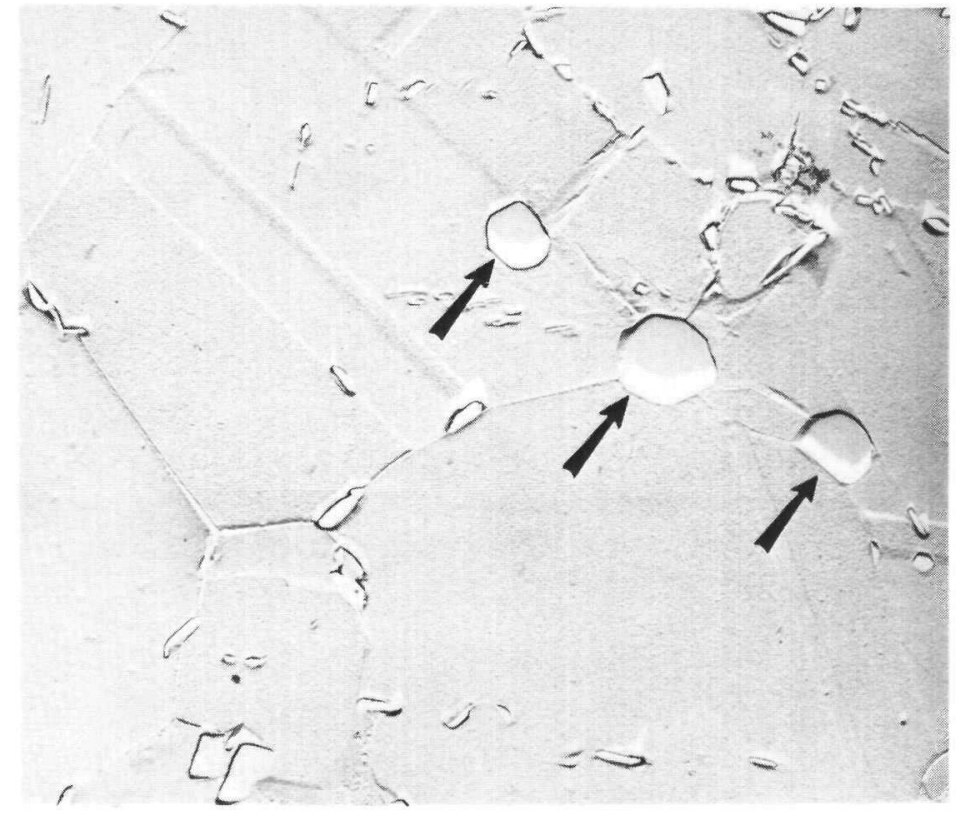

(b)

Figure 3. Surface replica micrographs of Heat A given the "conventional" heat treatment.

(a) Typical microstructure illustrating coarse $\delta$ precipitates along the grain boundaries. (2100X)

(b) Higher magnification of grain boundary region. Note the MC-type carbide inclusions (denoted by arrows) and the acicular $\delta$ particles along grain boundaries and annealing twin boundaries. (3465X) 
large-grain bands (Figures $4 \mathrm{a}$ and $4 \mathrm{~b}$ ) however, grain boundaries were found to contain a lower concentration of carbide and $\delta$ phase particles. Higher magnification of the interface between the two different grain size regions (Figure 4c) revealed that the fine $\gamma^{\prime \prime}$ precipitate structure appearing in the background was essentially the same in both regions.

Surface replication of the "modified" heat treated Alloy 718 revealed the presence of a fine network of Widmanstatten $\delta$ precipitates along grain boundaries (Figure $5 a$ ) in comparison to the coarse $\delta$ particles observed in the "conventional" material (Figure 3). In addition to the $\delta$ phase network, a few MC-type carbides decorated the grain boundaries, as shown in figure 5b. Apparently, these large carbides tend to pin the grain boundaries durng the $1093^{\circ} \mathrm{C}$ solution anneal.

To characterize the effect of heat treatment on the intragranular precipitates, thin foils from heat treated Alloy 718 specimens were examined by electron diffraction, dark field, and bright field methods. A systematic analys is of the precipitate morphology is given in Figures 6 and 7 for the "conventionally" heat treated material; the "modified" precipitation behavior is shown in Figure 8 . Thin foils were tilted into a [001] orientation, which provides a diffraction pattern revealing $\gamma^{\prime}$ and $\gamma^{\prime \prime}$ precipitates. The resulting [001] diffraction patterns (Figures 6a, 7a, and $8 \mathrm{a}$ ), indexed with respect to the fcc matrix, were found to be essentialily the same regardless of heat treatment. Based on the work of Paulonis, et a1. (2), the superlattice reflections indexed 010 are allowed for both $\gamma^{\prime}$ particles and the [010] variant of the bct $\gamma^{\prime \prime}$ platelets, whereas $1 \frac{1}{2} 0$ reflections are allowed for only the [010] $\gamma^{\prime \prime}$ variant. Consequently, comparison of dark field images from the 010 and $1 \frac{1}{2} 0$ reflections enables the $\gamma^{\prime}$ and $\gamma^{\prime \prime}$ phases to be identified unambiguously (i.e., precipitates that appear in both the 010 and $1 \frac{1}{2} 0$ dark field images must be $\gamma^{\prime \prime}$, whereas precipitates that appear only in the 010 dark field image must be $\gamma^{\prime}$ ). 


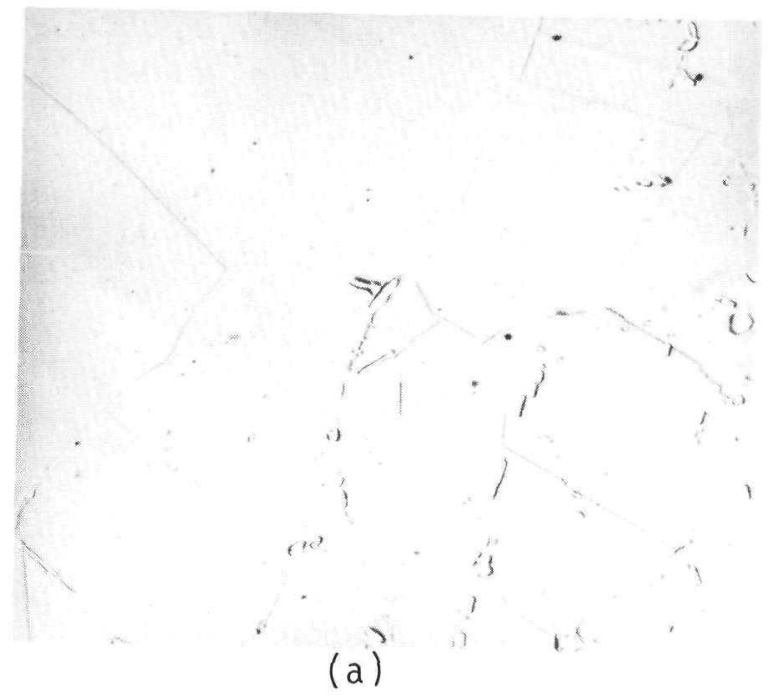

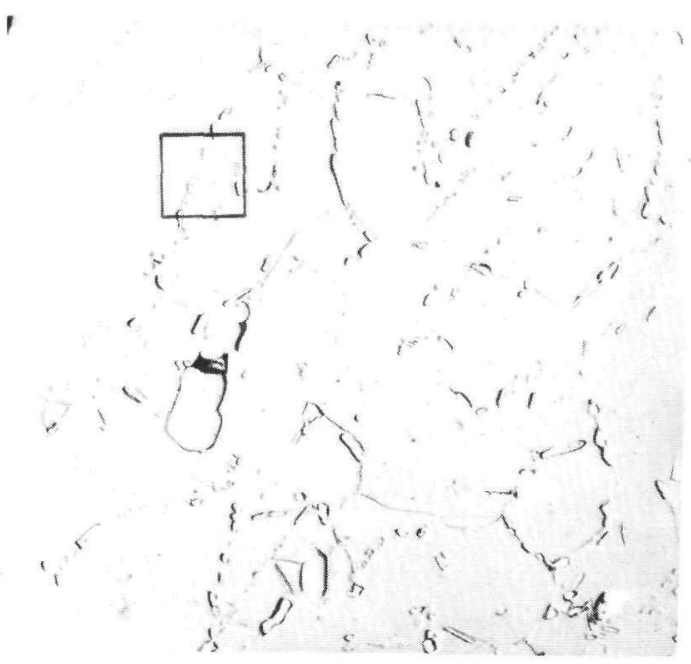

(b)

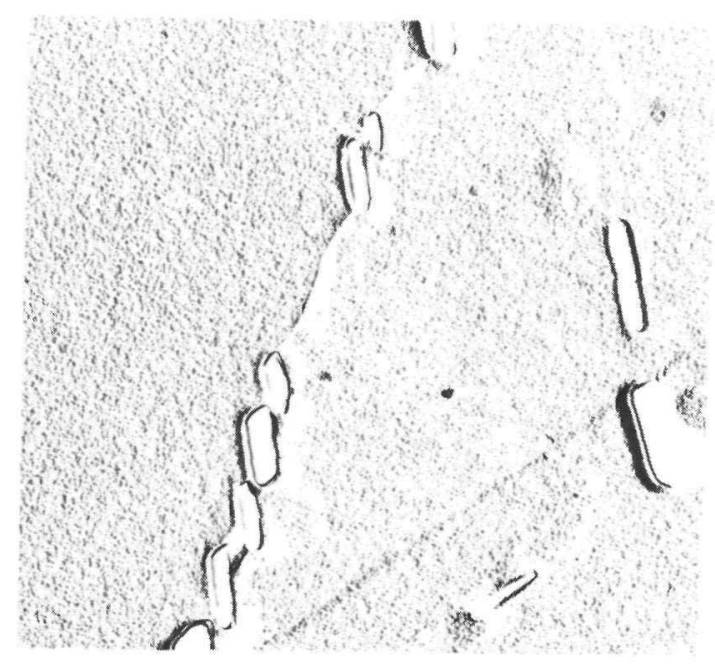

(c)

Figure 4. Surface replica micrographs of Heat A given the "conventional" heat treatment.

(a) Large grain size region illustrated on left side of micrograph. Note that grain boundaries within the large grain band were not decorated with carbide or $\delta$ particles. (1650X)

(b) Elongated large grain band in upper-left corner. (1650x)

(c) Higher magnification of the enclosed region in Figure 4b illustrating that the fine precipitate surface appearing in the background was the same in the normal grain size region (right side) as it was in the abnormally large grain size band (left side). $(15,560 \mathrm{X})$ 


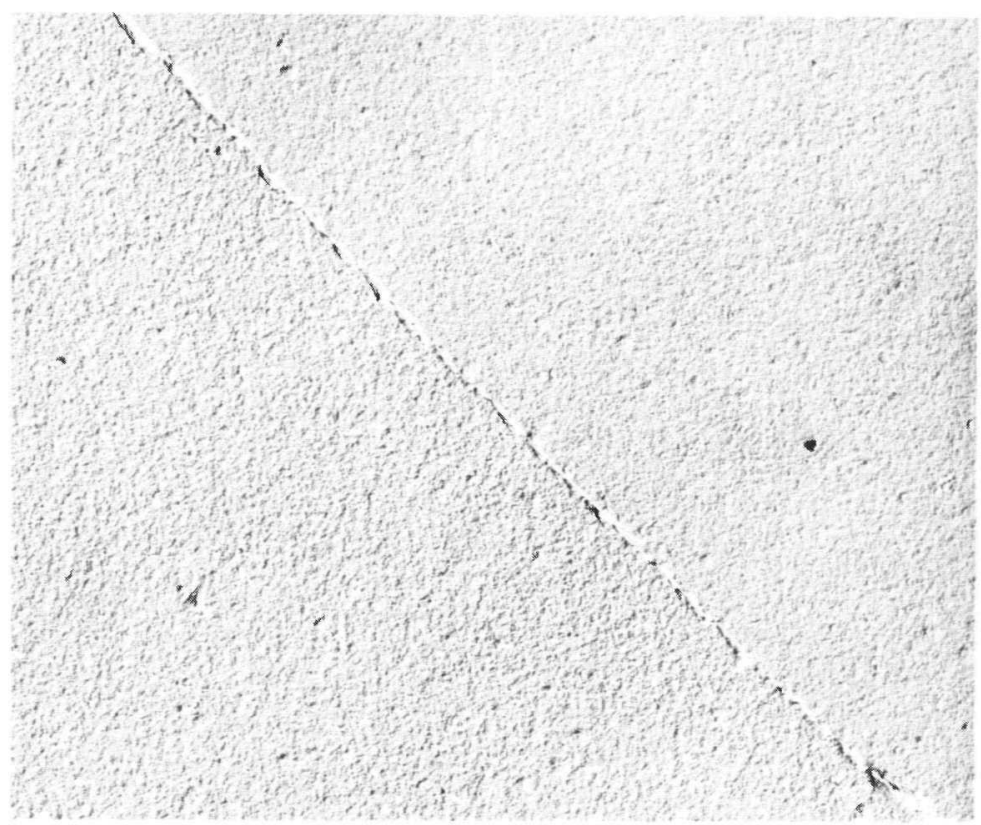

(a)

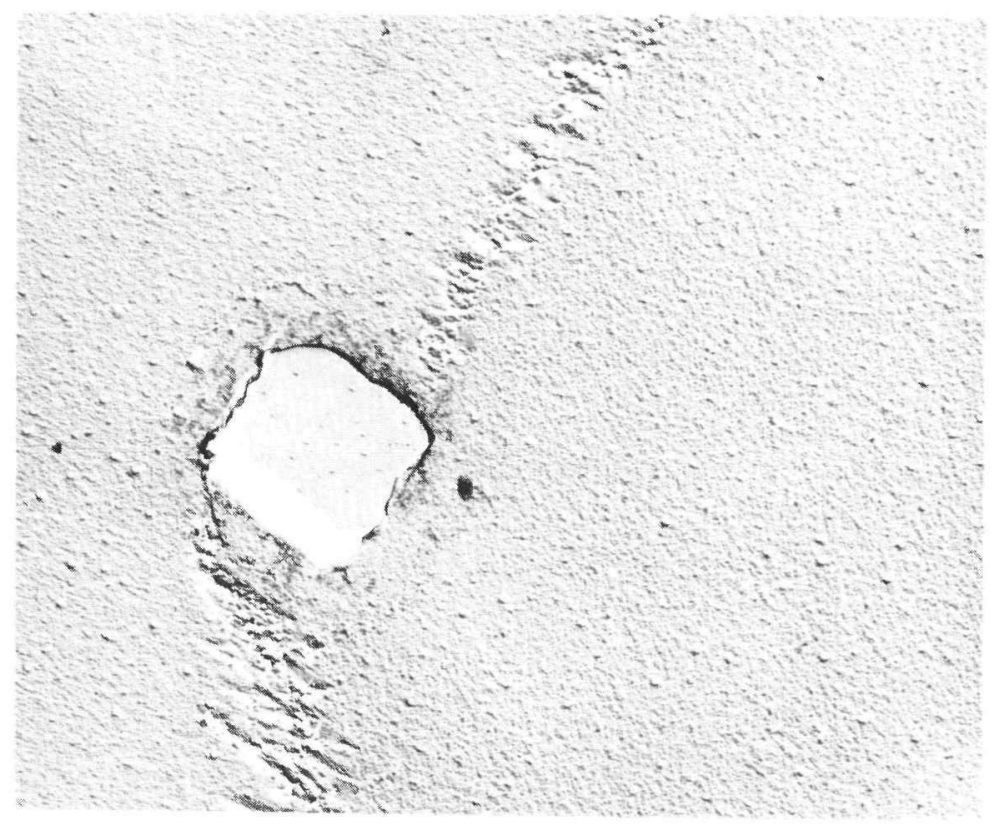

(b)

Figure 5. Electron surface replica micrographs of Heat $A$ given the "modified" precipitation treatment illustrating:

(a) A fine $\delta$ precipitate structure along the grain boundary. (5040X)

(b) A MC-type carbide inclusion in addition to the fine $\delta$ phase along the grain boundary. (5040X) 


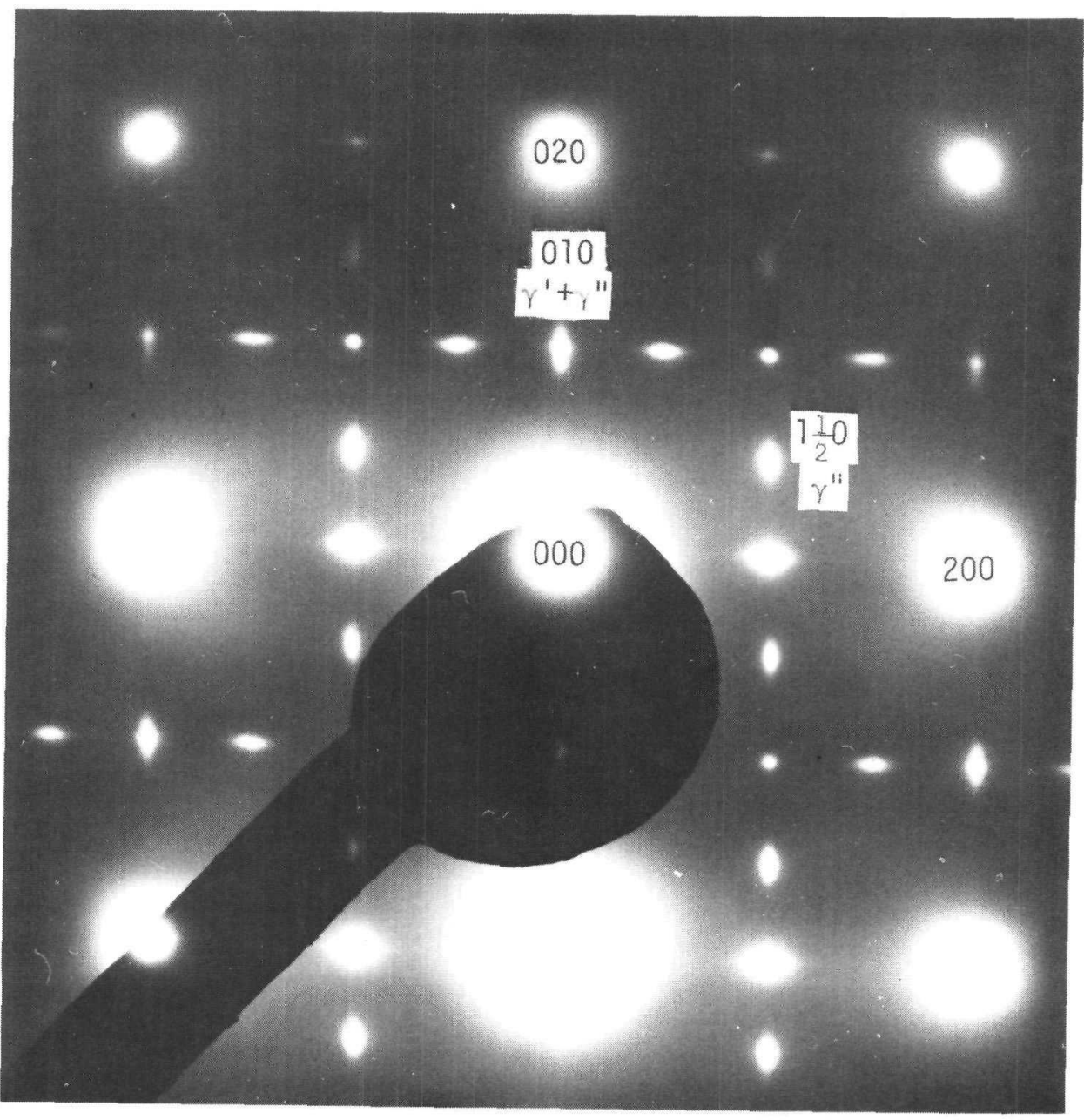
Figure 6. Thin foil micrographs of "conventionally" heat treated Alloy
718 (Heat A).

(a) [001] electron diffraction pattern showing the presence of the fcc matrix, $\gamma^{\prime}$ and $\gamma^{\prime \prime}$ precipitates. 


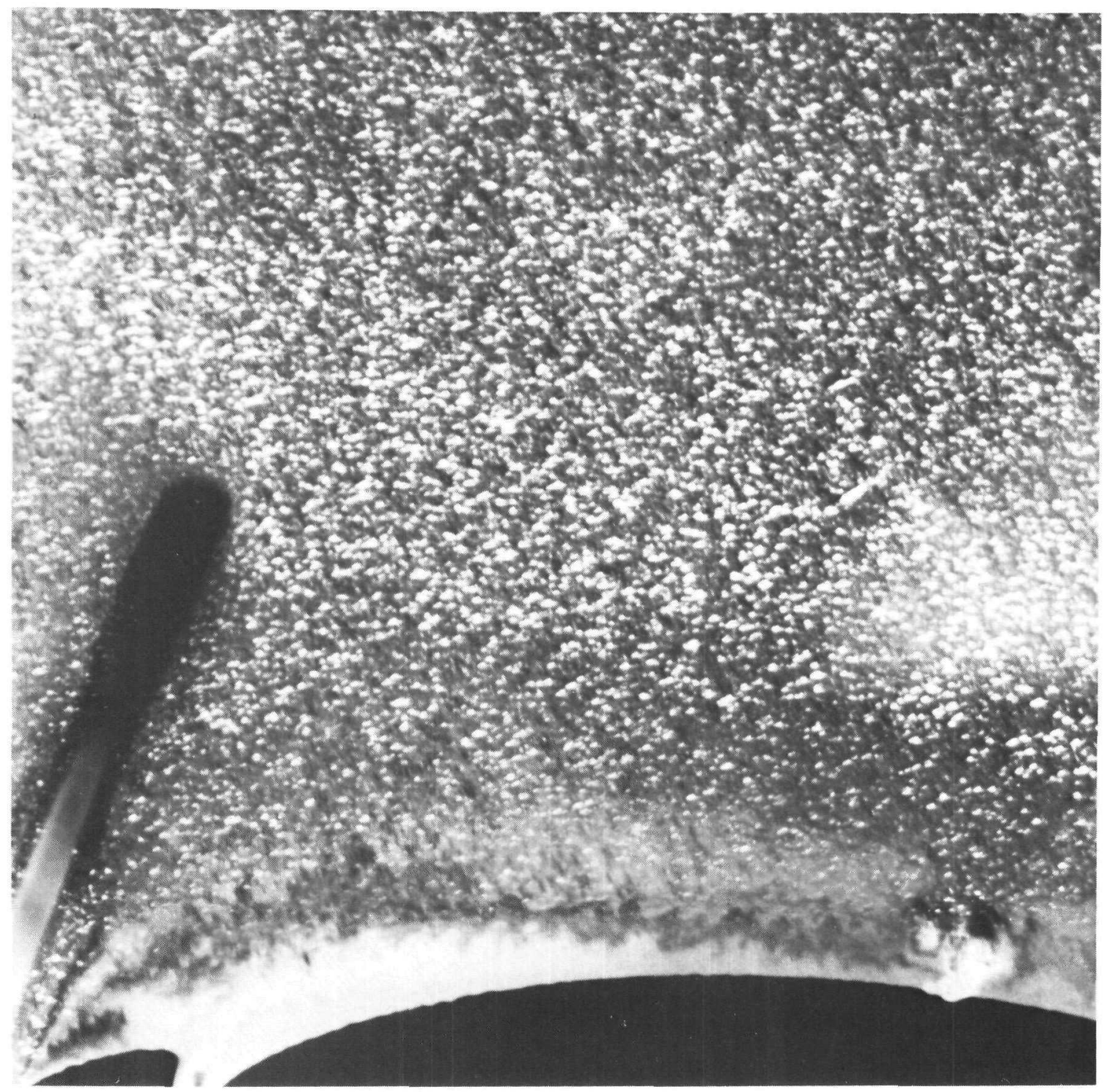

Figure 6 (cont'd). Thin foil micrographs of "conventionally" heat treated Alloy 718 (Heat A).

(b) 010 dark field photograph imaging both $\gamma^{\prime}$ and $\gamma^{\prime \prime}$ precipitates. Note the acicular $\delta$ precipitate in the lower left corner. $(66,000 x)$ 


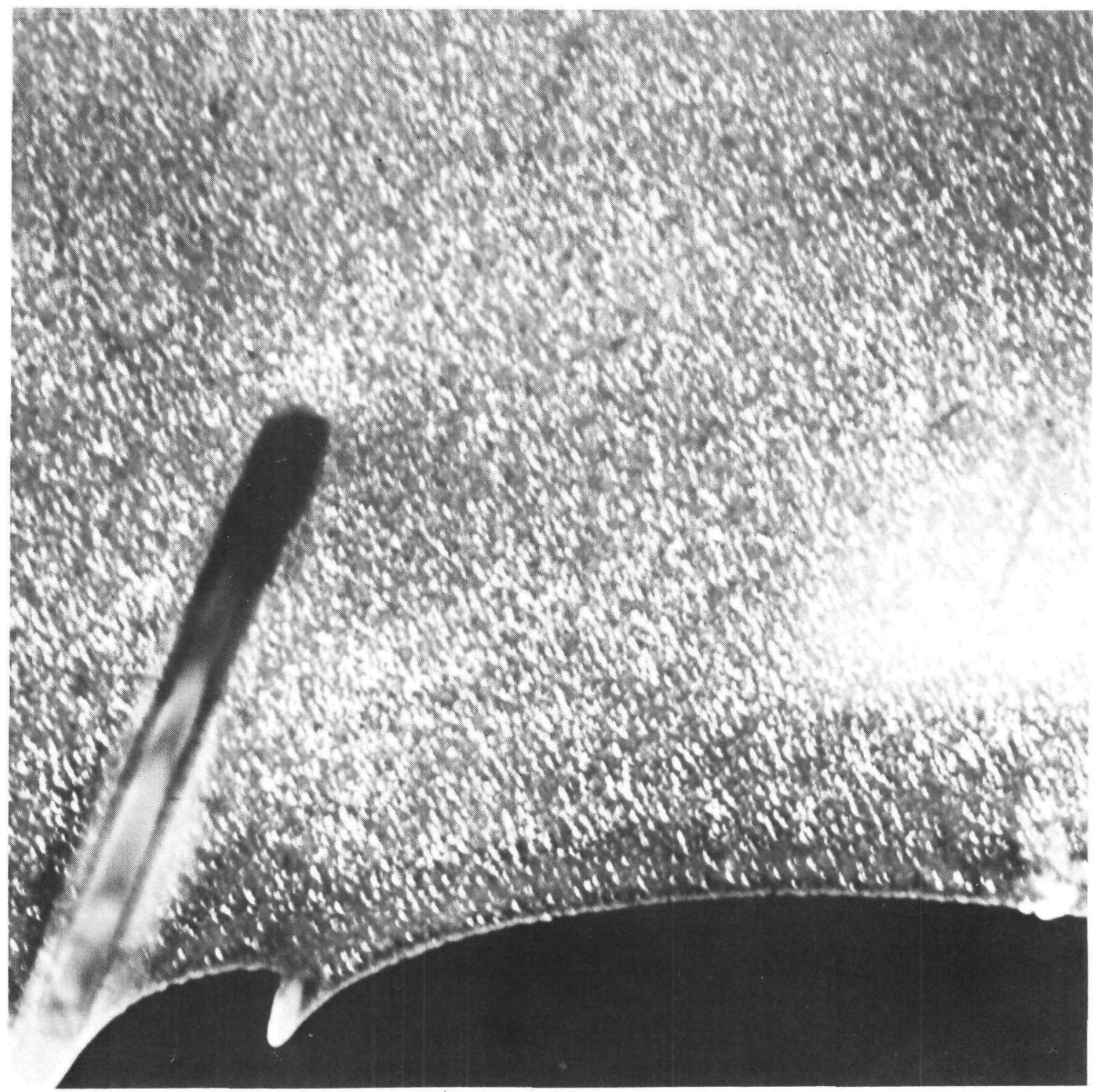

Figure 6 (cont'd). Thin foil micrographs of "conventionally" heat treated Alloy 718 (Heat A).

(c) $1 \frac{1}{2} 0$ dark field photograph imaging only $r^{\prime \prime}$ platelets. $(60,000 x)$ 


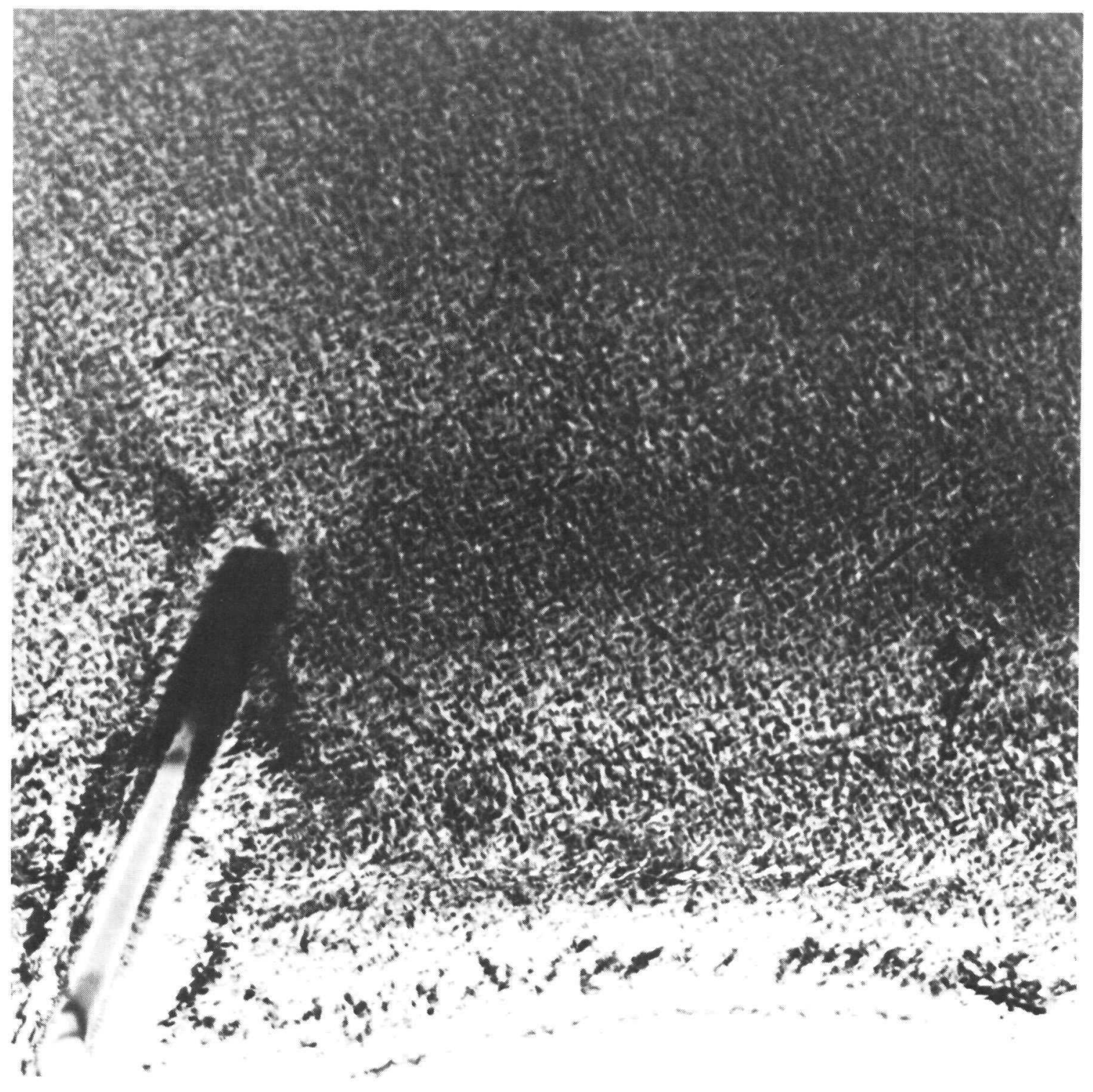

Figure 6 (cont'd). Thin foil micrographs of "conventionally" heat treated Alloy 718 (Heat A).

(d) Low magnification micrograph of the bright field. $(66,000 x)$ 


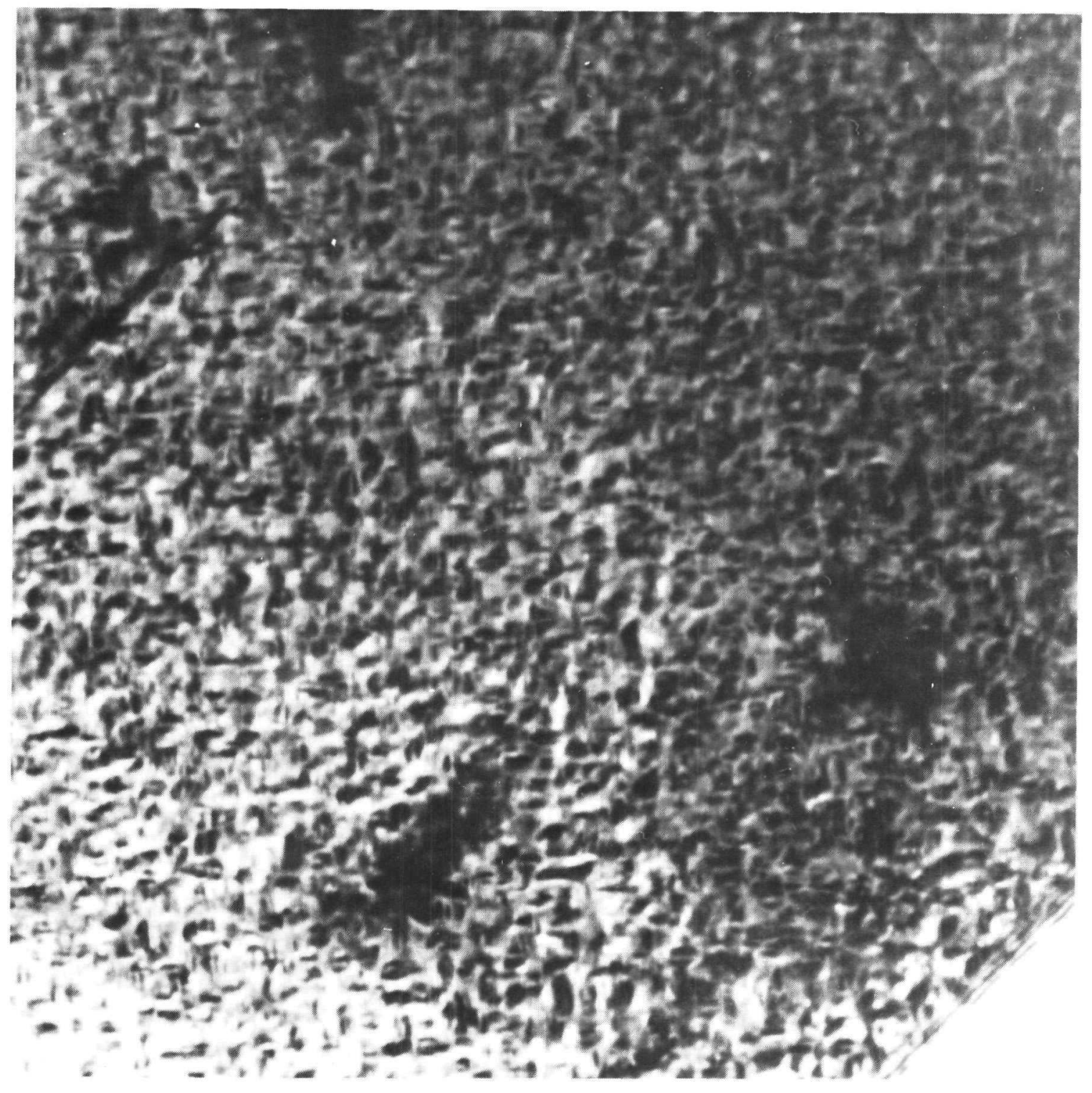

Figure 6 (cont'd). Thin foil micrographs of "conventionally" heat treated Alloy 718 (Heat A).

(e) High magnification micrograph of the bright field illustrating rather large coherency strain contrast around the $\gamma^{\prime \prime}$ precipitates. $(169,000 \mathrm{X})$ 


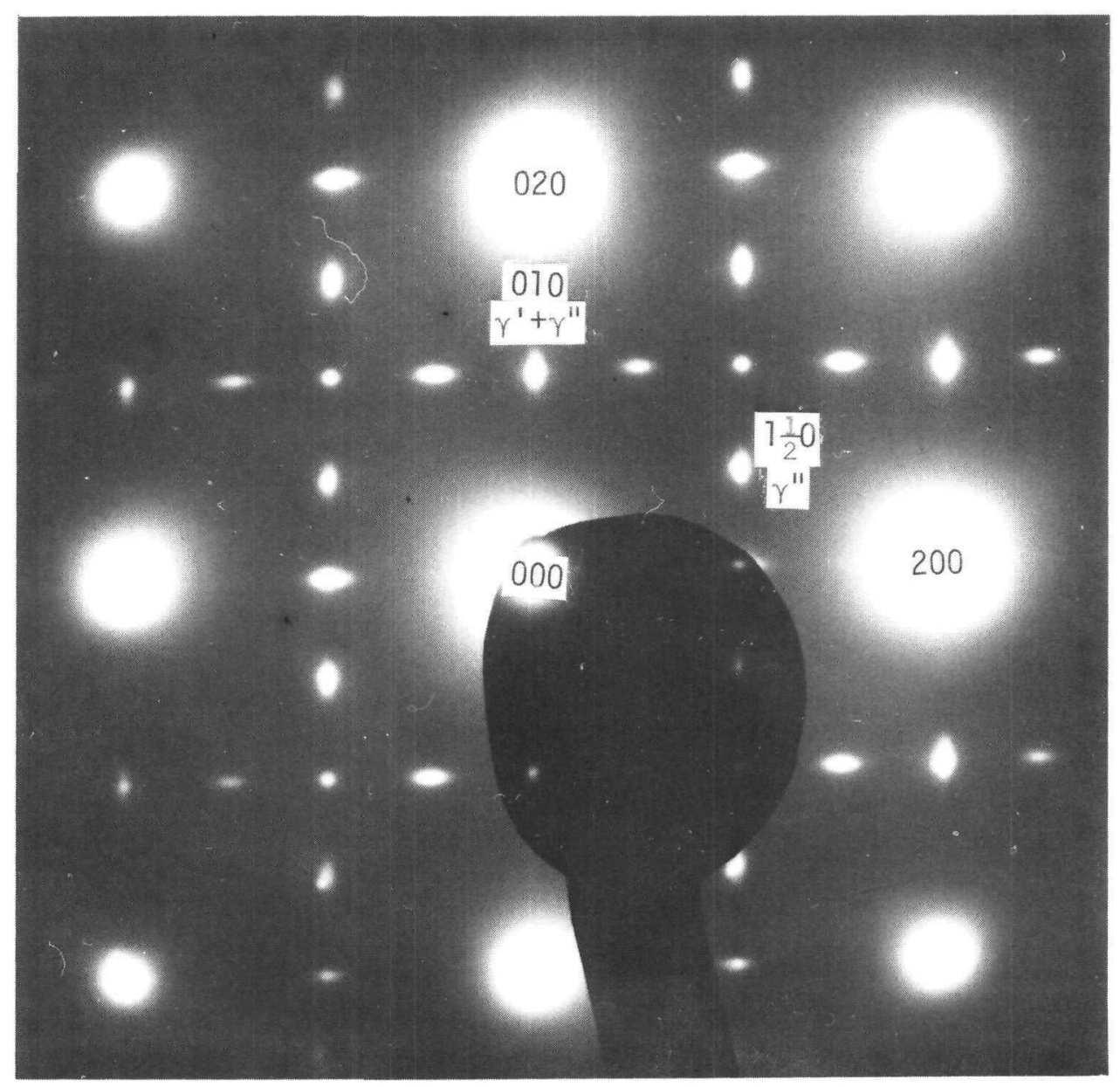

Figure 7. Thin foil micrographs of Heat A given the "conventional" heat treatment.

(a) [001] electron diffraction pattern revealing both $\gamma^{\prime}$ and $\gamma^{\prime \prime}$ precipitates. 


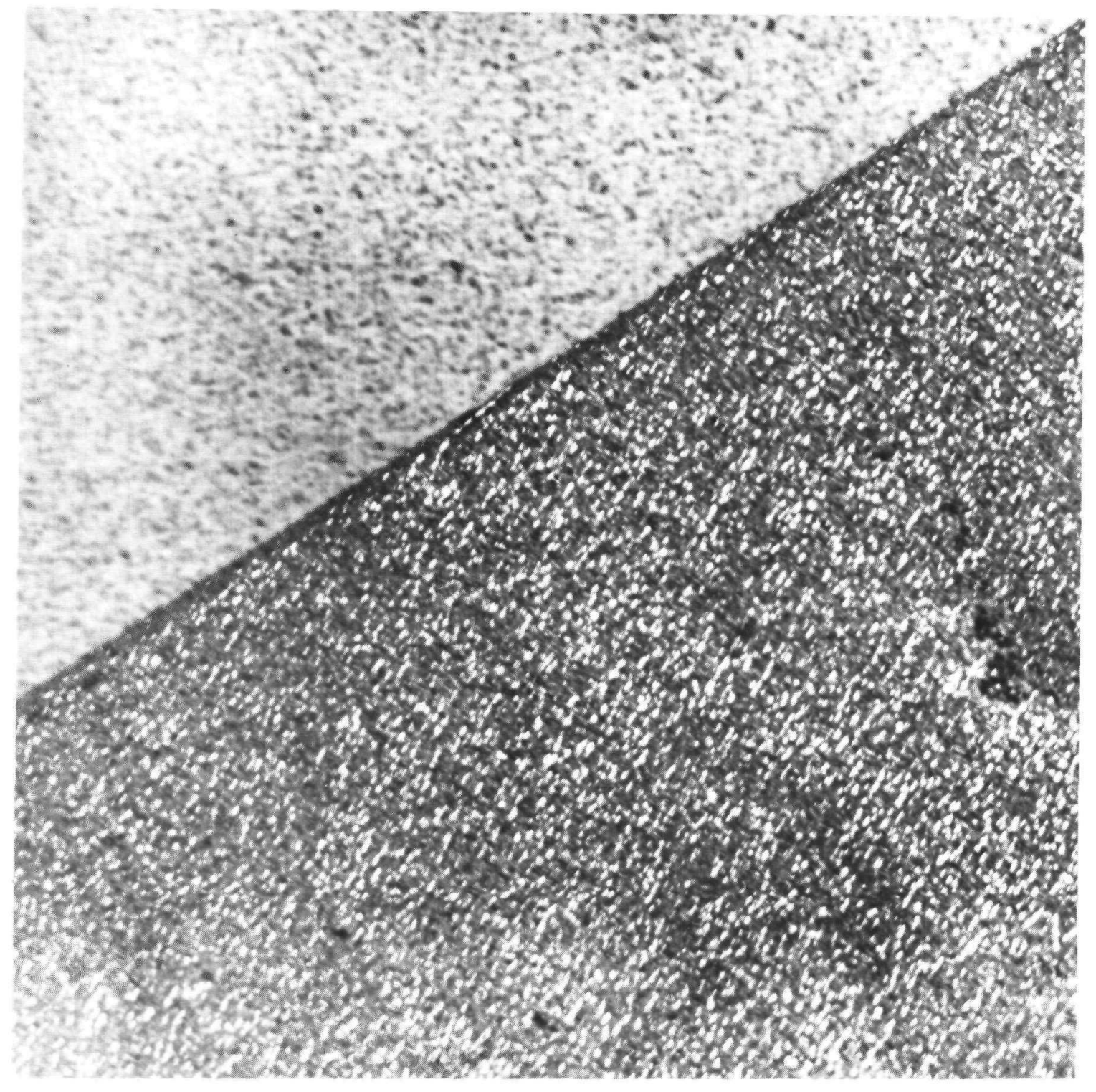

Figure 7 (cont'd). Thin foil micrographs of Heat A given the "conventional" heat treatment.

(b) 010 dark field photograph imaging both $\gamma^{\prime}$ and $\gamma^{\prime \prime}$. There appears to be no denuding along the grain boundary. $(66,000 \mathrm{X})$ 


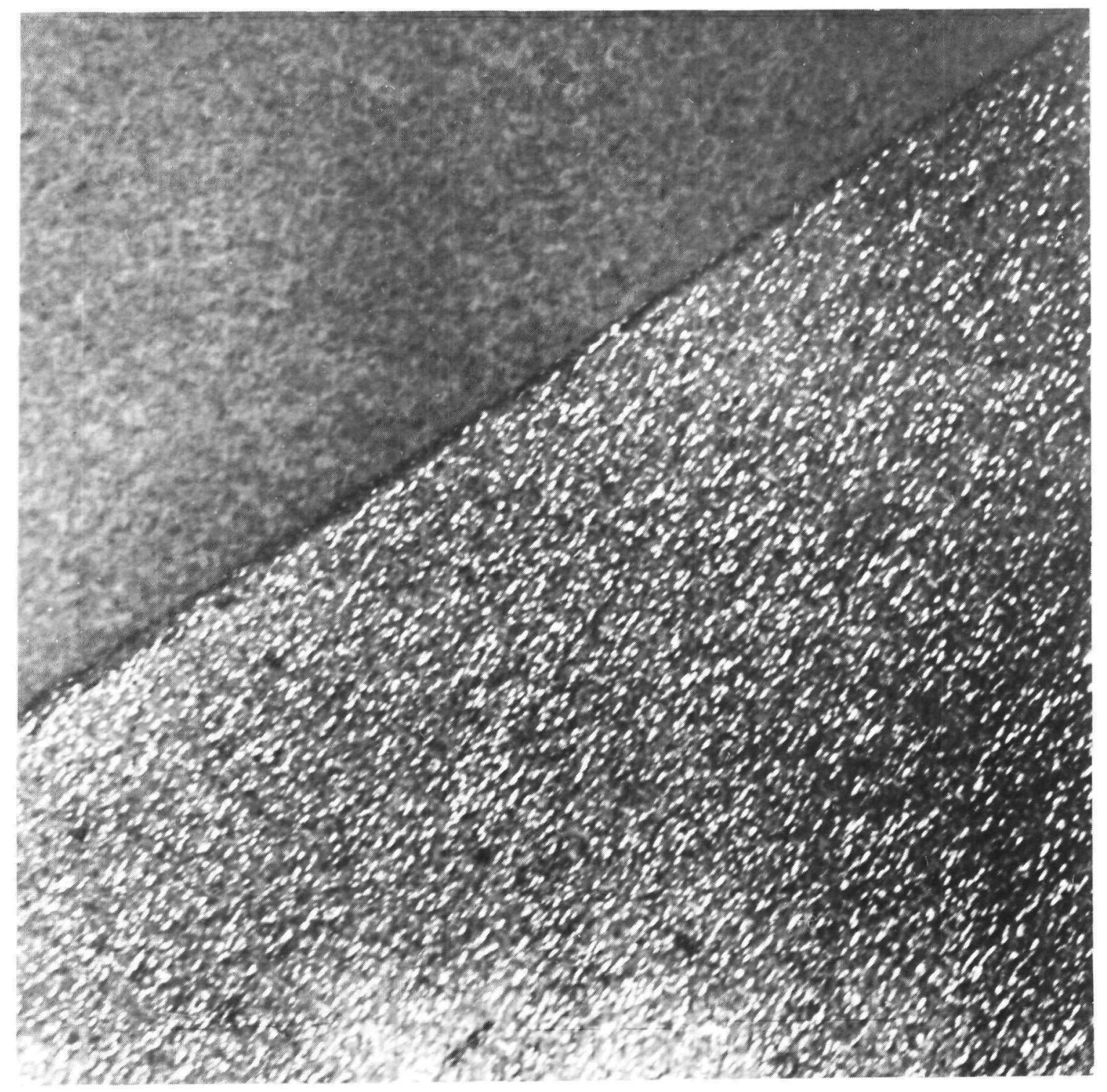

Figure 7 (cont'd). Thin foil micrographs of Heat A given the "conventional" heat treatment.

(c) $1 \frac{1}{2} 0$ dark field imaging only $\gamma^{\prime \prime}$ platelets. No evidence of $\gamma^{\prime \prime}$ denuding along the grain boundary. $(66,000 x)$ 


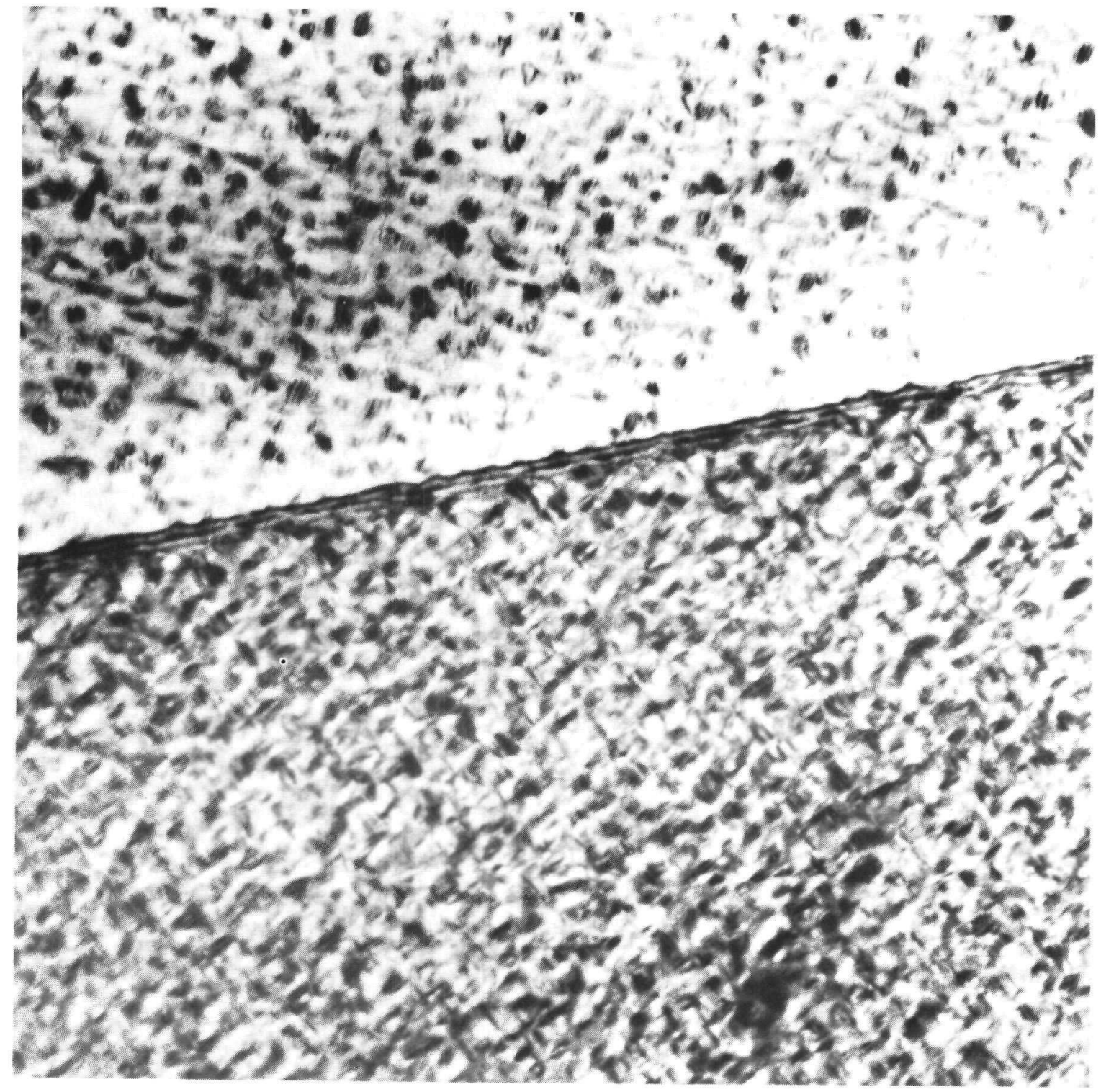

Figure 7 (cont'd). Thin foil micrographs of Heat A given the "conventional" heat treatment.

(d) Bright field. (169,000X) 


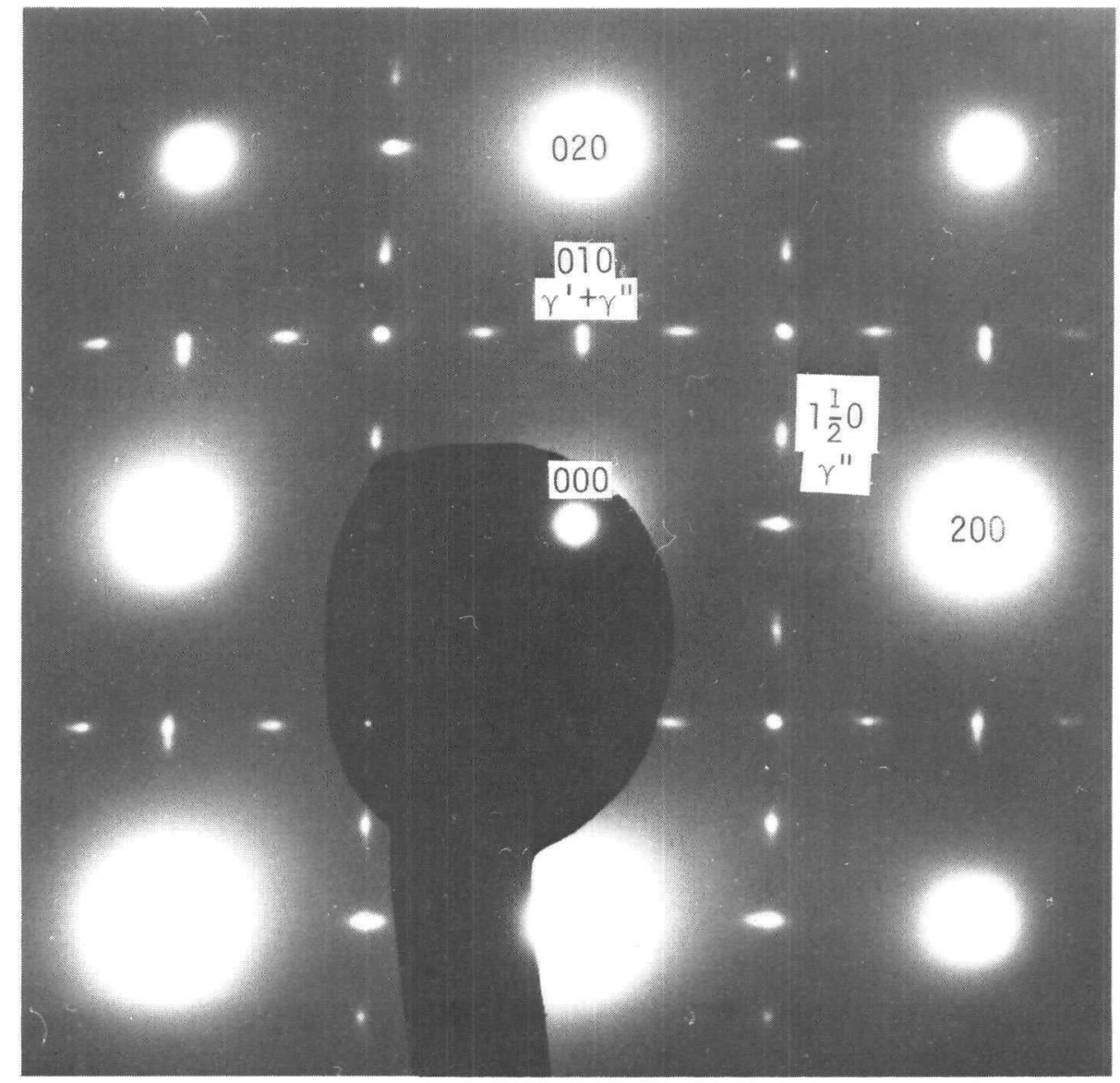

Figure 8. Thin foil micrographs of "modified" treated Heat A. (a) [001] electron diffraction pattern showing the existence of the fcc matrix, $\gamma^{\prime}$ and $\gamma^{\prime \prime}$ precipitates. 


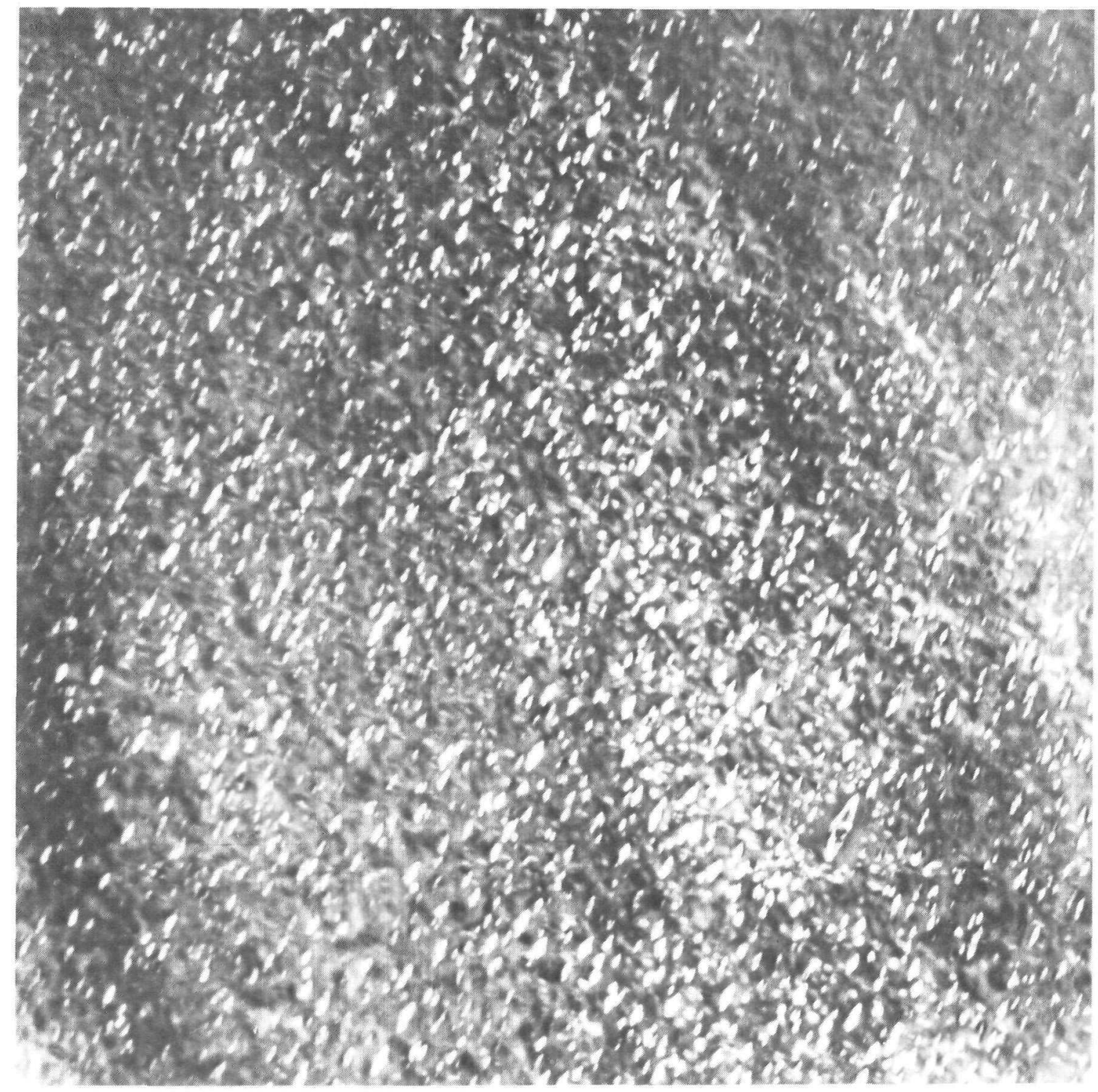

Figure 8 (cont'd). Thin foil micrographs of "modified" treated Heat A.

(b) 010 dark field photograph imaging both $\gamma^{\prime}$ and $\gamma^{\prime \prime}$ particles. $(66,000 \mathrm{X})$ 


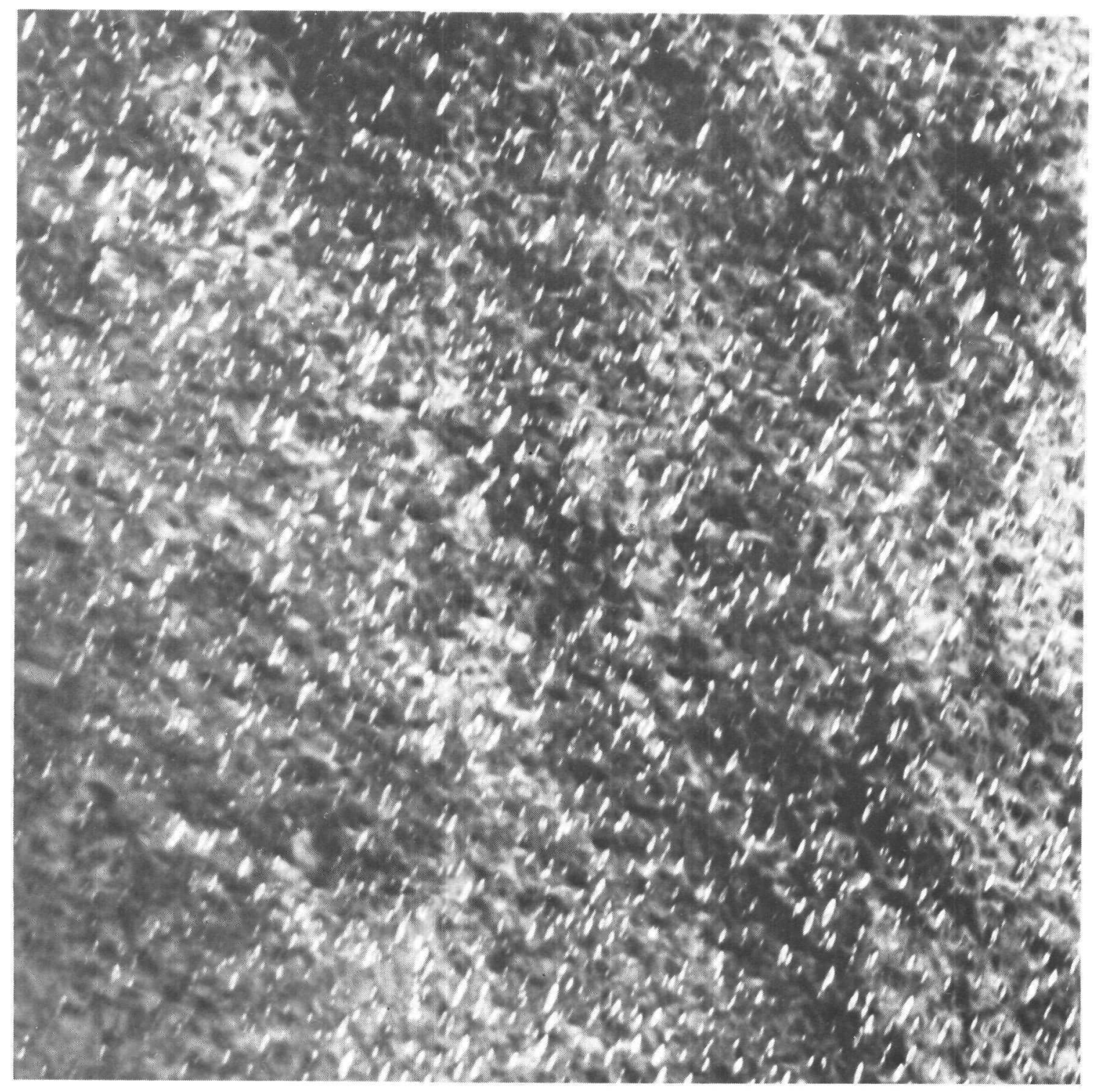

Figure 8 (cont'd). Thin foil micrographs of "modified" treated Heat A. (c) $1 \frac{1}{2} 0$ dark field image illustrating only $\gamma^{\prime \prime}$ platelets. $(66,000 \mathrm{X})$ 


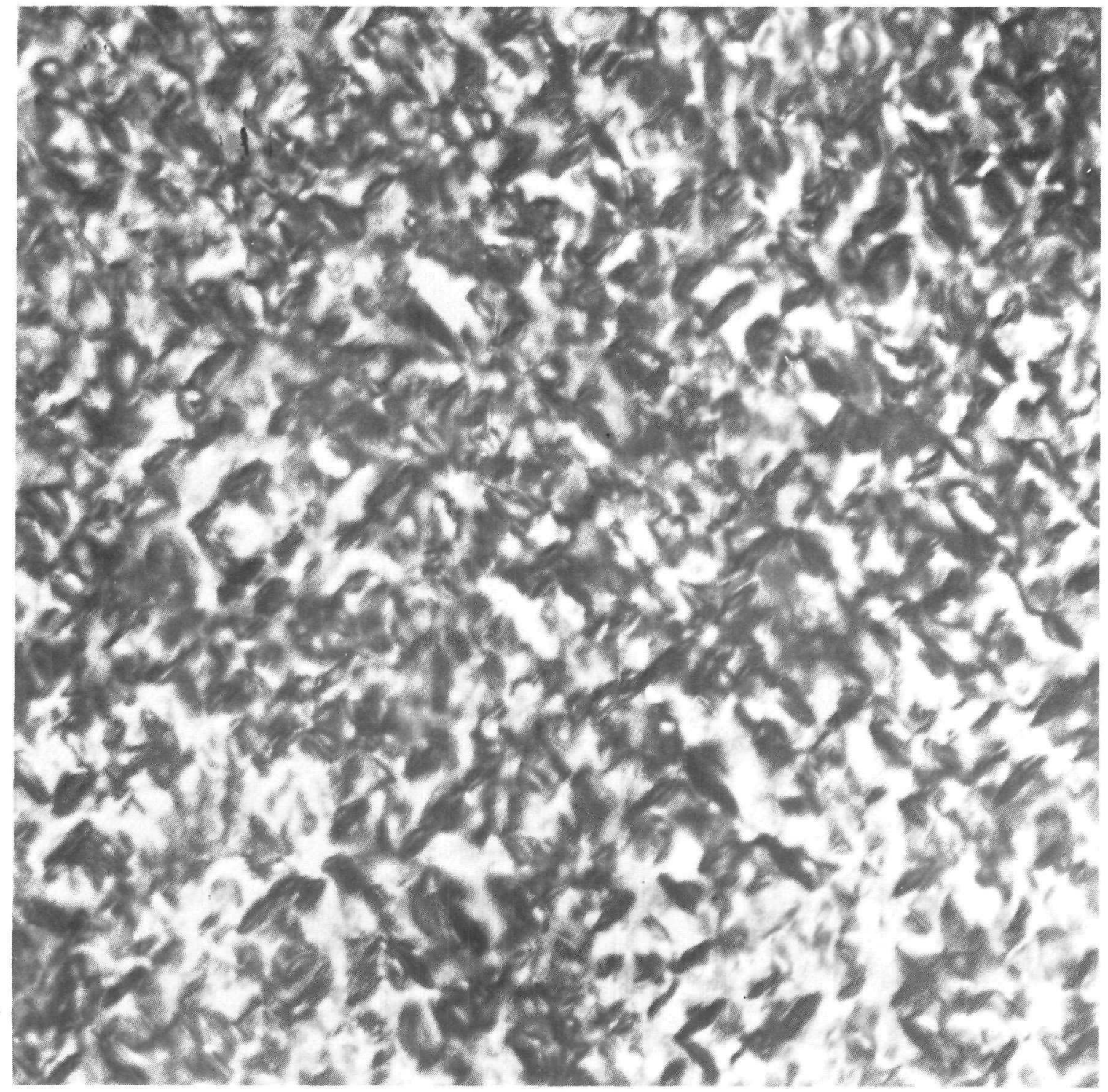

Figure 8 (cont'd). Thin foil micrographs of "modified" treated Heat $A$. (d) Bright field photograph illustrating large coherency strain contrast around $\gamma^{\prime \prime}$ precipitates. $(169,000 \mathrm{X})$ 
A systematic dark field analys is of the 010 and $1 \frac{1}{2} 0$ super lattice reflections is shown in Figures $6 b$ and $c, 7 b$ and $c$, and $8 b$ and $c$. The large disk-shaped precipitates imaged in both dark field micrographs represent a single variant (the [010] variant) of the $\gamma^{\prime \prime}$ phase. In addition to the $\gamma^{\prime \prime}$, a few faint, round particles were observed in only the 010 dark field micrograph; hence, these smaller precipitates were identified as $\gamma^{\prime}$. The overall morphology of the $\gamma^{\prime}$ and $\gamma^{\prime \prime}$ phases for the "conventionally" treated Alloy 718 (Figures 6b and $c$ and $7 b$ and $c$ ) was found to be very similar to that of the "modified" material (Figures $8 b$ and $c$ ). In fact, the only difference noted was the presence of the lenticular $\delta$ phase in the "conventionally" treated material (Figure 6) and a slight variation in the $\gamma^{\prime \prime}$ platelet size distribution.

The $\gamma^{\prime \prime}$ platelet size for each heat treatment was established by measuring over 500 particle widths and diameters from the $1 \frac{1}{2} 0$ dark field micrographs. The platelet size distributions for Heat $A$ are given in Figure 9 and Table VII. The $\gamma^{\prime \prime}$ platelet width resulting from the two heat treatments had approximately the same size and distribution. On the other hand, the $r "$ platelet diameter distribution was found to be dependent on heat treatment. Figure 9 and Table VII reveal that the range of $\gamma^{\prime \prime}$ diameters resulting from the "modified" heat treatment $(90-700 \AA)$ was considerably larger than that resulting from the "conventional" heat treatment $(80-450 \AA)$. Figure 9 also illustrates that the "modified" Alloy 718 exhibited a higher percentage of large $\gamma^{\prime \prime}$ platelet diameters (in excess of $300 \AA$ ) but essentially the same platelet width in comparison to the "conventional " $r$ " particle size, thereby suggesting that coarsening of the $r$ " precipitates during the "modified" heat treatment occurred primarily along the diameter dimension. In all likelihood, the larger $\gamma$ " precipitates observed in the "modified" heat treated Alloy 718 are associated with the high solution anneal ing temperature $\left(1093^{\circ} \mathrm{C}\right)$ coupled with the slow cooling rates $\left(55^{\circ} \mathrm{C} / \mathrm{hr}\right)$ employed during the "modified" treatment (recall Table III). The high temperature anneal caused the $\mathrm{Nb}$-rich $\delta$ (orthorhomb ic $\mathrm{Ni}_{3} \mathrm{Nb}$ ) phase to go into solution, thereby providing an additional supersaturation of $N b$ in the matrix. Since the coarse $\delta$ particles did not form during the "modified" heat treatment, th is 


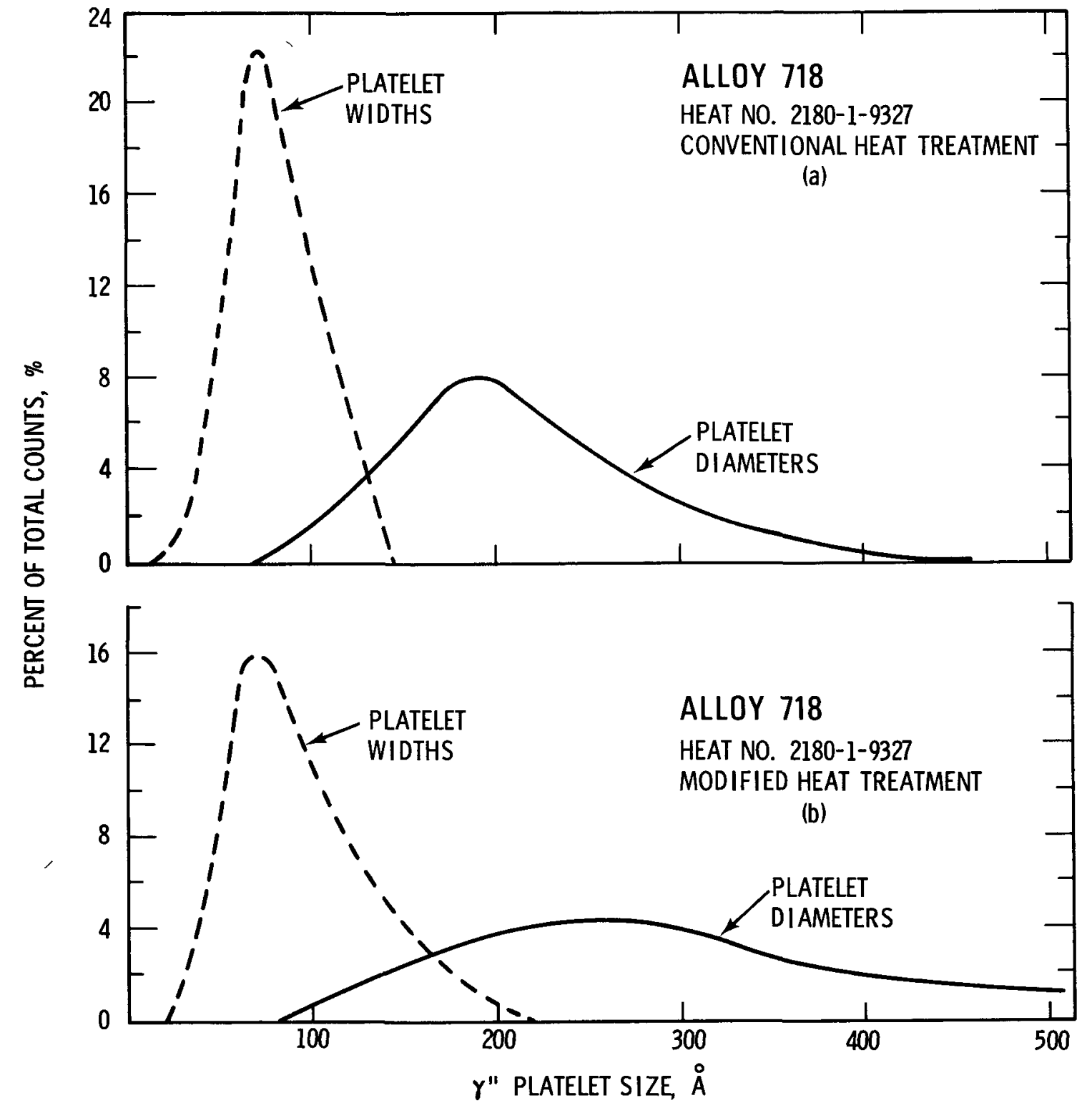

Figure 9. $\gamma^{\prime \prime}$ platelet size distribution for Heat $A$.

(a) "Conventiona1" heat treatment.

(b) "Modified" heat treatment. 
TABLE VII

$\gamma^{\prime \prime}$ PLATELET SIZE

\begin{tabular}{|c|c|c|c|}
\hline Material & $\begin{array}{c}\text { Heat } \\
\text { Treatment } \\
\end{array}$ & $\begin{array}{c}\text { Platelet Width } \\
\text { Average (Range) } \\
(\AA \AA A) \\
\end{array}$ & $\begin{array}{c}\text { Platelet Diameter } \\
\text { Average (Range) } \\
(\AA \dot{A})\end{array}$ \\
\hline Heat $A$ & "Conventional" & $82(25-140)$ & $217(80-450)$ \\
\hline Heat $A$ & "Modified" & $95(25-210)$ & $310(90-700)$ \\
\hline Heat $B$ & "Conventional" & $78(35-170)$ & $190(70-380)$ \\
\hline Heat $B$ & "Modified" & $85(35-200)$ & $318(100-670)$ \\
\hline
\end{tabular}


increased Nb content was then available for the formation of larger $\gamma^{\prime \prime}$ (bct $\mathrm{Ni}_{3} \mathrm{Nb}$ ) precipitates. Morever, the slow cooling rate following the solution anneal enabled the $\gamma$ " to nucleate and grow at temperatures above the standard aging temperature, resulting in a coarsening of the $\gamma^{\prime \prime}$ precipitates.

The bright field micrographs for the "conventional" (Figures 6e and 7d) and "modified" (Figure 8d) Alloy 718 reveal a rather large coherency strain contrast around individual $r$ " particles. Comparison of the bright field pictures for the two heat treatments (all three bright field photographs are at the same magnification) suggests that the precipitate strain fields were larger in the "modified" treated material; however, the overall precipitate density appeared to be greater for the "conventionally" treated alloys. Hence, in comparison to the "modified" treatment, the "conventional" heat treatment resulted in the formation of a finer, more closely spaced $\gamma^{\prime \prime}$ precipitate morphology throughout the matrix.

\subsubsection{Heat B (Heat No. 52C9EK)}

Typical microstructures for Heat B resulting from the "standard" and "modified" heat treatments are given in Figures $10 \mathrm{a}$ and $10 \mathrm{~b}$, respectively. Here again, it is obvious that the higher temperature solution anneal employed in the "modified" heat treatment caused considerable grain growth (see Table VI). Numerous annealing twins and coarse MC-type carbides were again found throughout the matrix regardless of heat treatment.

Figure 10a also reveals the presence of pronounced banding (the dark regions in Figure 10a) parallel to the primary rolling direction in the "conventionally" heat treated Heat B. Similar banding has been reported in a previous study $(27)$ of this same heat of Alloy 718 . The presence of banding is common in complex nickel-base superalloys, and it usually arises from segregation in the original casting. Surface replication of Heat $B$ revealed that the banded regions exhibited concentrated Widmanstätten $\delta$ precipitates (orthorhombic $\mathrm{Ni}_{3} \mathrm{Nb}$ ), as shown in Figure $11 \mathrm{a}$, thereby 


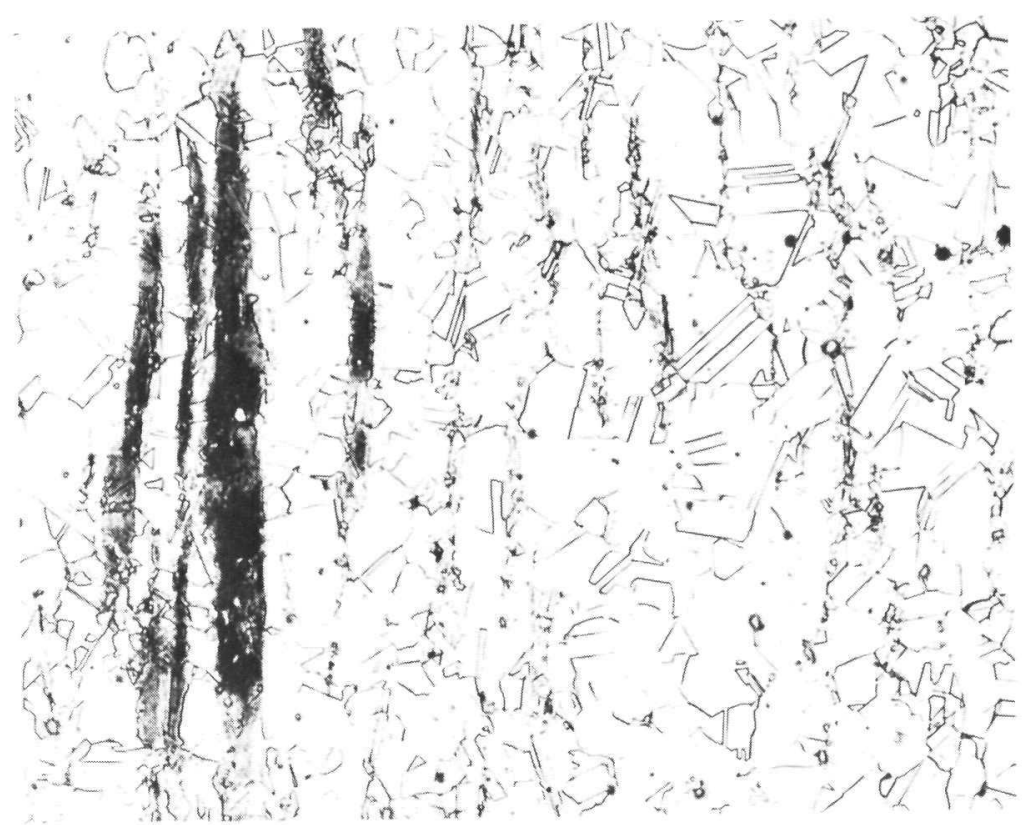

(a)

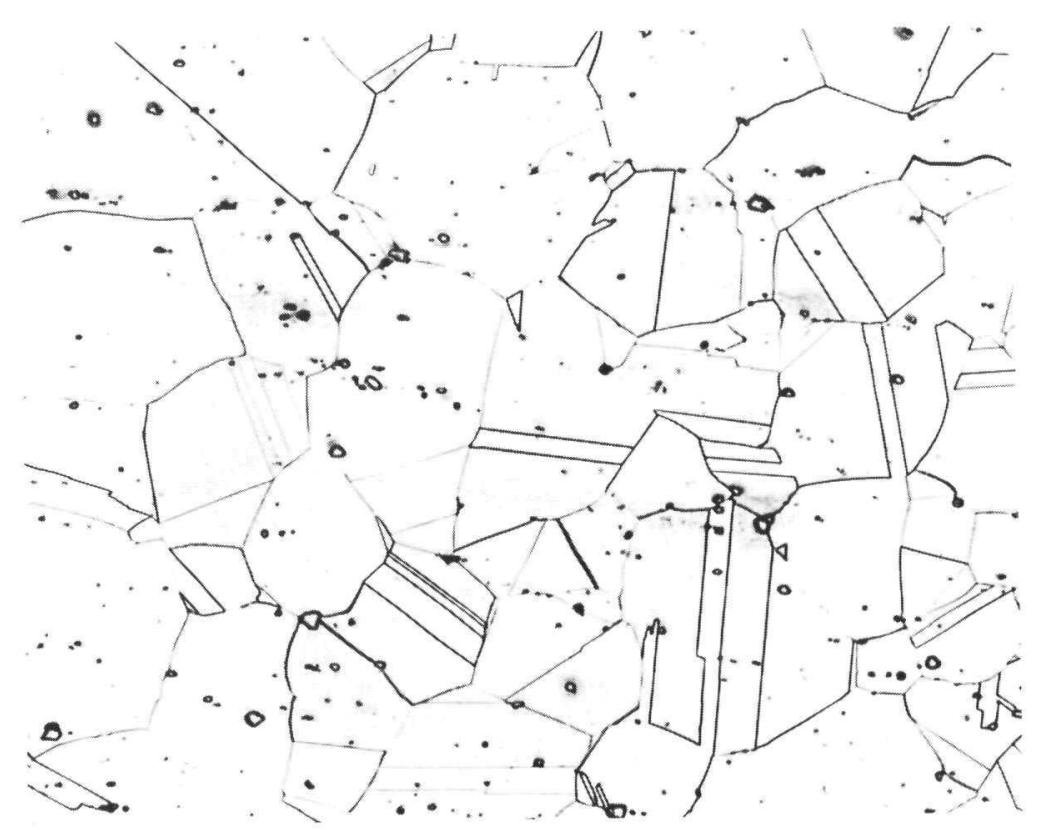

(b)

Figure 10. Microstructure of Heat B.

(a) "Conventional" heat treatment. (100X)

(b) "Modified" heat treatment. (100X) 


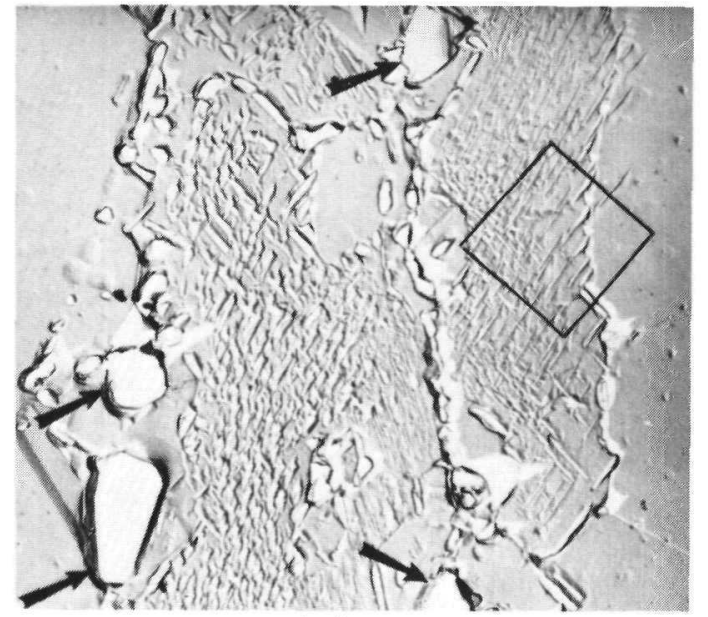

(a)

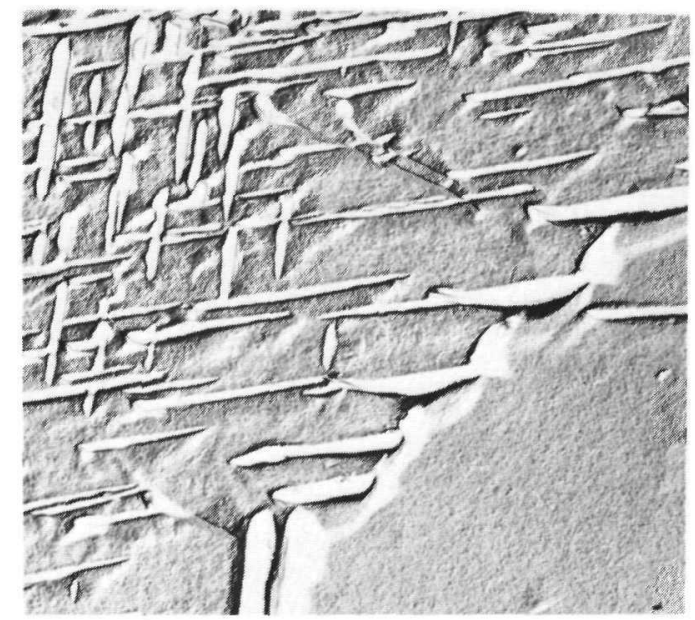

(b)

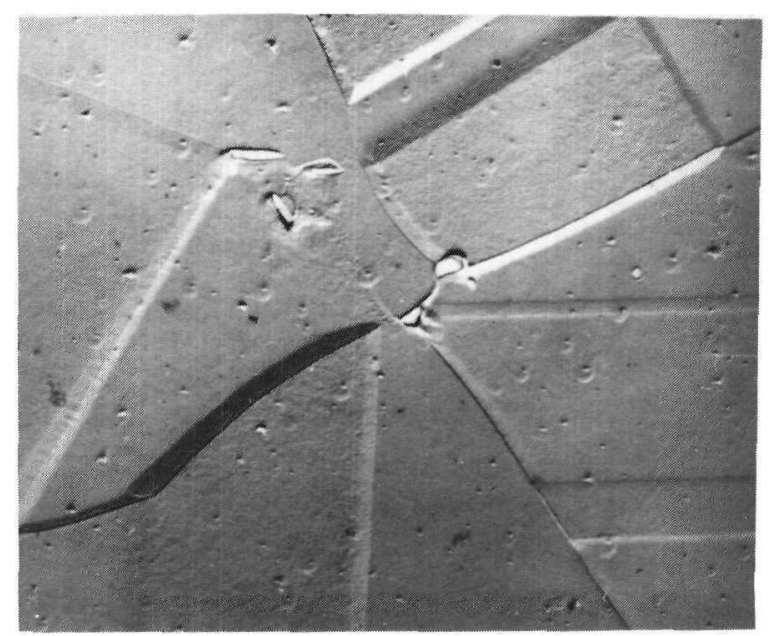

(c)

Figure 11. Electron micrographs of Heat B given the "conventional" treatment.

(a) Widmanstätten $\delta$ phase within the dark banded regions. Arrows denote MC-type carbide inclusions. (1640X)

(b) Higher magnification of enclosed area of Figure 11(a). Note that the orientation of the $\delta$ precipitates along the grain boundary was consistent with the orientation of the intragranular $\delta$ platelets.

(c) Relatively clean grain boundaries outside the $(8410 x)$ banded regions. (2310X) 
suggesting that these segregated regions possessed excessive amounts of Mb. Furthermore, Figure 11a illustrates that the grain boundaries within the banded areas were decorated with a considerable amount of acicular $\delta$ coupled with a few large MC-type inclusions (see arrows). Higher magnification of the grain boundary regions. (Figure 11b) suggests that the $\delta$ precipitates initiated along the grain boundary and then grew into the matrix. On the other hand, grain boundaries outside the banded regions were relatively clean (as shown in Figure 11c), exhibiting only very fine precipitate networks.

When Heat $B$ was given the "modified" heat treatment, no evidence of banding was observed optically (Figure 10b), and examination of surface replicas (Figures $12 \mathrm{a}$ and $\mathrm{b}$ ) revealed no evidence of $\delta$ precipitates within the grain interior. The higher solution annealing temperature employed during the "modified" heat treatment appears to create a more homogeneous microstructure, thereby precluding the presence of concentrated $\delta$ phase banding. However, Figure 12 does reveal a fine $\delta$ precipitate structure along the grain boundaries and a few large carbide inclusions that apparently pinned the grain boundary during the $1093^{\circ} \mathrm{C}$ solution anneal. The fine grain boundary $\delta$ phase network along with the intragranular $\gamma$ " precipitate morphology are better illustrated in Figure 13. In summary, the overall microstructure for the "modified" treatment (Figures 12 and 13) was found to be very similar to that observed in Heat $A$ (Figure 5 ).

To fully characterize the effect of heat treatment on the primary strengthening $\gamma^{\prime \prime}$ phase, thin foils were prepared from Heat B and examined using dark field and bright field techniques. The systematic dark field and bright field analyses for the "conventional" and "modified" heat treated Alloy 718 are illustrated in Figures 14 and 15 and Figure 16, respectively. (Recall that both $\gamma^{\prime}$ and $\gamma^{\prime \prime}$ precipitates are imaged in the 010 dark field micrographs, while only the $\gamma^{\prime \prime}$ platelets are imaged in the $1 \frac{1}{2} 0$ dark field micrographs.) Examination of these micrographs revealed that precipitate morphologies of Heats A (Figures 6-8) and B (Figures 14-16) were very similar, as both heats exhibited evidence of rather large disc-shaped $\gamma "$ 


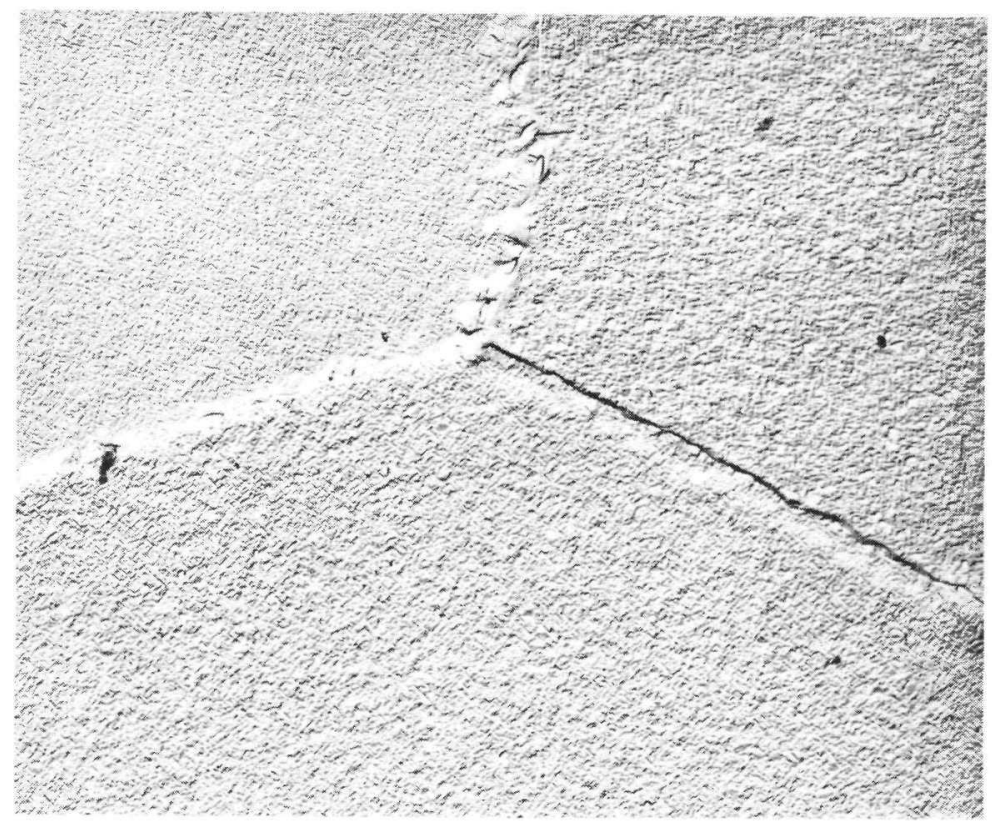

(a)

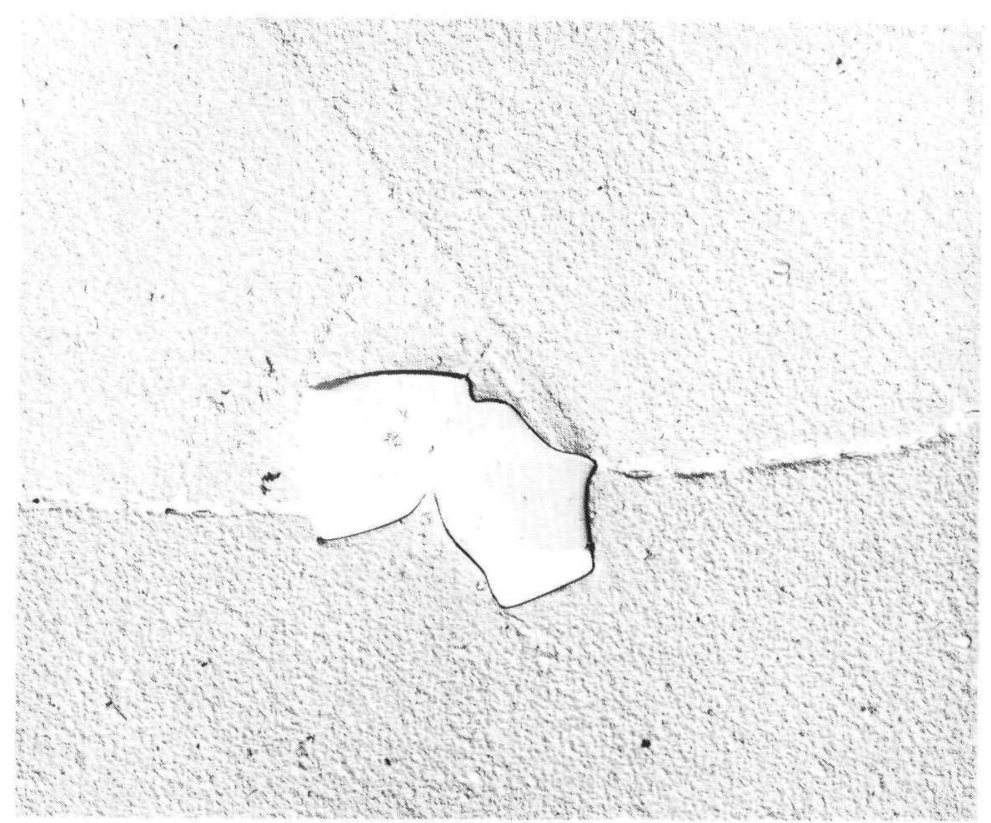

(b)

Figure 12. Electron micrographs of Heat B given the "modified" heat treatment illustrating:

(a) A fine $\delta$ phase network decorating the grain boundary. (8508X)

(b) A MC-type carbide inclusion in addition to the fine $\delta$ precipitates along the grain boundary. (3465X) 


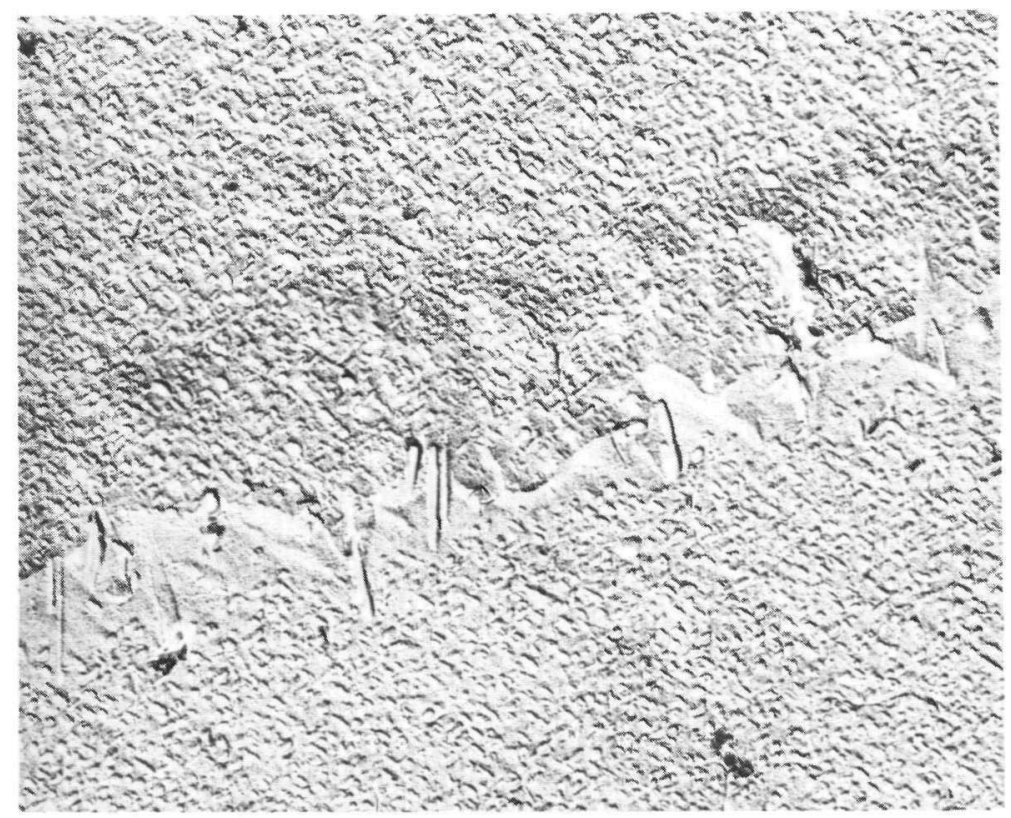

(a)

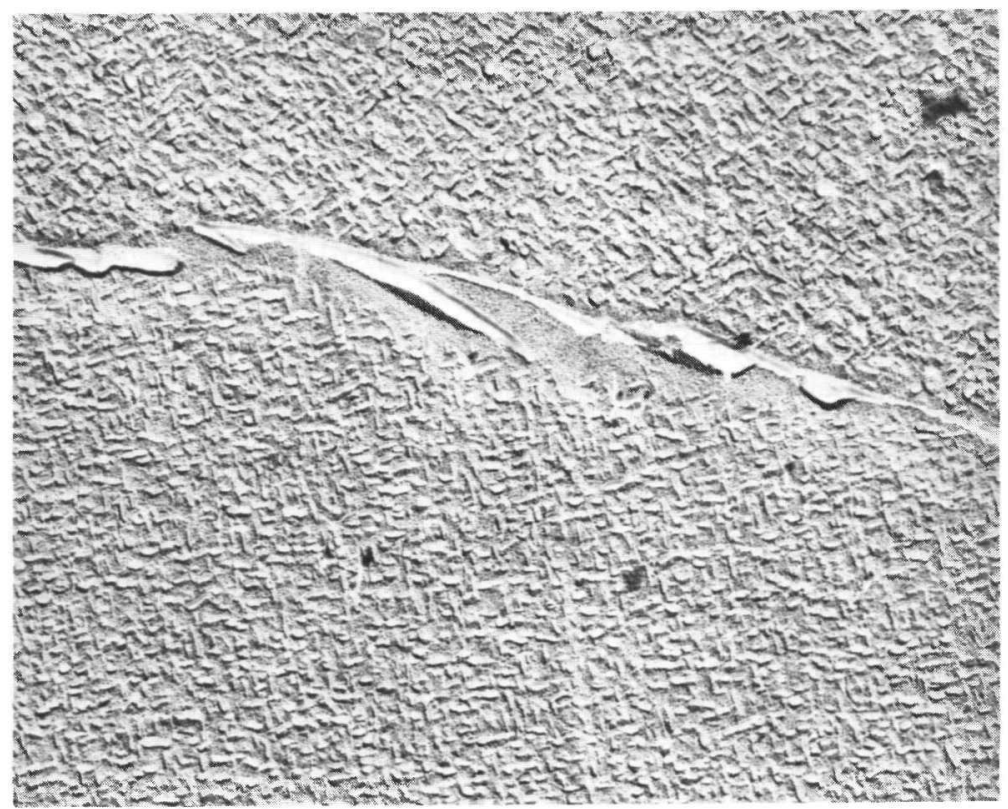

(b)

Figure 13. Electron surface replica micrographs of the "modified" treated Heat B grain boundary regions.

(a) Fine, needle-like $\delta$ particles along the grain boundary. $(19,810 X)$

(b) Slight denuding of $\gamma^{\prime \prime}$ platelets along grain boundary region. This behavior, however, was confined to a limited number of regions. $(28,280 \mathrm{X})$ 


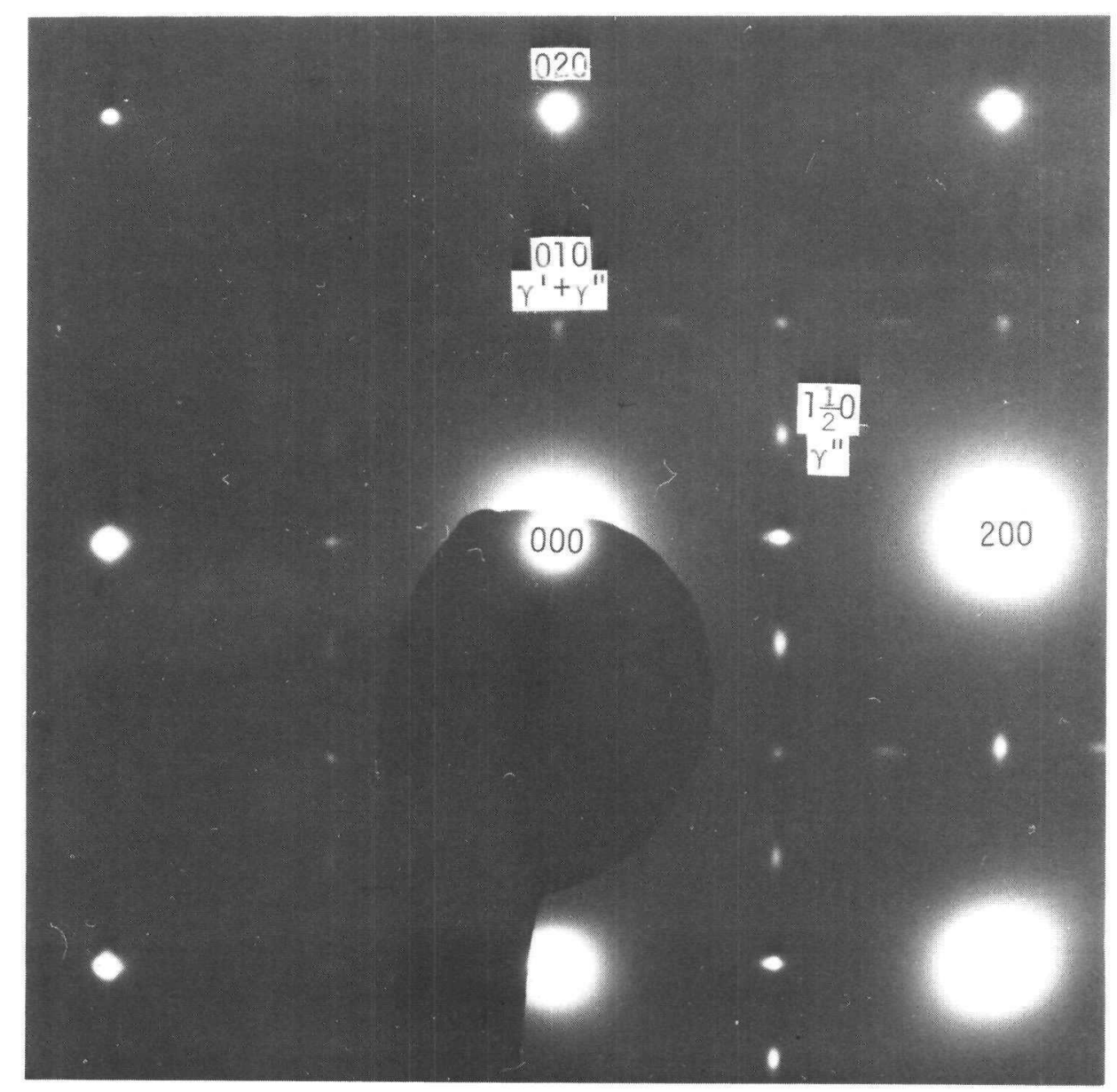

Figure 14. Thin foil micrographs of "conventionally" treated A1loy 718 (Heat B).

(a) [001] electron diffraction pattern revealing both $\gamma^{\prime}$ and $\gamma^{\prime \prime}$ precipitates. 


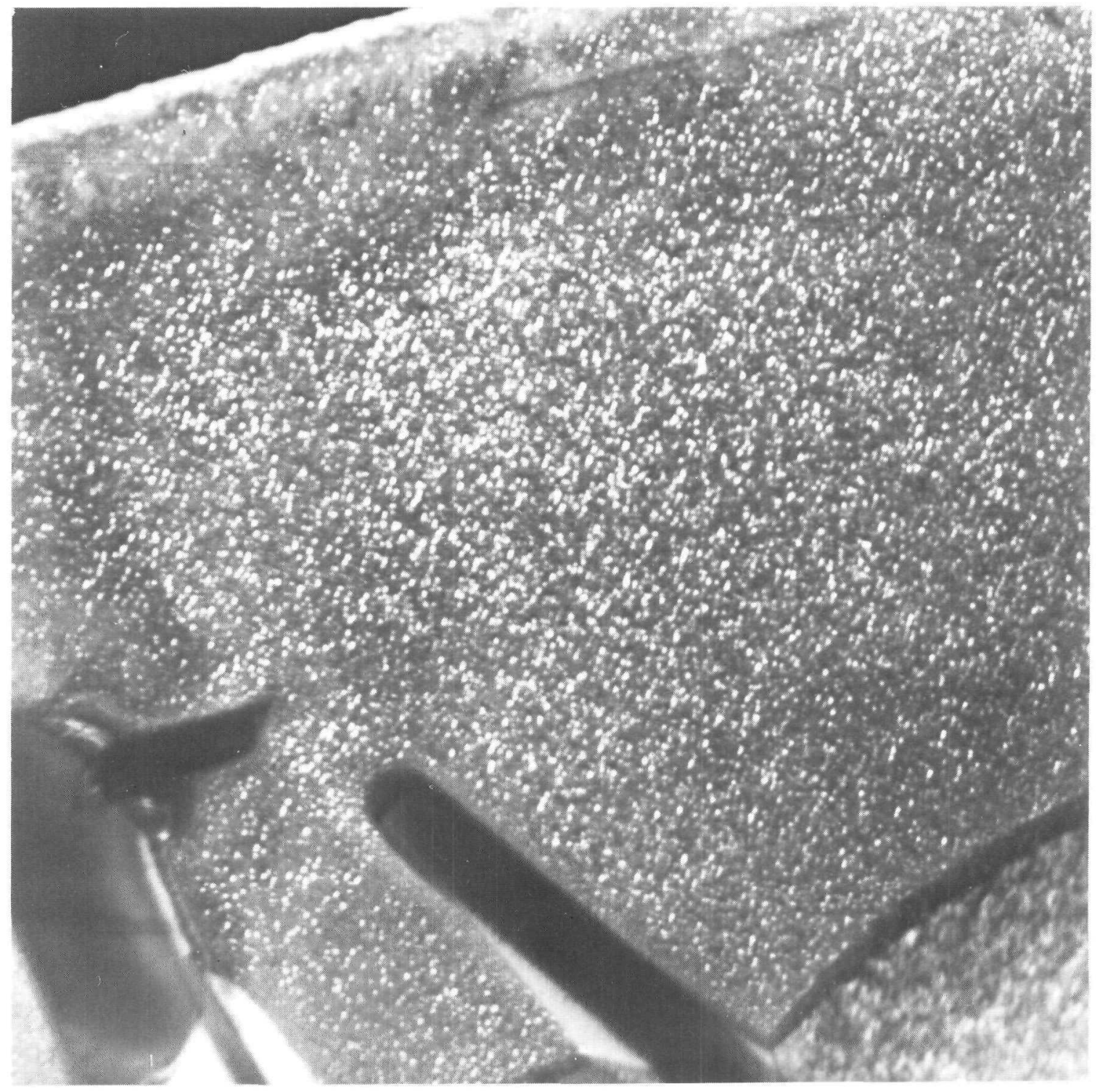

Figure 14 (cont'd). Thin foil micrographs of "conventionally" treated A1loy 718 (Heat B).

(b) 010 dark field photgraph imaging both $\gamma^{\prime}$ and $\gamma^{\prime \prime}$ particles. There appears to be no denuding along the grain boundary. Note the acicular $\delta$ precipitates that initiated along the grain boundary. $(66,000 x)$ 


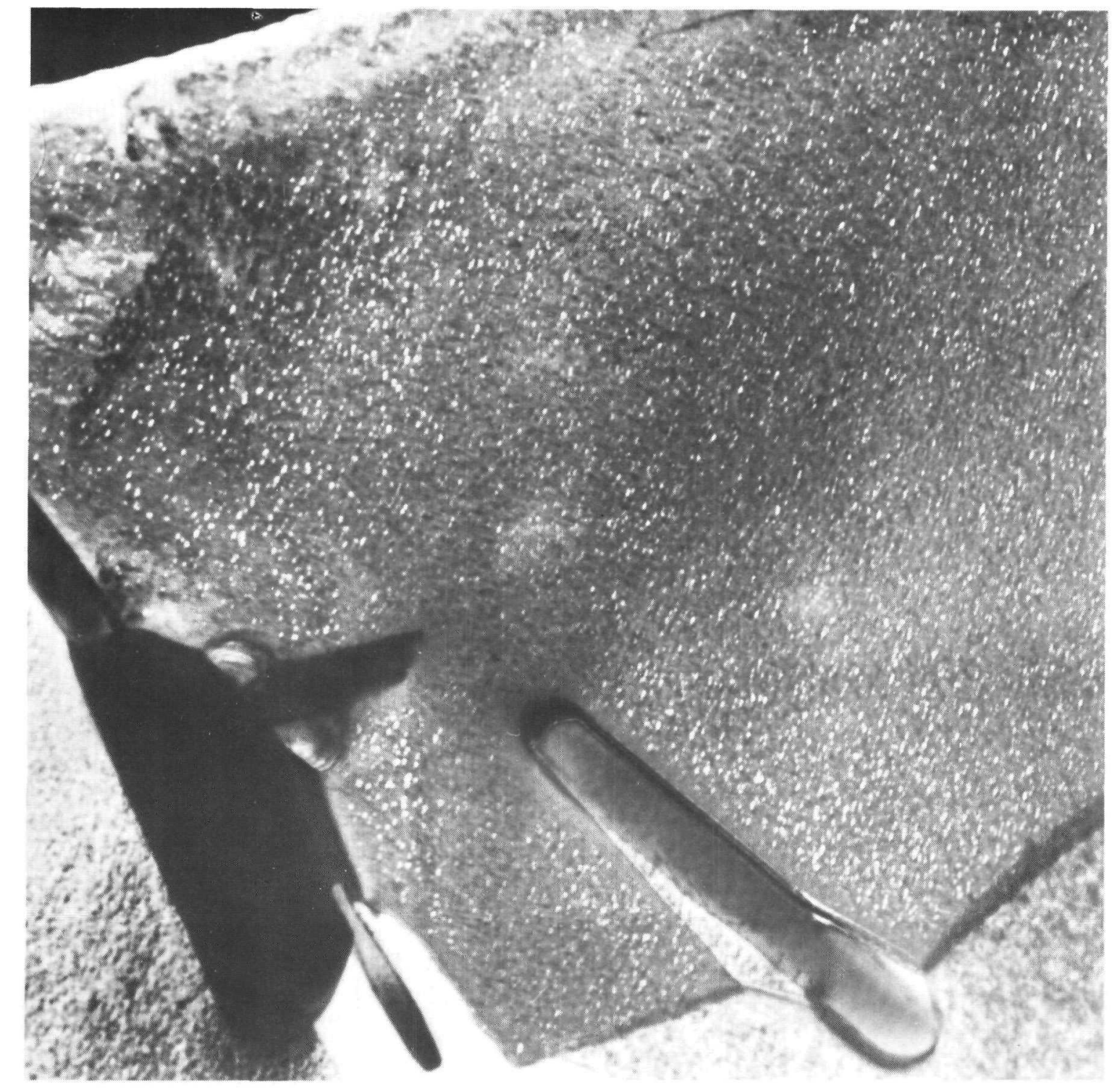

Figure 14 (cont'd). Thin foil micrographs of "conventionally" treated Alloy 718 (Heat B).

(c) $1 \frac{1}{2} 0$ dark field image illustrating only $\gamma^{\pi}$ platelets. No evidence of $\gamma^{\prime \prime}$ denuding along the grain boundary. Note the Widmanstäten $\delta$ precipitates that initiated along the grain boundary. $(66,000 x)$ 


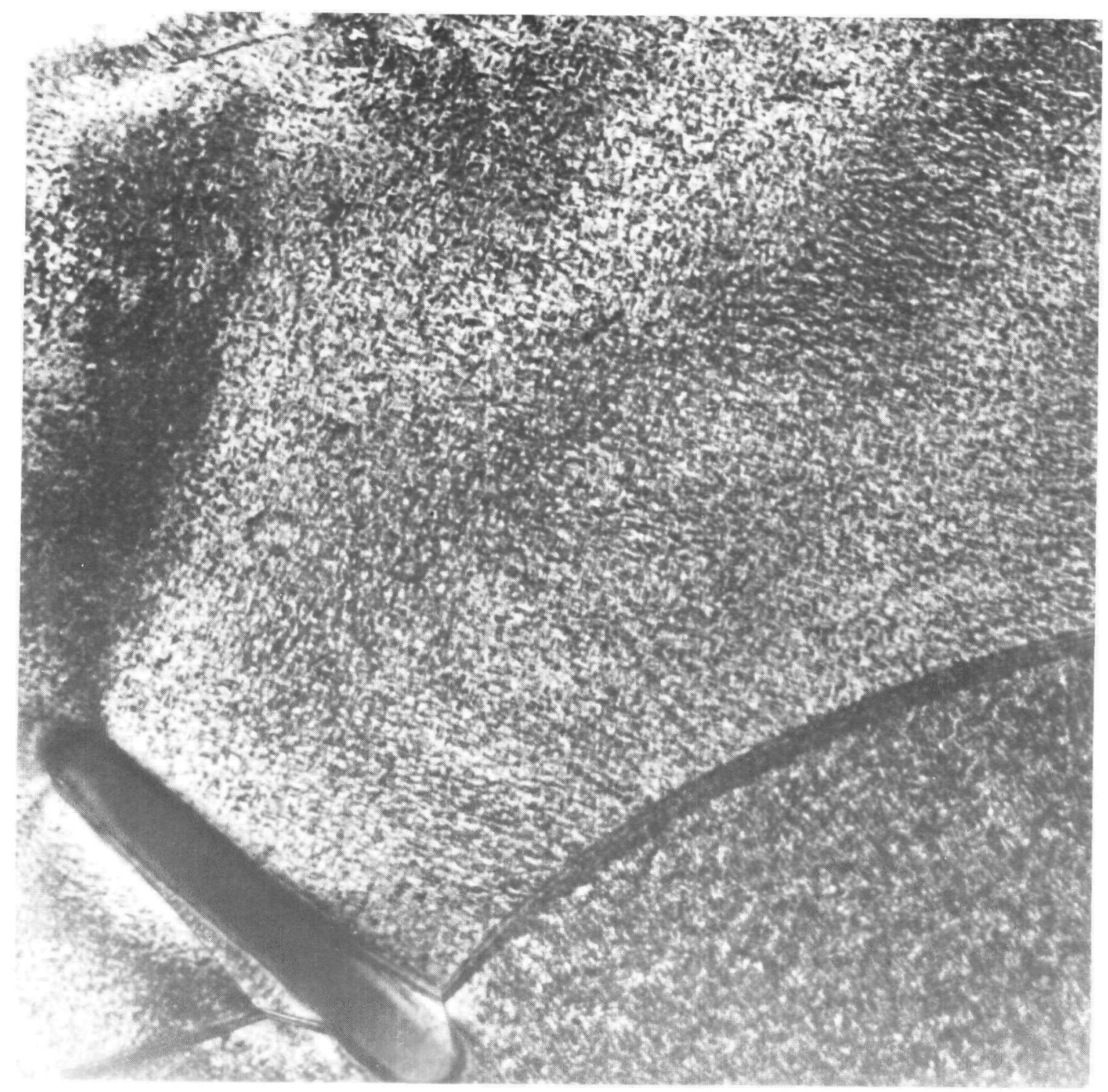

Figure 14 (cont'd). Thin foil micrographs of "conventionally" treated Alloy 718 (Heat B).

(d) Low magnification micrograph of the bright field revealing the acicular $\delta$ precipitate that initiated along the grain boundary $(66,000 \mathrm{X})$ 


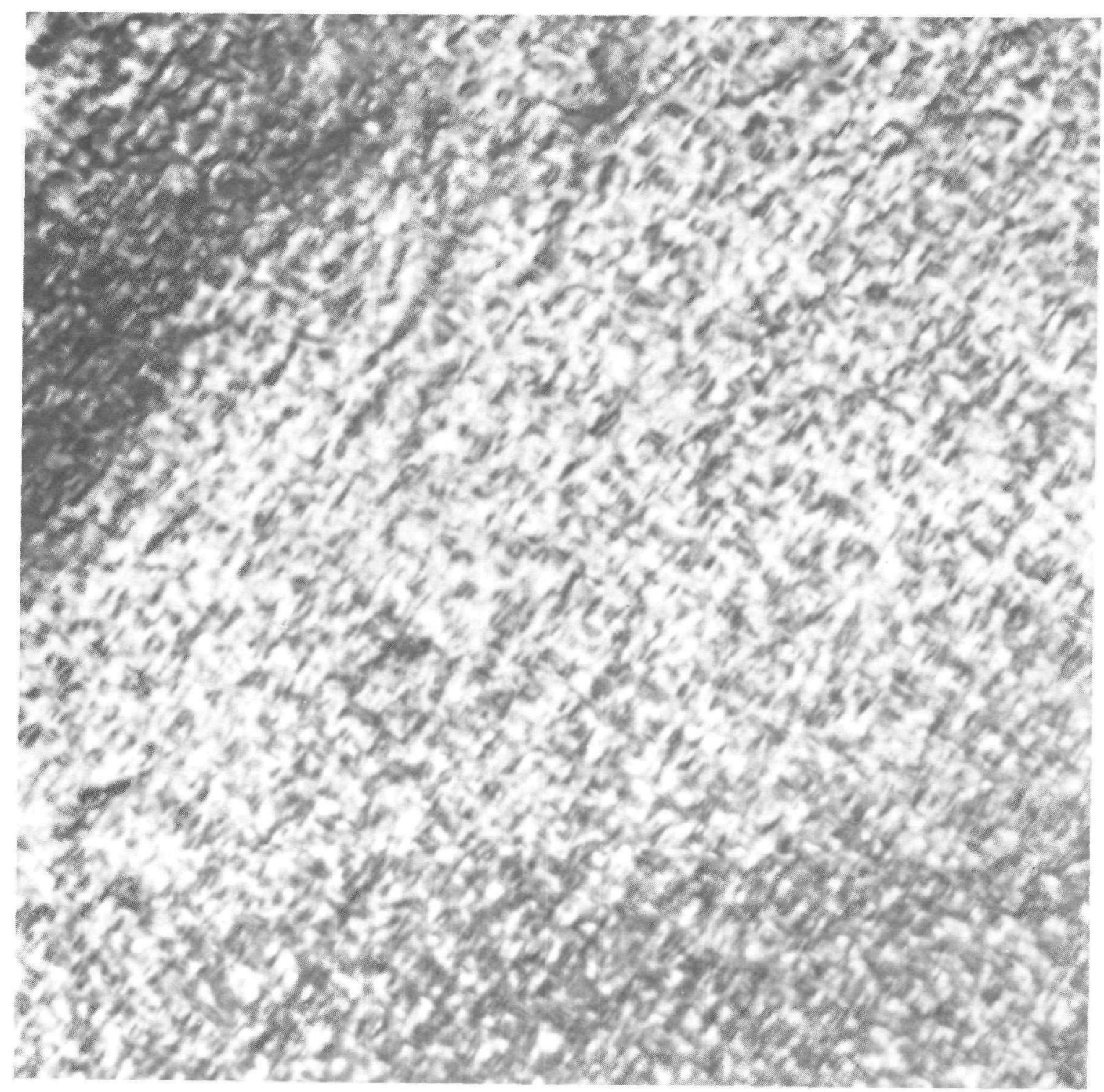

Figure 14 (cont'd). Thin foil micrographs of "conventionally" treated Alloy 718 (Heat B).

(e) High magnification micrograph of the bright field illustrating large coherency strain contrast around $\gamma^{\prime \prime}$ precipitates. $(169,000 x)$ 


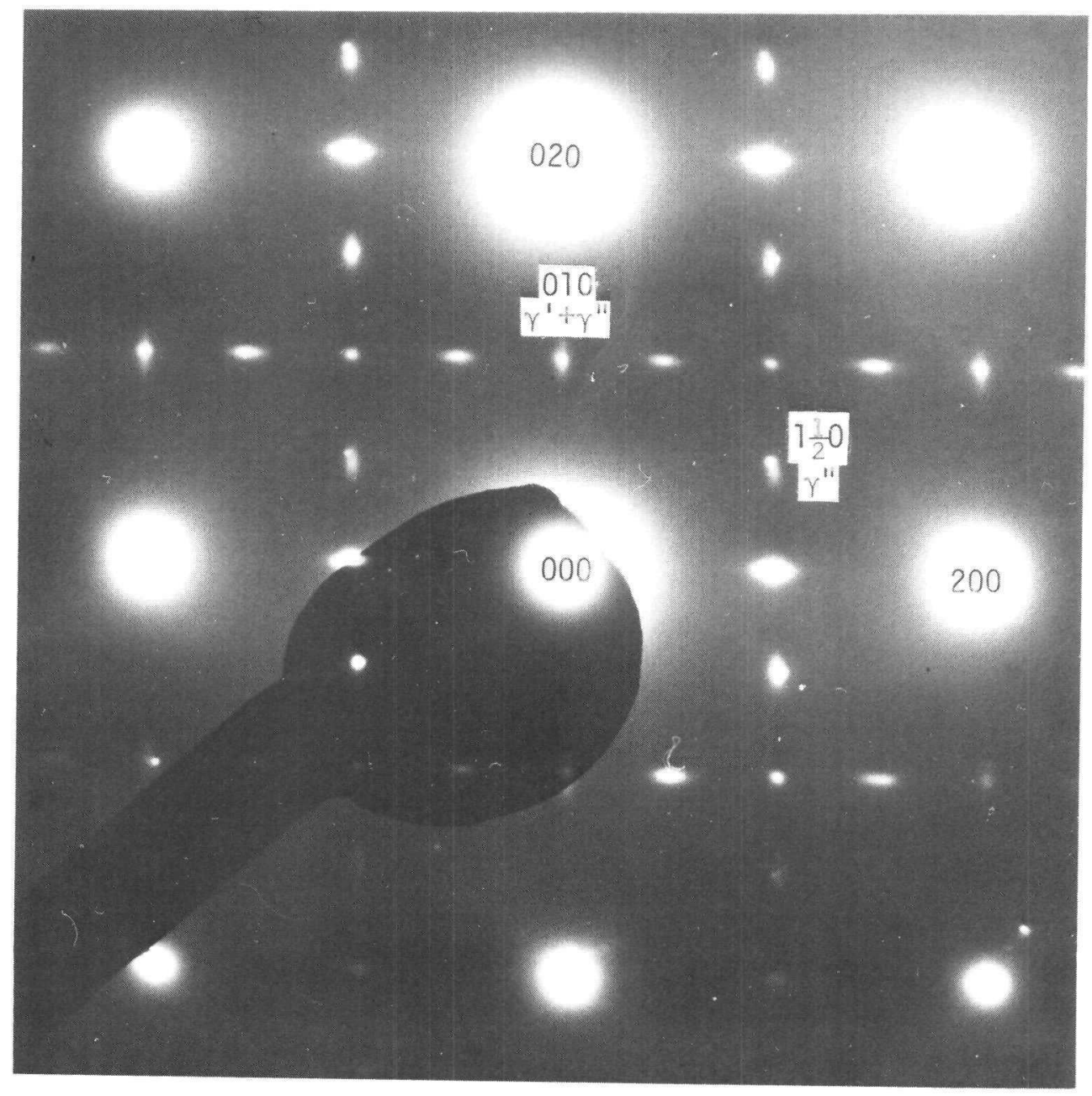

Figure 15. Thin foil micrographs of "conventionally" treated Heat B.

(a) [001] electron diffraction pattern revealing both $\gamma^{\prime}$ and $\gamma^{\prime \prime}$ precipitates. 


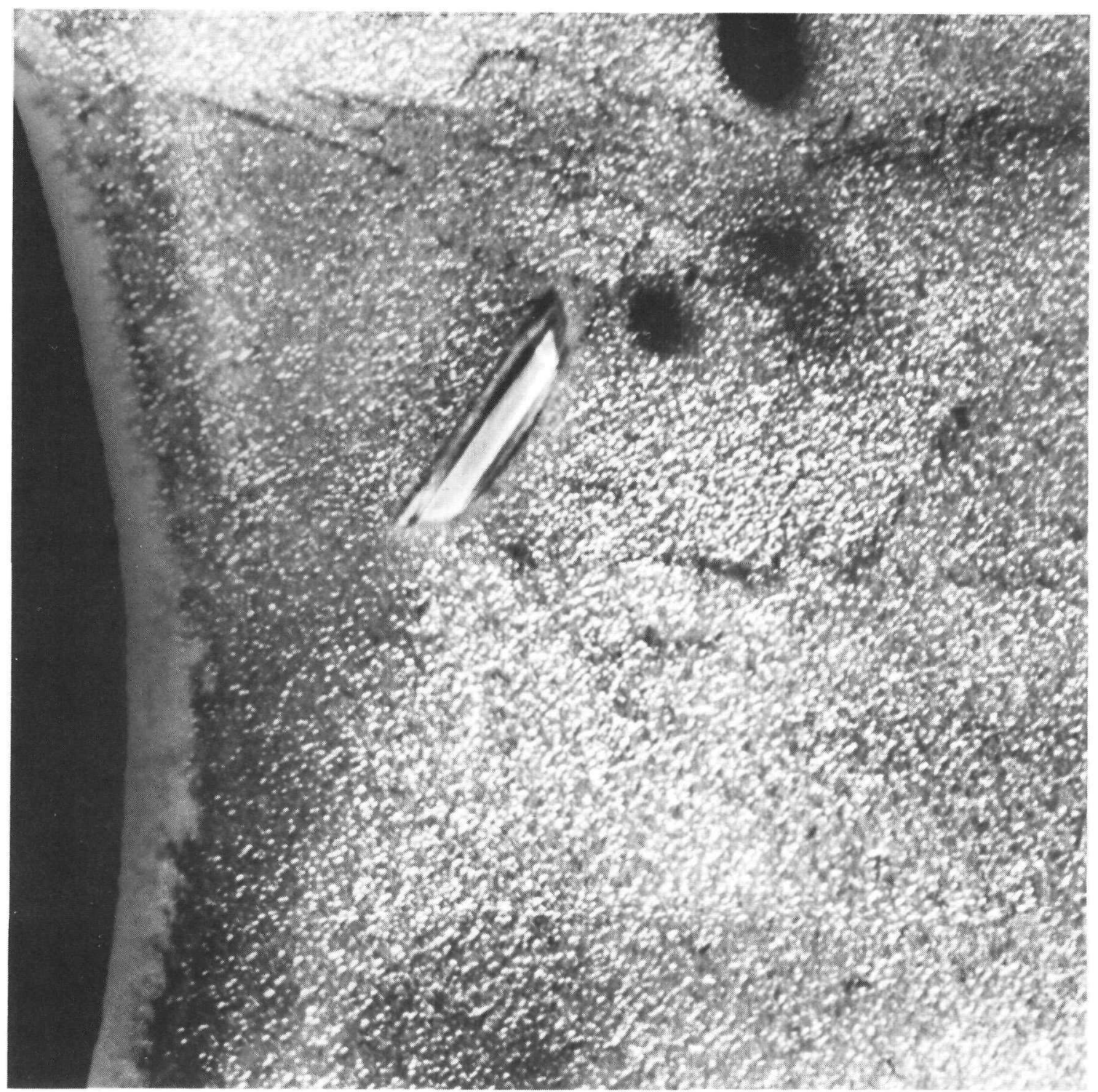

Figure 15 (cont'd). Thin foil micrographs of "conventionally" treated Heat B.

(b) 010 dark field photograph imaging both $\gamma^{\prime}$ and $\gamma^{\prime \prime}$ particles. Note the $\delta$ precipitate. $(66,000 x)$ 


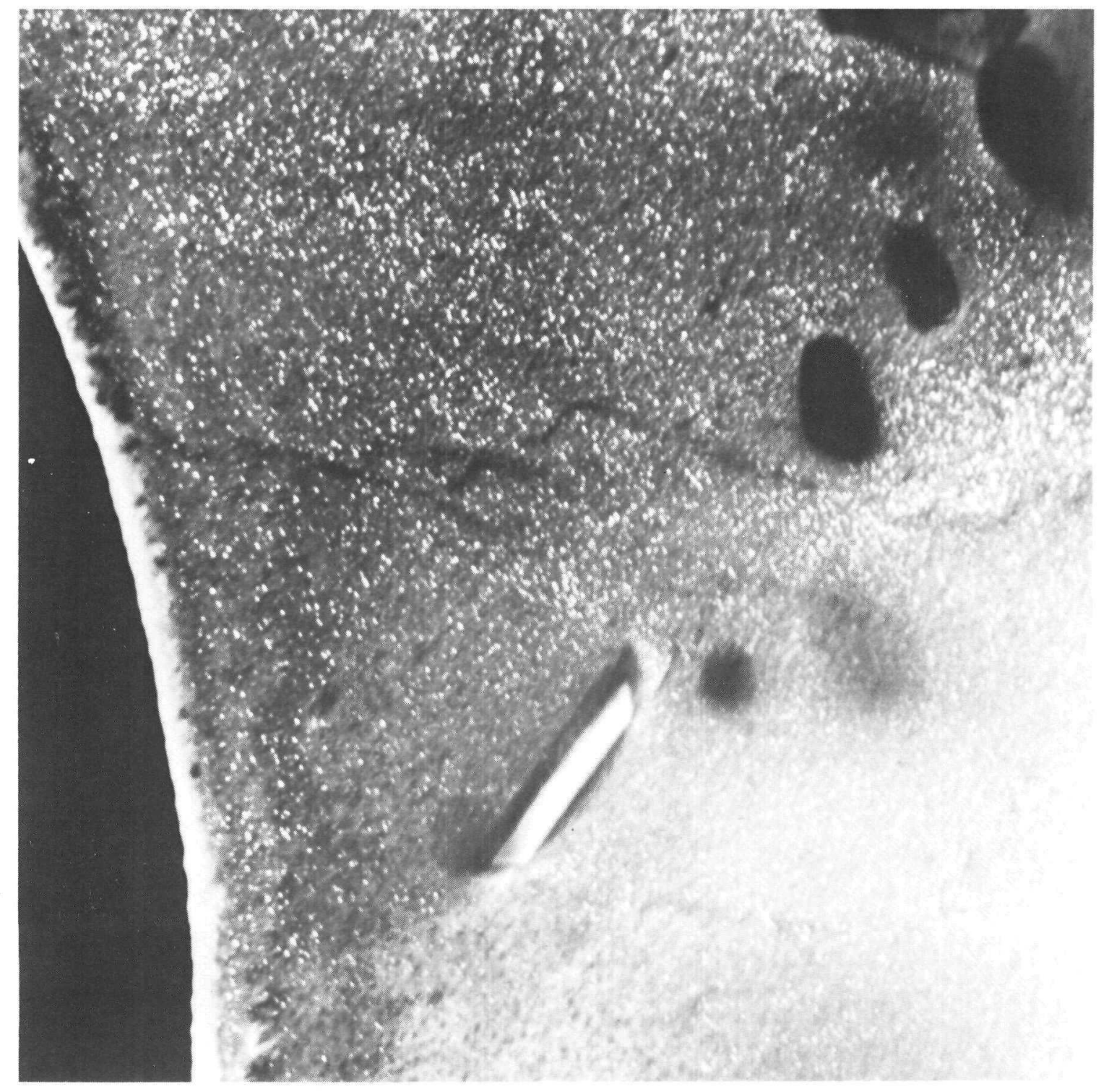

Figure 15 (cont'd). Thin foil micrographs of "conventionally" treated Heat B.

(c) $1 \frac{1}{2} 0$ dark field image illustrating $\gamma^{\prime \prime}$ platelets and a $\delta$ precipitate. $(66,000 \mathrm{X})$ 


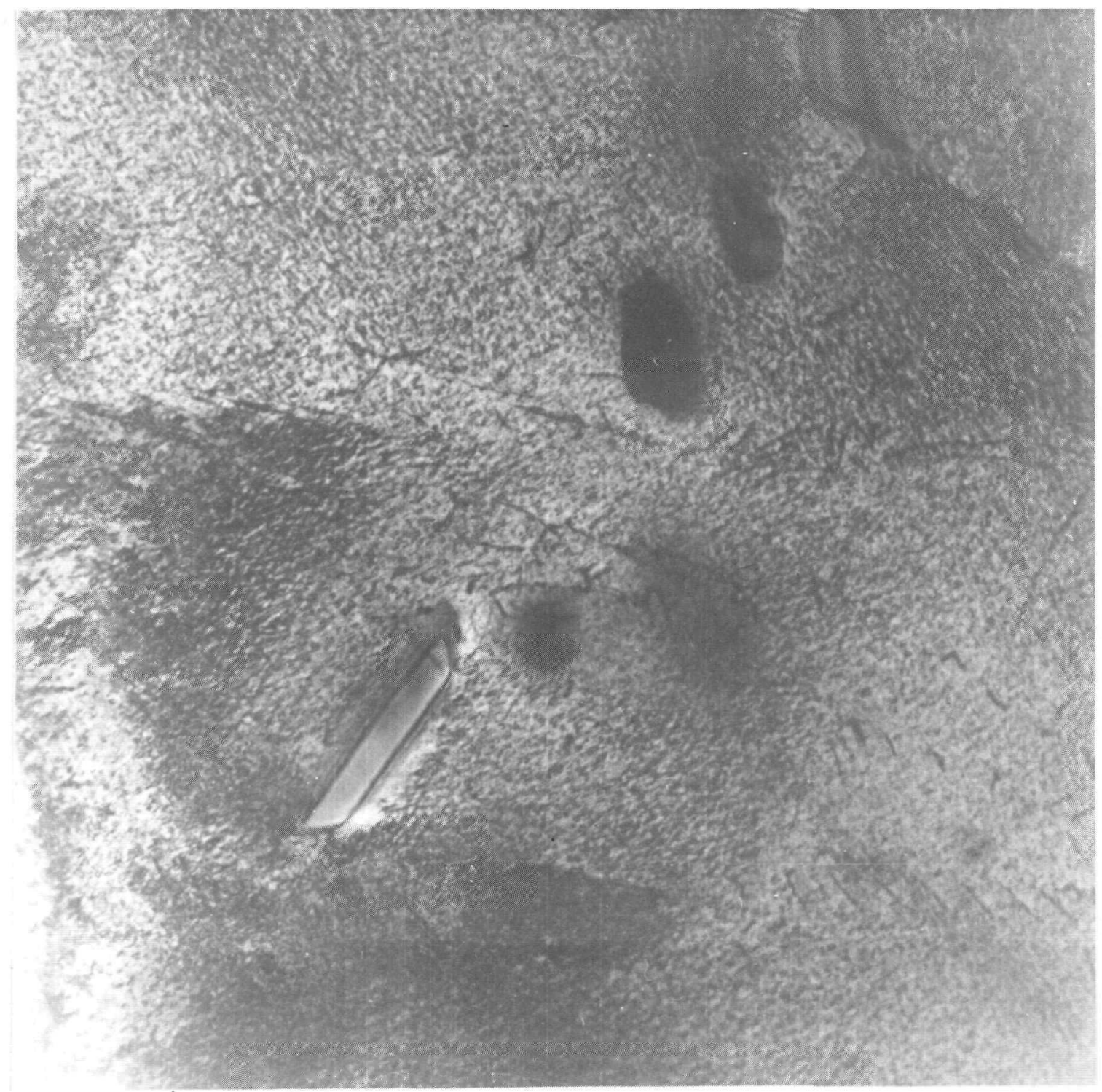

Figure 15 (cont'd). Thin foil micrographs of "conventionally" treated Heat B.

(d) Bright field photograph illustrating large coherency strain contrast around $\gamma^{\prime \prime}$ precipitates. Note the presence of $\delta$ precipitates and dislocations within the fcc matrix.

$(66,000 x)$ 


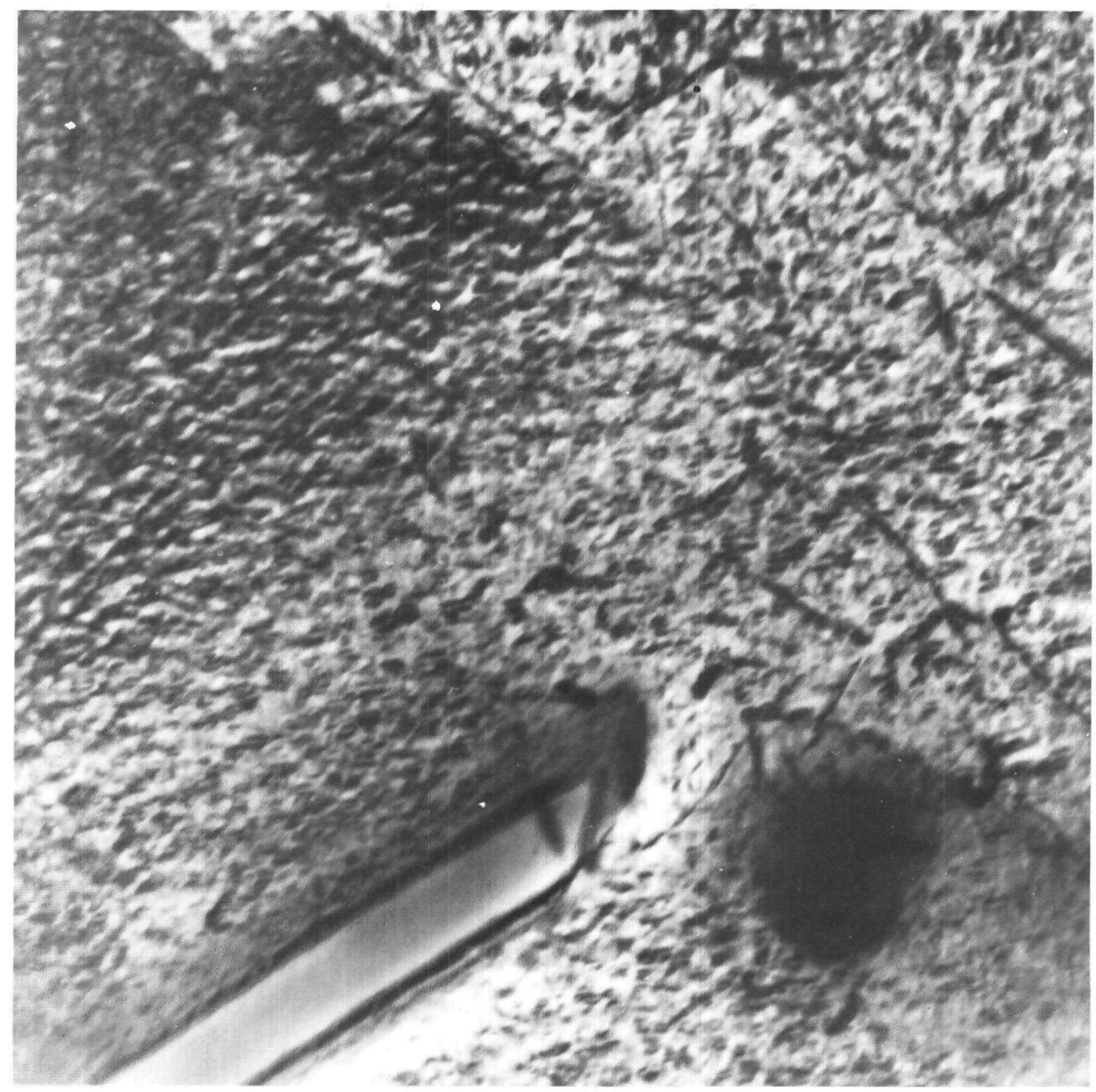

Figure 15 (cont'd). Thin foil micrographs of "conventionally" treated Heat B.

(e) High magnification micrograph of the bright field illustrating large coherency strain contrast around $\gamma^{\prime \prime}$ precipitates. $(169,000 x)$ 


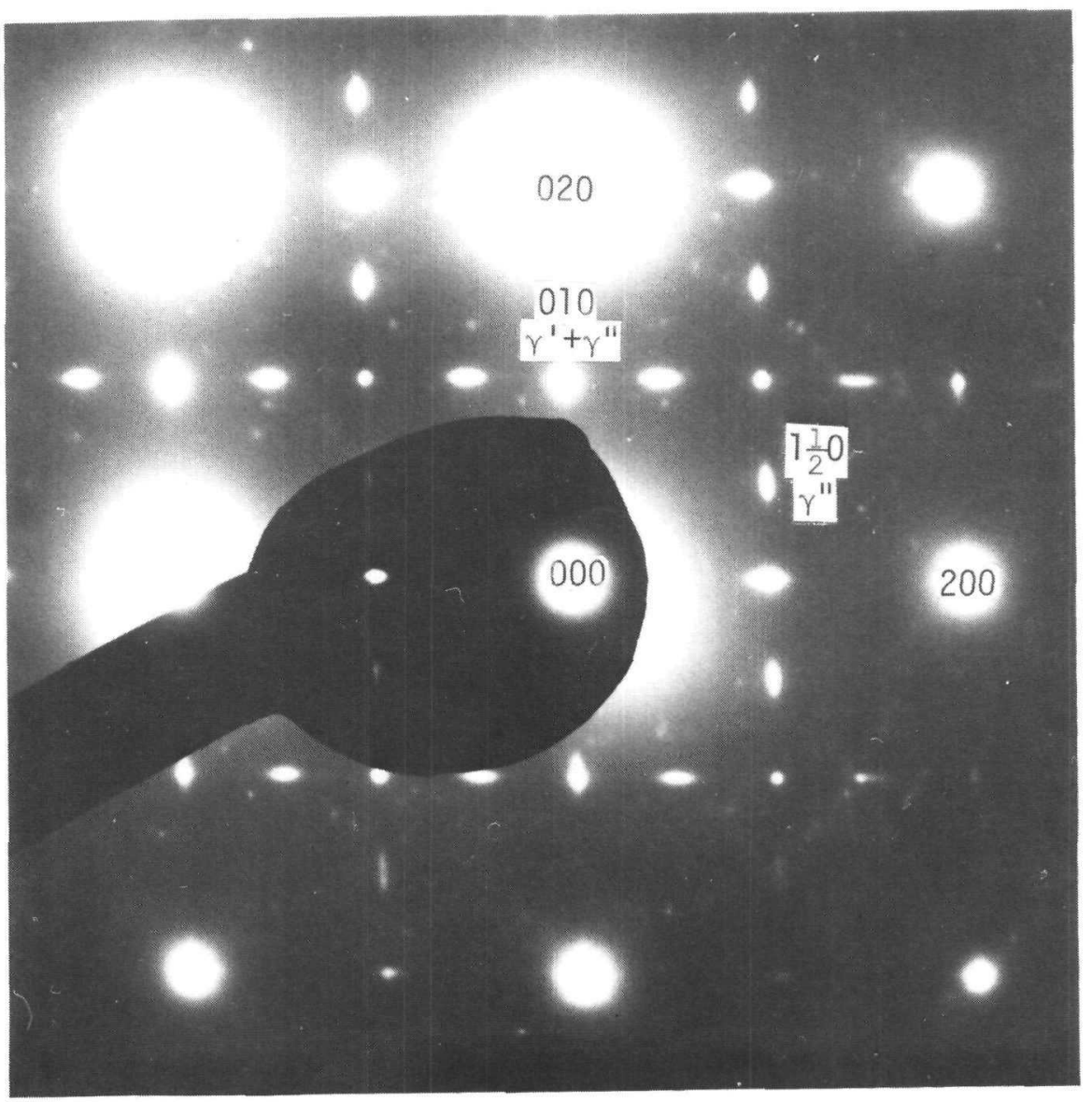

Figure 16. Thin foil micrographs of "modified" heat treated Alloy 718 (Heat B).

(a) [001] electron diffraction pattern showing the existence of the fcc matrix, $\gamma^{\prime}$ and $\gamma^{\prime \prime}$ precipitates. 


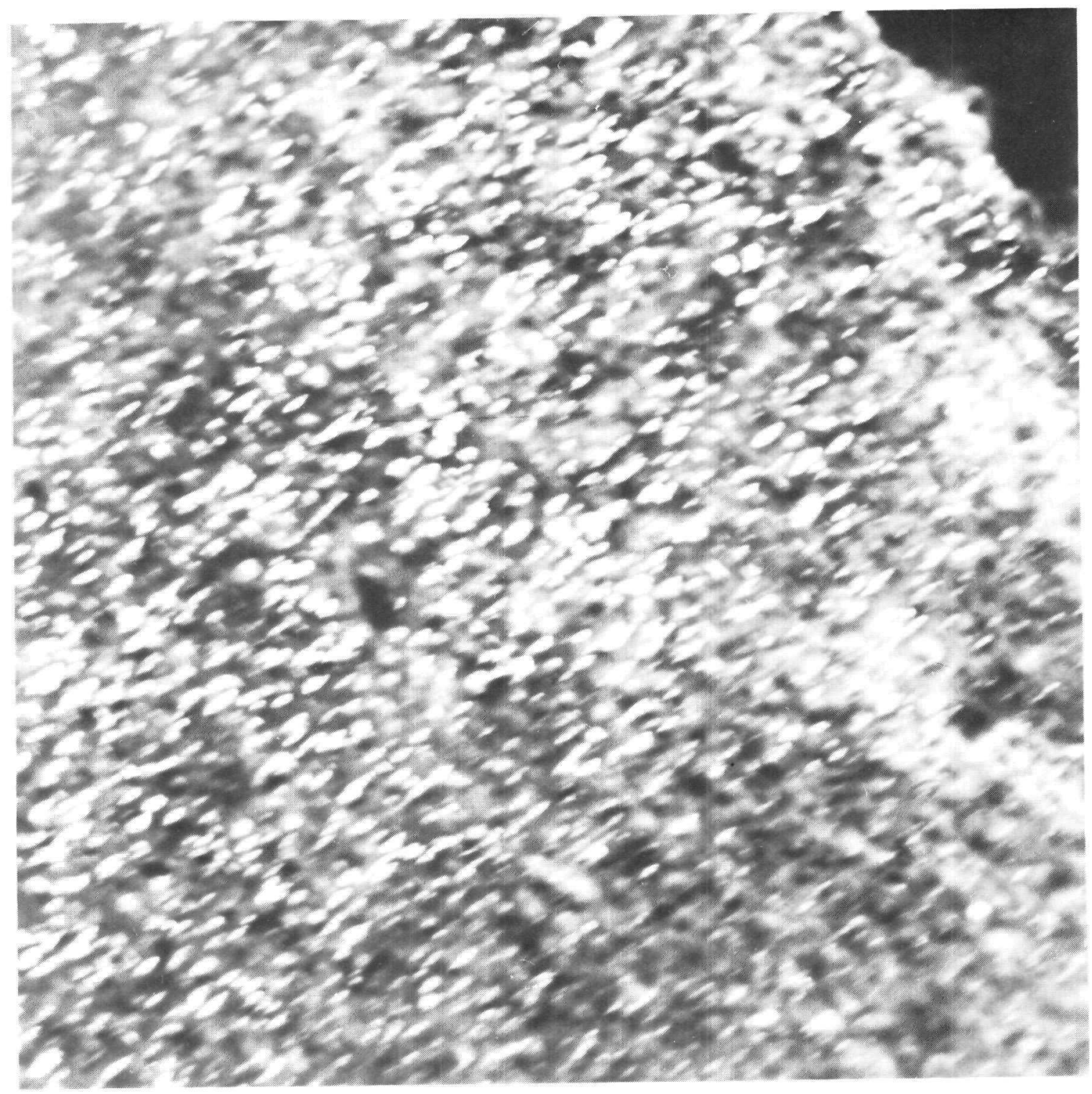

Figure 16 (cont'd). Thin foil micrographs of "modified" heat treated Alloy 718 (Heat B).

(b) 010 dark field photographs imaging both $\gamma^{\prime}$ and $\gamma^{\prime \prime}$ precipitates. $(66,000 \mathrm{X})$. 


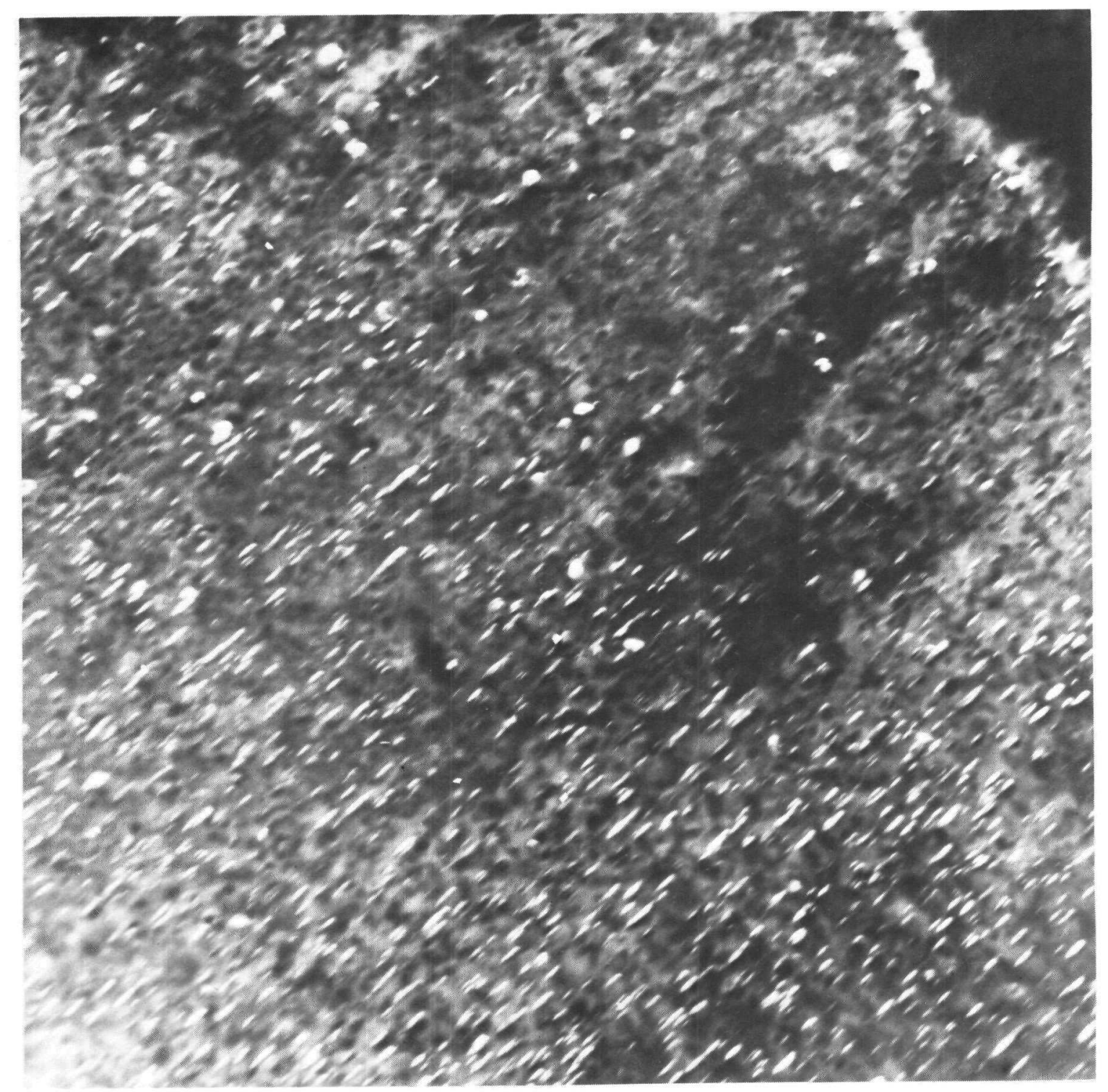

Figure 16 (cont'd). Thin foil micrographs of "modified" heat treated Alloy 718 (Heat B).

(c) $1 \frac{1}{2} 0$ dark field photograph imaging only $\gamma^{\prime \prime}$ platelets. $(66,000 \mathrm{X})$. 


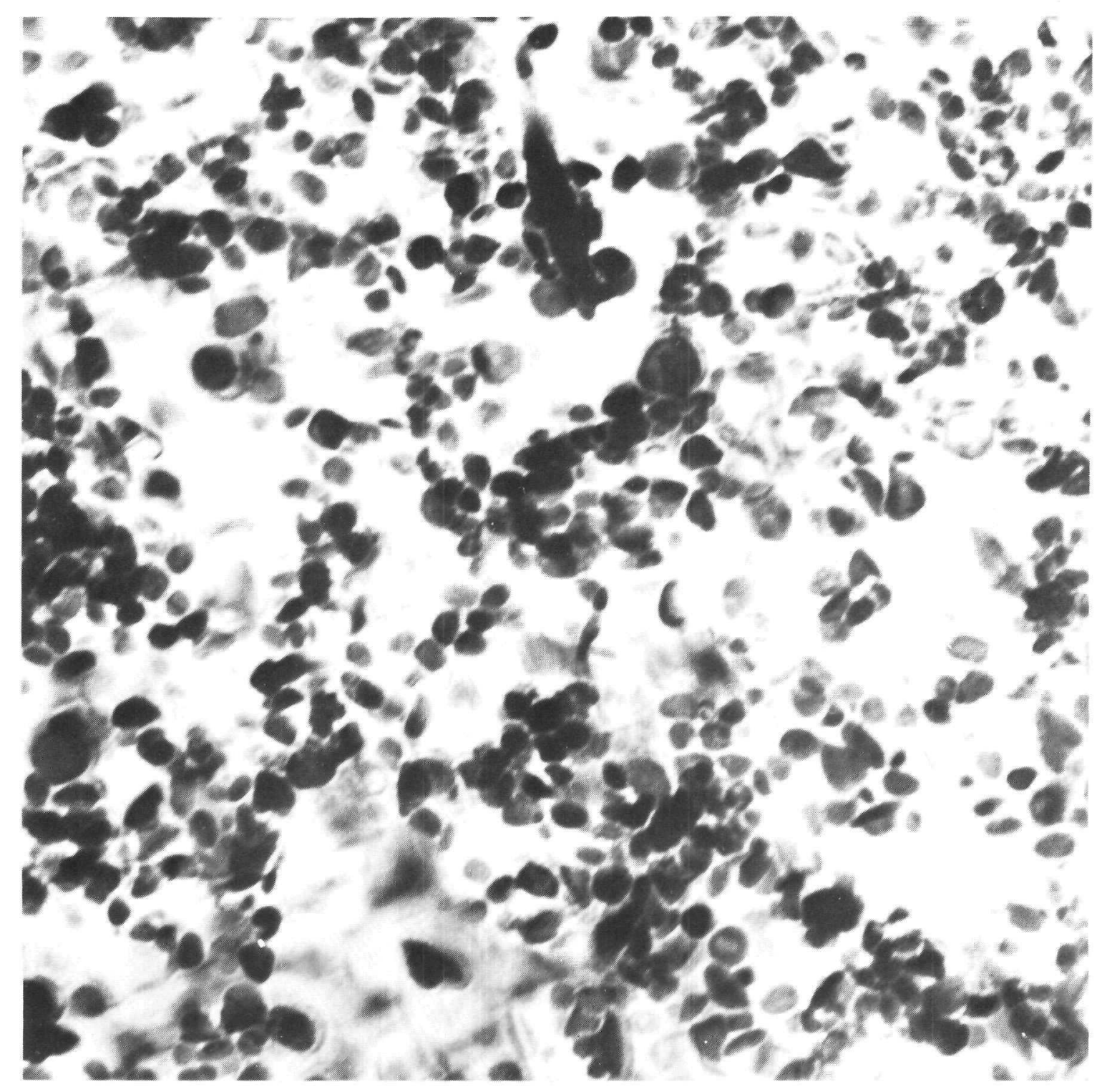

Figure 16 (cont'd). Thin foil micrographs of "modified" heat treated Alloy 718 (Heat B).

(d) High magnification micrograph of the bright field illustrating the large coherency strain contrast around the $\gamma^{\prime \prime}$ precipitates. $(169,000 \mathrm{X})$ 
platelets in addition to a few faint, round $\gamma^{\prime}$ particles. Furthermore, coarse Widmanstätten $\delta$ precipitates were observed only in the "conventionally" treated condition for both Heats A (Figure 6) and B (Figures 14 and 15).

The $\gamma^{\prime \prime}$ platelet size distributions for Heat $B$, established by measuring the dimensions of over 500 platelets from the $1 \frac{1}{2} 0$ dark field micrographs, are given in Figure 17 and Table VII. The average $\gamma^{\prime \prime}$ platelet width was approximately the same for both heat treated conditions; however, the overall $\gamma^{\prime \prime}$ diamter distribution was found to be dependent on heat treatment: $70-380$ $\AA$ for the "conventional" material versus 100 - $670 \AA$ for the "modified" material. In addition, Figure 17 illustrates that the "modified" heat treatment resulted in a higher percentage of large $r$ " platelet diameters (in excess of $300 \AA$ ) with respect to the "conventional " $r$ " diameter distribution, once again indicating that the $\gamma^{\prime \prime}$ platelets tend to coarsen along the diameter dimension during the "modified" heat treatment. The bright field micrographs (Figures $14 \mathrm{c}, 15 \mathrm{c}$, and $16 \mathrm{~d}$ - all at the same magnification) provide evidence that the $r$ " precipitate strain fields were larger for the "modified" treated material, whereas the $\gamma$ " precipitation density once again appeared to be greater in the "conventional" condition. In conclusion, a finer, more closely spaced $r$ " platelet morphology was observed throughout the "conventionally" heat treated matrices of both Heats $A$ and $B$.

\subsubsection{Heat C (Heat No. H-673)}

The microstructures for the Heat $C$ material given the "conventional" and "modified" heat treatments are shown in Figures 18a and 18b, respectively. The grain size differential resulting from the two heat treatments was larger for Heat $C$ than it was for Heats A or B (see Table VI). The "conventional" alloy had a very fine grain structure (ASTM grain size of 11-1/2) as compared to the coarse grain size (ASTM grain size of 4 ) observed in the 


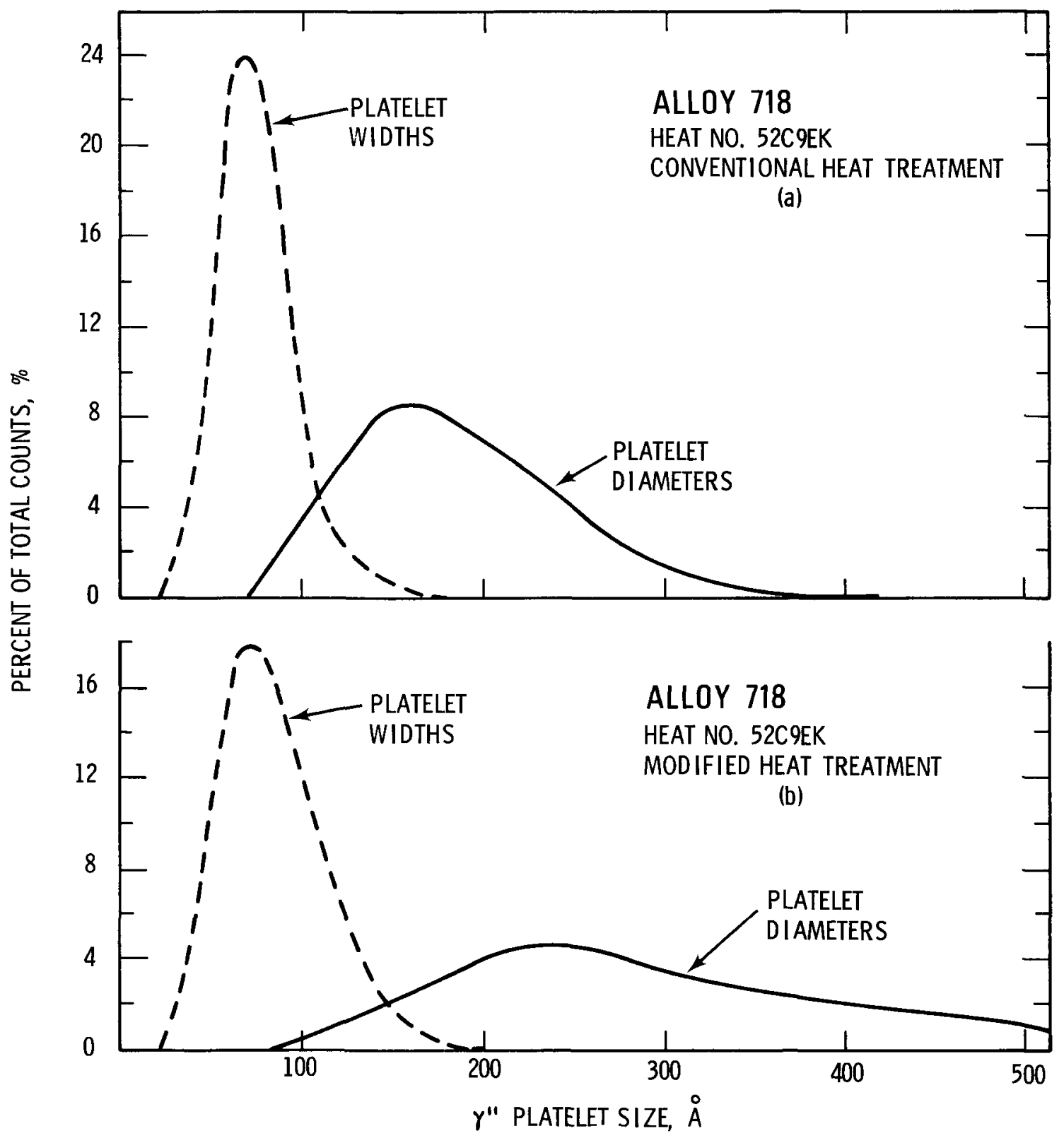

Figure 17. $\quad \gamma^{\prime \prime}$ platelet size distribution for Heat B.

(a) "Conventional" heat treatment.

(b) "Modified" heat treatment. 


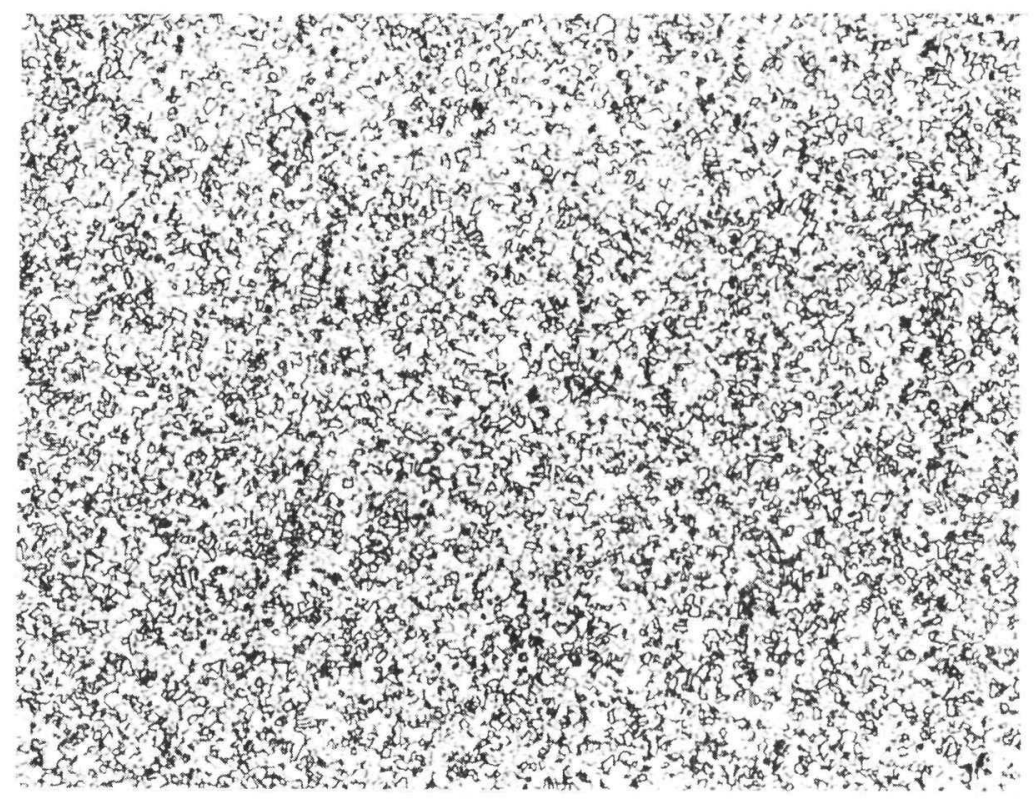

(a)

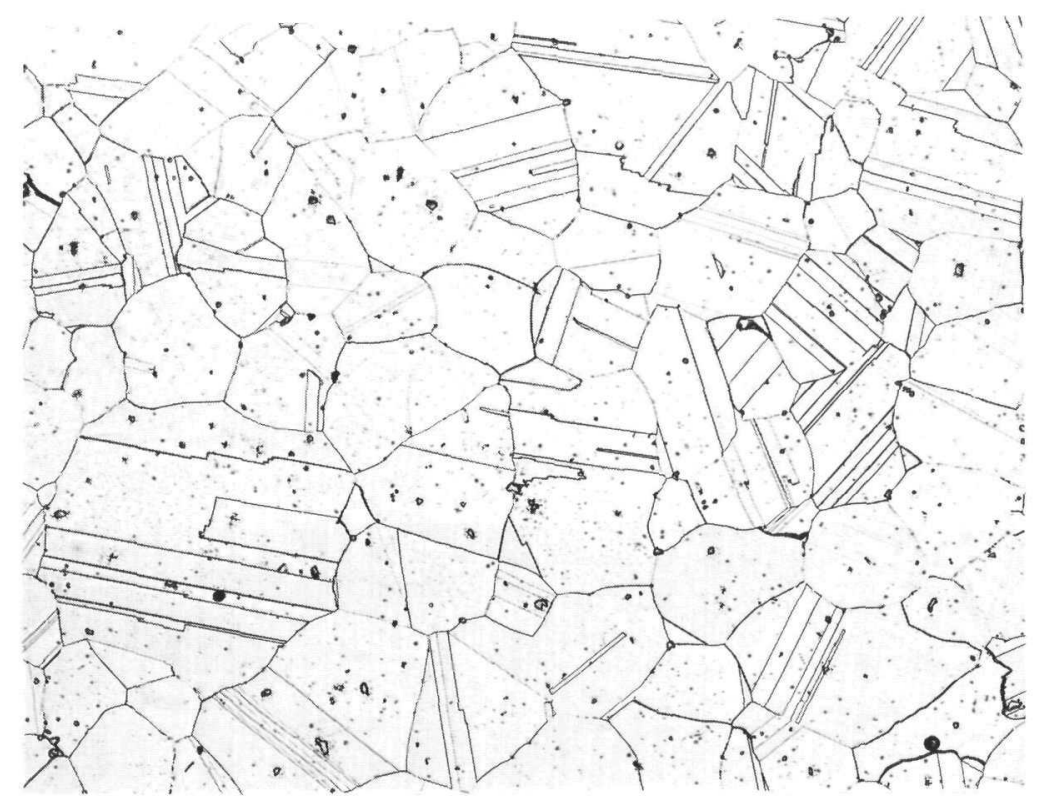

(b)

Figure 18. Microstructure of Heat C.

(a) "Conventiona 7" heat treatment. (100x)

(b) "Modified" heat treatment. (100X) 
"modified" material. Figure 18 also reveals the presence of numerous annealing twins and large MC-type carbide inclusions in both the "conventional" and "modified" microstructures, which is consistent with previous observations for Heats $A$ and $B$.

The precipitate morphology for Heat $C$ is illustrated in Figures 19-21. In the "conventionally" heat-treated condition (Figure 19), coarse lenticular $\delta$ phase particles were found along grain boundaries. In a few regions, intragranular $\delta$ precipitates were observed; however, it is possible that these particles nucleated at a grain boundary and then extended into the grain interior. No evidence of concentrated $\delta$ phase banding was observed in Heat C. Finally, it is interesting to note that the "conventional" precipitate morphology is similar for Heats $A$ and $C$ (Figures 3 and 19, respectively) even though they were produced by different melt practices.

The Heat $C$ material given the "modified" heat treatment exhibited an extremely fine precipitate metwork along the grain boundary, as shown in Figure 20. In addition to this fine intergranular structure, a few large $M C-t y p e$ inclusions were also observed along the grain boundaries (Figure 21); here again, these coarse carbides apparently pinned the grain boundaries during the high temperature anneal employed in the "modified" heat treatment.

By way of summary, the microstructures of all three heats of Alloy 718 given the "modified" treatment were found to be essentially the same. Each heat exhibited a coarse grain microstructure with fine $\delta$ precipitates and a few MC-type carbides along grain boundaries. Furthermore, the "modified" treated material did not exhibit evidence of the abnormal grain structures or severe banding that was observed in the "conventional" condition, thereby suggesting that the high temperature solution anneal $\left(1093^{\circ} \mathrm{C}\right.$ ) used during the "modified" heat treatment produced considerable grain growth, and resulted in a more homogeneous microstructure. 


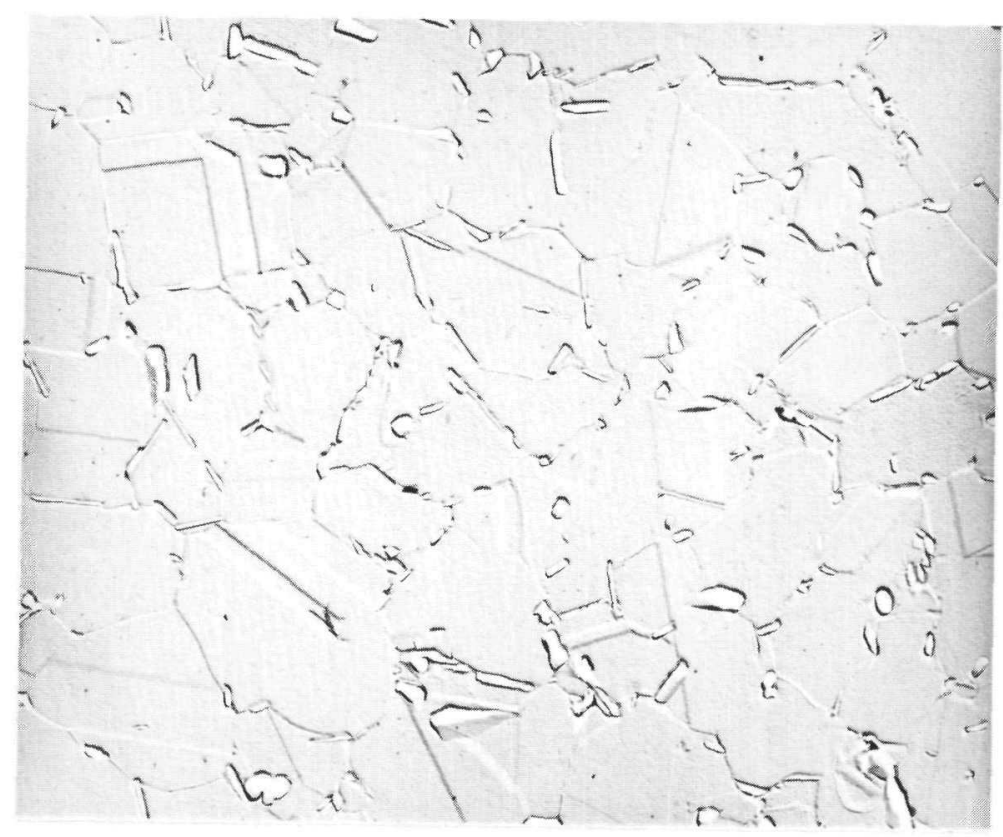

(a)

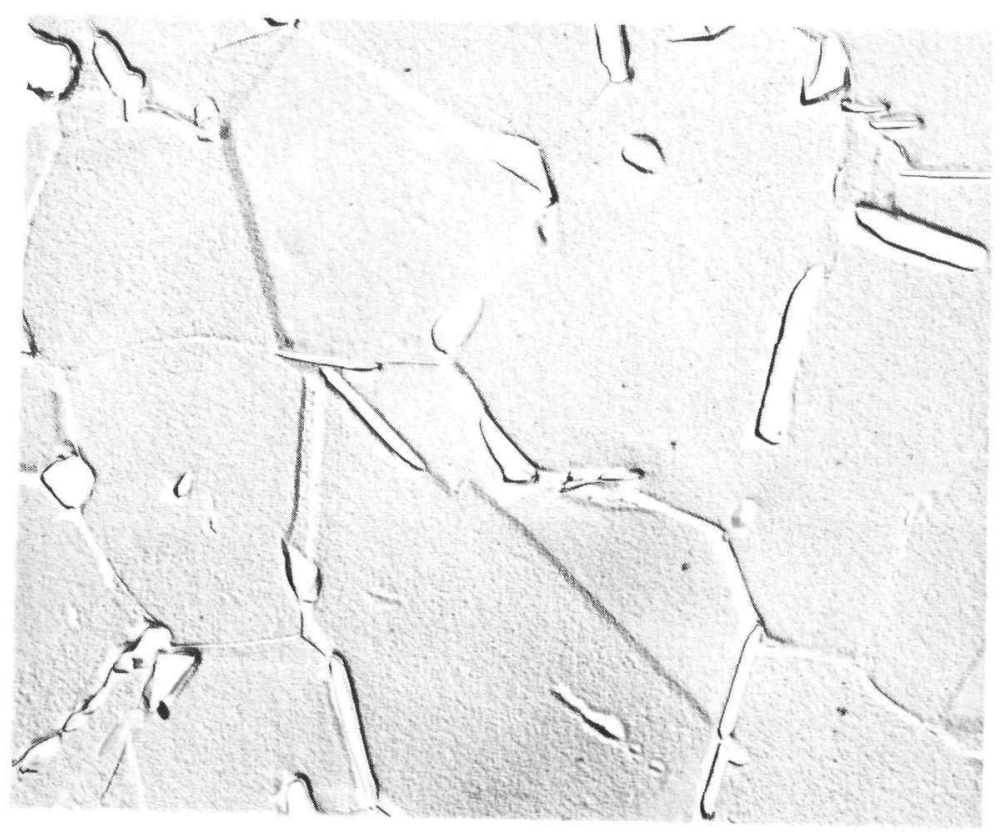

(b)

Figure 19. Surface replica micrographs of Heat $C$ given the "conventional" heat treatment.

(a) Typical microstructure with coarse $\delta$ precipitates decorating the grain boundaries. (2100X)

(b) Higher magnification of the grain boundary region. Note the formation of needle-like $\delta$ particles along the annealing twins. (6216X) 


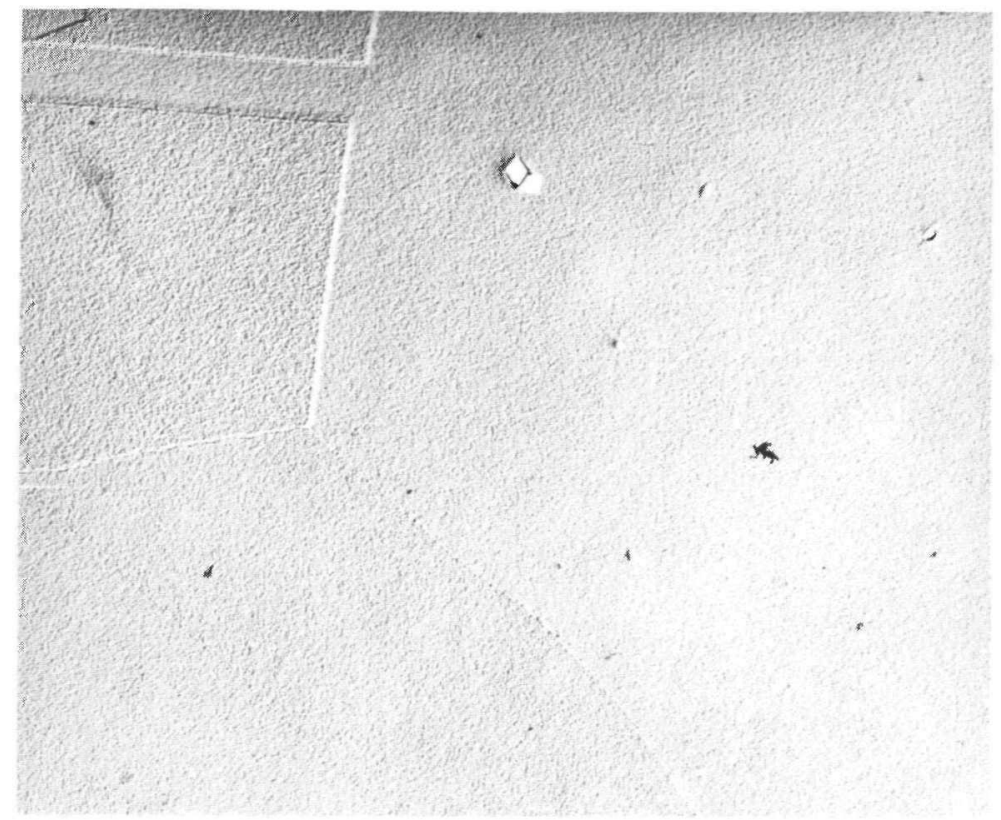

(a)

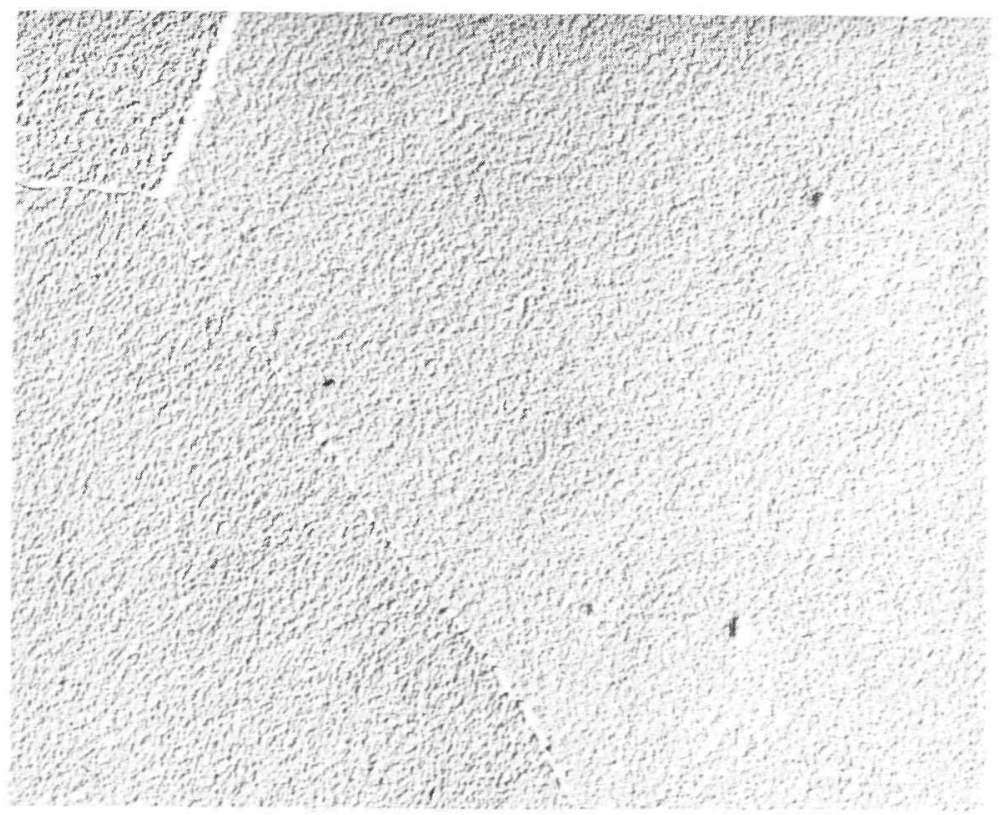

(b)

Figure 20. Electron surface replica micrographs of Heat $B$ given the "modified" precipitation heat treatment.

(a) Typical microstructure with relatively clean grain boundaries and annealing twin boundaries. (2940X)

(b) Higher magnification of the grain boundary triple point region reveals an extremely fine precipitation network along the grain boundary. (6216X) 


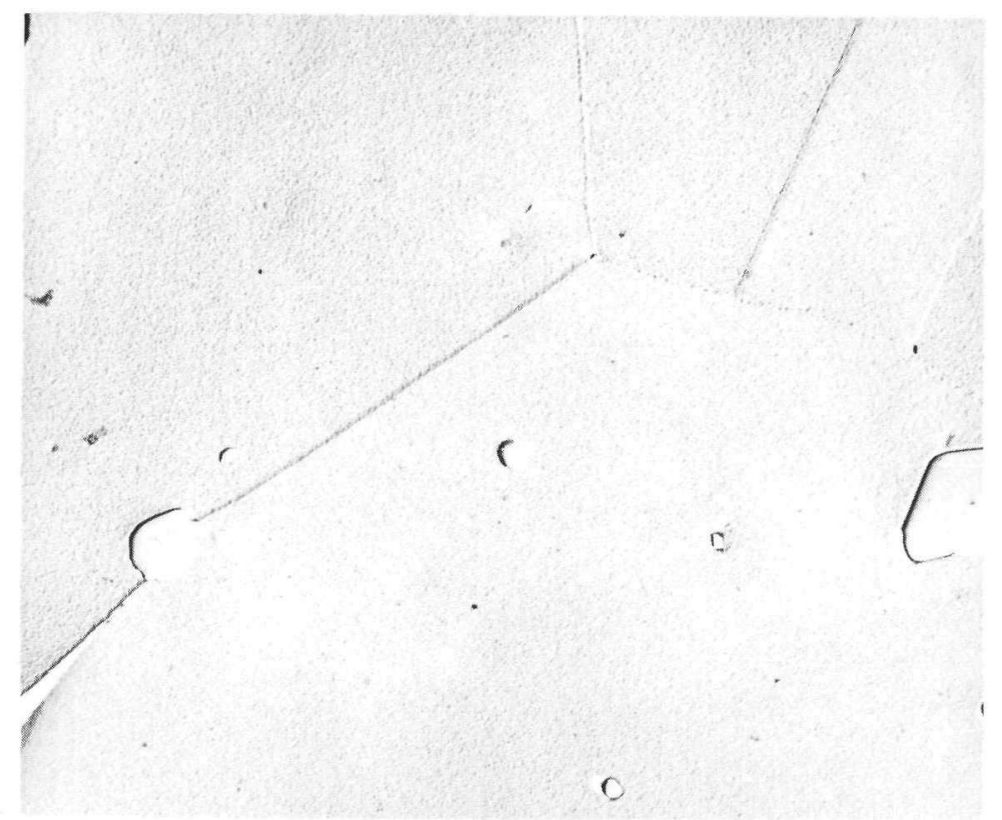

(a)

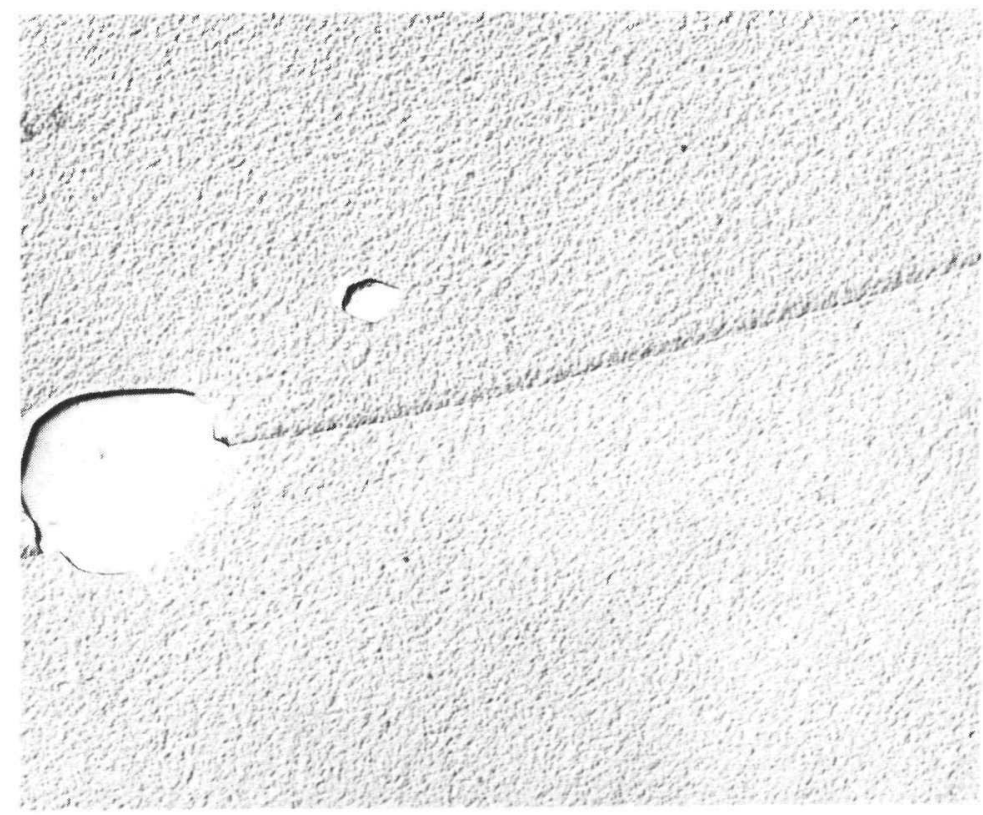

(b)

Figure 21. Surface replica micrographs of Heat $C$ given the "modified" heat treatment.

(a) A few large MC-type inclusions were observed along the grain boundaries and inside the grain interiors. (2100X)

(b) Higher magnification of the grain boundary region of Figure 21a. (6216X) 


\subsection{MECHANICAL PROPERTIES OF ALLOY 718}

Room temperature and elevated temperature tensile property data for the three heats of Alloy 718 are tabulated in Table VIII and illustrated in Figures 22-24. Although the absolute tensile property values were found to be somewhat dependent on heat treatment, both the "conventially" and "modified" treated materials exhibited similar trends in tensile behavior over the test temperature $r$ ange. For example, the $0.2 \%$ offset yield strength for each heat of Alloy 718 was found to be relatively insensitive to temperature (decreasing on $1 y$ about $15 \%$ from room temperature to $649^{\circ} \mathrm{C}$ ), whereas a larger reduction in ultimate strength (approximately $30 \%$ ) was observed over the test temperature range. The ductility parameters, elongation and reduction in area, remained essentially constant up to $538^{\circ} \mathrm{C}$, but at $649^{\circ} \mathrm{C}$ a marked decrease in ductility was detected regardless of heat treatment. This overall tensile behavior for precipitation strengthened Alloy 718 is consistent with that reported in previous investigations. $(21,28-31)$

Comparison of the mechanical response resulting from the two heat treatments revealed that the strength of the "conventionally" treated Heats $A$ and $C$ (Figures 22 and 24) was somewhat greater than that of the "modified" treated superalloy. This behavior is believed to be related to the coarse ' $\gamma$ " precipitate and strain field morphology (Table VII) and large grain size (Table VI) observed in the "modified" heat treated material. Recall that the "modified" treatment resulted in larger $r$ " particles coupled with a

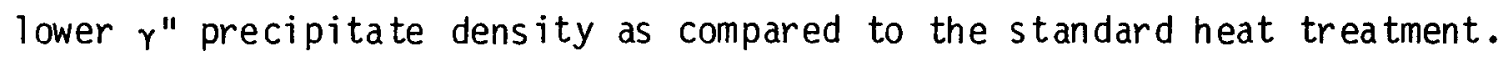
These coarse, widely spaced $\gamma$ " platelets observed in the "modified" age hardened condition adversely affected the strength of this superalloy. In addition, the "modified" material exhibited a larger grain size which is also generally associated with a reduction in strength. It follows, therefore, that the slightly lower strength levels observed in the "modified" treated Heats $A$ and $C$ were caused by the large grain size and the coarse $\gamma^{\prime \prime}$ morphology. 
TABLE VIII

SUMMARY OF MECHANICAL PROPERTIES FOR

PRECIPITATION STRENGTHENED ALLOY 718

\begin{tabular}{|c|c|c|c|c|c|c|c|}
\hline $\begin{array}{c}\text { Heat } \\
\text { Ident. }\end{array}$ & $\begin{array}{c}\text { Heat } \\
\text { Treatment } \\
\end{array}$ & $\begin{array}{l}\text { Test } \\
\text { Temp. } \\
\left({ }^{\circ} \mathrm{C}\right) \\
\end{array}$ & $\begin{array}{c}0.2 \% \text { Yield } \\
\text { Strength } \\
\text { (MPa) } \\
\end{array}$ & $\begin{array}{l}\text { Ul timate } \\
\text { Strength } \\
\text { (MPa) } \\
\end{array}$ & $\begin{array}{c}\text { Uniform } \\
\text { Elong. } \\
(\%) \\
\end{array}$ & $\begin{array}{l}\text { Total } \\
\text { Elong. } \\
(\%) \\
\end{array}$ & $\begin{array}{c}\text { Reduction } \\
\text { in Area } \\
(\%)\end{array}$ \\
\hline $\begin{array}{l}\text { A } \\
" 1 \\
\text { " } \\
\text { " }\end{array}$ & $\begin{array}{c}\text { "Conventional" } \\
\text { " } \\
1 " \\
"\end{array}$ & $\begin{array}{r}24 \\
427 \\
427 \\
538 \\
538\end{array}$ & $\begin{array}{r}1153 \\
942 \\
1037 \\
1013 \\
1000\end{array}$ & $\begin{array}{l}1417 \\
1227 \\
1245 \\
1238 \\
1231\end{array}$ & $\begin{array}{l}13 \\
13 \\
14 \\
14 \\
15\end{array}$ & $\begin{array}{l}16 \\
17 \\
22 \\
17 \\
18\end{array}$ & $\begin{array}{l}37 \\
38 \\
42 \\
43 \\
38\end{array}$ \\
\hline $\begin{array}{l}\text { A } \\
\text { " } \\
\text { " } \\
\text { " }\end{array}$ & $\begin{array}{c}\text { "Modified" } \\
" \\
" \\
" \\
" \\
"\end{array}$ & $\begin{array}{r}24 \\
24 \\
427 \\
427 \\
538 \\
538\end{array}$ & $\begin{array}{r}1027 \\
1029 \\
922 \\
912 \\
918 \\
873\end{array}$ & $\begin{array}{l}1333 \\
1333 \\
1143 \\
1180 \\
1133 \\
1160\end{array}$ & $\begin{array}{l}13 \\
21 \\
13 \\
16 \\
12 \\
13\end{array}$ & $\begin{array}{l}16 \\
22 \\
16 \\
18 \\
15 \\
21\end{array}$ & $\begin{array}{l}36 \\
34 \\
41 \\
35 \\
42 \\
41\end{array}$ \\
\hline $\begin{array}{l}\text { B } \\
" 1 \\
" 1 \\
" 1 \\
" \\
" \\
\text { " } \\
\text { " } \\
\text { " } \\
\text { " }\end{array}$ & $\begin{array}{c}\text { "Conventional" } \\
\text { "" } \\
\text { " } \\
\text { " } \\
\text { " } \\
\text { " } \\
\text { " } \\
\text { " } \\
\text { " } \\
\text { " }\end{array}$ & $\begin{array}{r}24 \\
24 \\
24 \\
24 \\
316 \\
427 \\
427 \\
427 \\
538 \\
538 \\
538 \\
649 \\
649\end{array}$ & $\begin{array}{r}1065 \\
994 \\
984 \\
1038 \\
924 \\
931 \\
919 \\
977 \\
897 \\
889 \\
908 \\
826 \\
855\end{array}$ & $\begin{array}{l}1365 \\
1267 \\
1318 \\
1326 \\
1152 \\
1147 \\
1131 \\
1171 \\
1120 \\
1104 \\
1129 \\
939 \\
962\end{array}$ & $\begin{array}{l}16 \\
19 \\
18 \\
18 \\
16 \\
14 \\
14 \\
16 \\
16 \\
12 \\
17 \\
6 \\
7\end{array}$ & $\begin{array}{l}16 \\
20 \\
19 \\
20 \\
19 \\
17 \\
18 \\
18 \\
18 \\
14 \\
19 \\
7 \\
7\end{array}$ & $\begin{array}{l}31 \\
31 \\
28 \\
38 \\
32 \\
31 \\
31 \\
26 \\
30 \\
25 \\
33 \\
17 \\
15\end{array}$ \\
\hline
\end{tabular}


TABLE VIII (Continued)

\begin{tabular}{|c|c|c|c|c|c|c|c|}
\hline $\begin{array}{l}\text { Heat } \\
\text { Ident. }\end{array}$ & $\begin{array}{c}\text { Heat } \\
\text { Treatment } \\
\end{array}$ & $\begin{array}{l}\text { Test } \\
\text { Temp. } \\
\left({ }^{\circ} \mathrm{C}\right) \\
\end{array}$ & $\begin{array}{c}0.2 \% \text { Yield } \\
\text { Strength } \\
\text { (MPa) } \\
\end{array}$ & $\begin{array}{l}\text { Ultimate } \\
\text { Strength } \\
\text { (MPa) } \\
\end{array}$ & $\begin{array}{c}\text { Uniform } \\
\text { Elong. } \\
(\%) \\
\end{array}$ & $\begin{array}{l}\text { Total } \\
\text { Elong. } \\
(\%) \\
\end{array}$ & $\begin{array}{c}\text { Reduction } \\
\text { in Area } \\
(\%) \\
\end{array}$ \\
\hline $\begin{array}{l}\text { B } \\
" 1 \\
" 1 \\
" 1 \\
" 1 \\
" 1\end{array}$ & $\begin{array}{c}\text { "Modified" } \\
\text { " } \\
\text { " } \\
\text { " } \\
\text { " } \\
\text { " }\end{array}$ & $\begin{array}{r}24 \\
24 \\
316 \\
427 \\
427 \\
538 \\
538 \\
649\end{array}$ & $\begin{array}{r}1011 \\
1033 \\
943 \\
889 \\
901 \\
866 \\
880 \\
829\end{array}$ & $\begin{array}{r}1325 \\
1322 \\
1212 \\
1209 \\
1211 \\
1182 \\
1200 \\
907\end{array}$ & $\begin{array}{r}11 \\
18 \\
15 \\
12 \\
15 \\
13 \\
15 \\
6\end{array}$ & $\begin{array}{l}11 \\
19 \\
17 \\
13 \\
16 \\
15 \\
16 \\
10\end{array}$ & $\begin{array}{l}18 \\
28 \\
25 \\
18 \\
27 \\
24 \\
19 \\
18\end{array}$ \\
\hline $\begin{array}{l}\text { C } \\
1 " \\
1 " \\
1 " \\
" \\
\text { " } \\
\text { " }\end{array}$ & $\begin{array}{c}\text { "Conventiona]" } \\
\text { " } \\
\text { " } \\
\text { " } \\
\text { " } \\
\text { " }\end{array}$ & $\begin{array}{r}24 \\
24 \\
316 \\
427 \\
427 \\
538 \\
538 \\
649\end{array}$ & $\begin{array}{l}1154 \\
1120 \\
1085 \\
1065 \\
1065 \\
1061 \\
1015 \\
954\end{array}$ & $\begin{array}{l}1447 \\
1423 \\
1333 \\
1288 \\
1328 \\
1330 \\
1282 \\
1011\end{array}$ & $\begin{array}{r}17 \\
18 \\
18 \\
15 \\
17 \\
14 \\
15 \\
4\end{array}$ & $\begin{array}{l}20 \\
20 \\
21 \\
18 \\
20 \\
19 \\
20 \\
10\end{array}$ & $\begin{array}{l}37 \\
40 \\
42 \\
42 \\
42 \\
48 \\
49 \\
--\end{array}$ \\
\hline $\begin{array}{l}\text { C } \\
" 1 \\
1 " \\
1 " \\
" 1 \\
\text { " } \\
\text { " }\end{array}$ & $\begin{array}{c}\text { "Modified" } \\
\text { " } \\
\text { " } \\
\text { " } \\
\text { " } \\
\text { " }\end{array}$ & $\begin{array}{r}24 \\
24 \\
316 \\
427 \\
427 \\
538 \\
538 \\
649\end{array}$ & $\begin{array}{l}956 \\
967 \\
900 \\
862 \\
859 \\
838 \\
834 \\
827\end{array}$ & $\begin{array}{l}1299 \\
1310 \\
1195 \\
1175 \\
1148 \\
1137 \\
1147 \\
926\end{array}$ & $\begin{array}{r}21 \\
19 \\
16 \\
18 \\
15 \\
17 \\
18 \\
5\end{array}$ & $\begin{array}{r}23 \\
21 \\
17 \\
20 \\
17 \\
18 \\
21 \\
6\end{array}$ & $\begin{array}{l}42 \\
41 \\
38 \\
34 \\
37 \\
34 \\
32 \\
14\end{array}$ \\
\hline
\end{tabular}



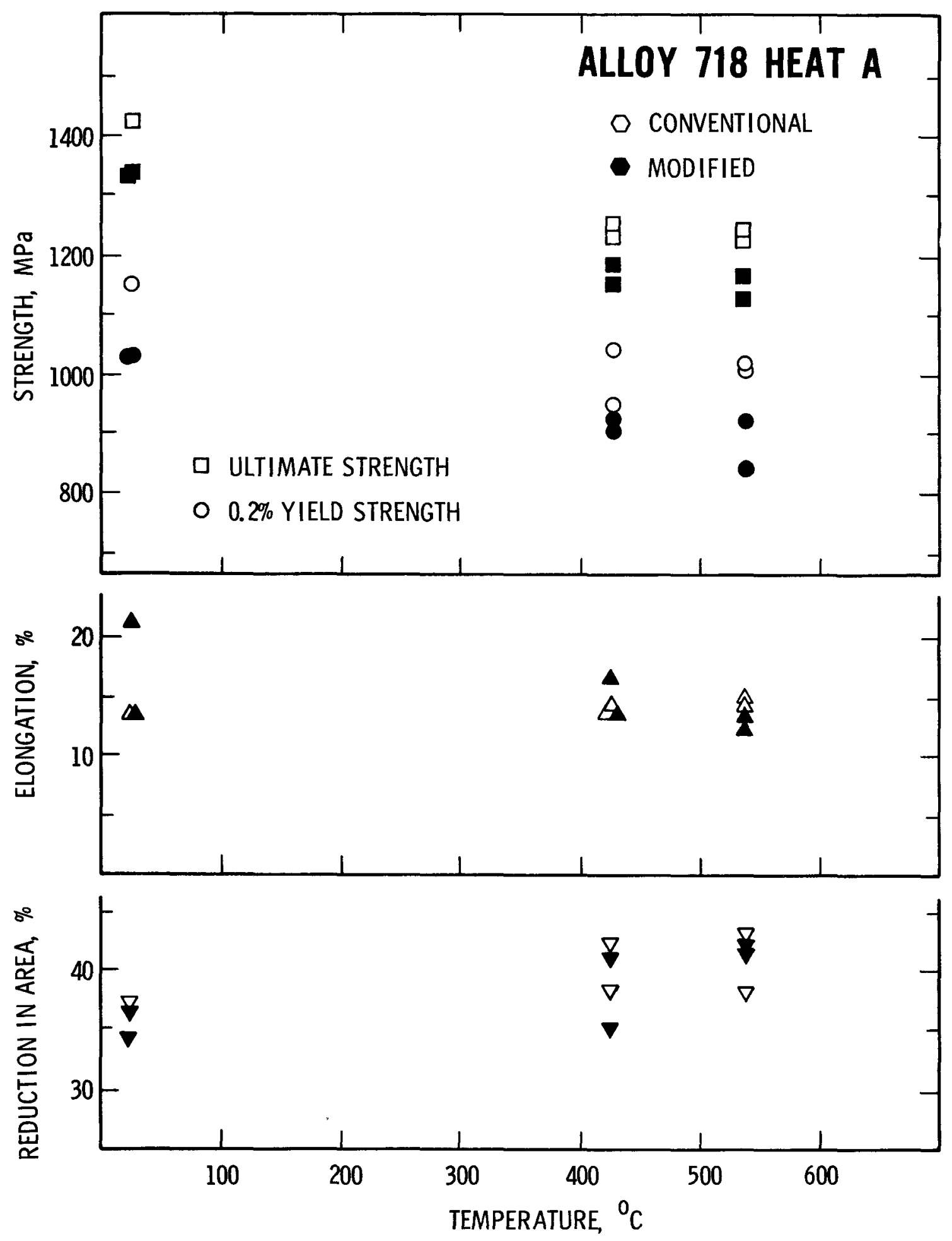

Figure 22. Effect of temperature on the tensile properties of precipitation heat treated Alloy 718 (Heat A). 


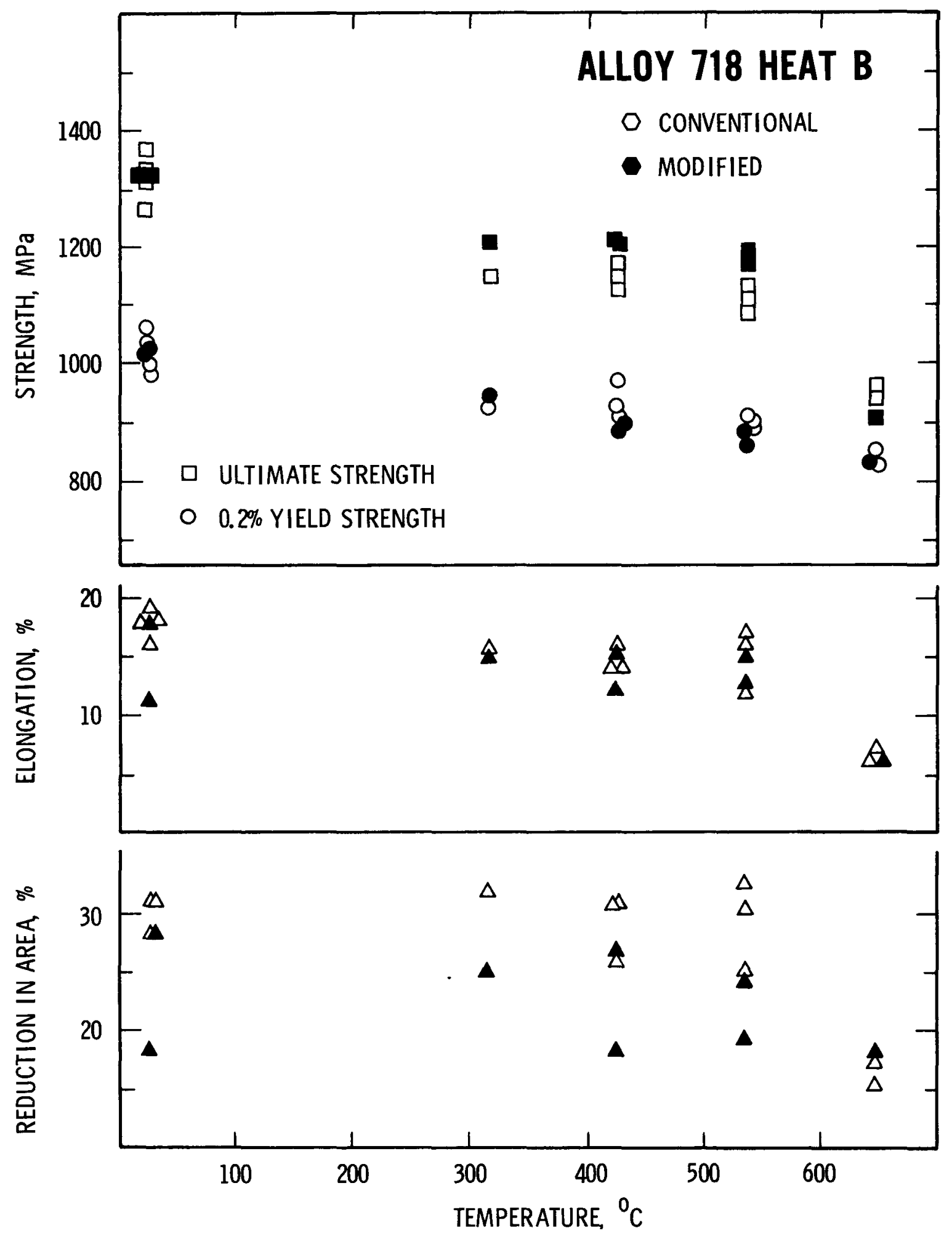

Figure 23. Effect of temperature on the tensile properties of precipitation heat treated A1loy 718 (Heat B). 

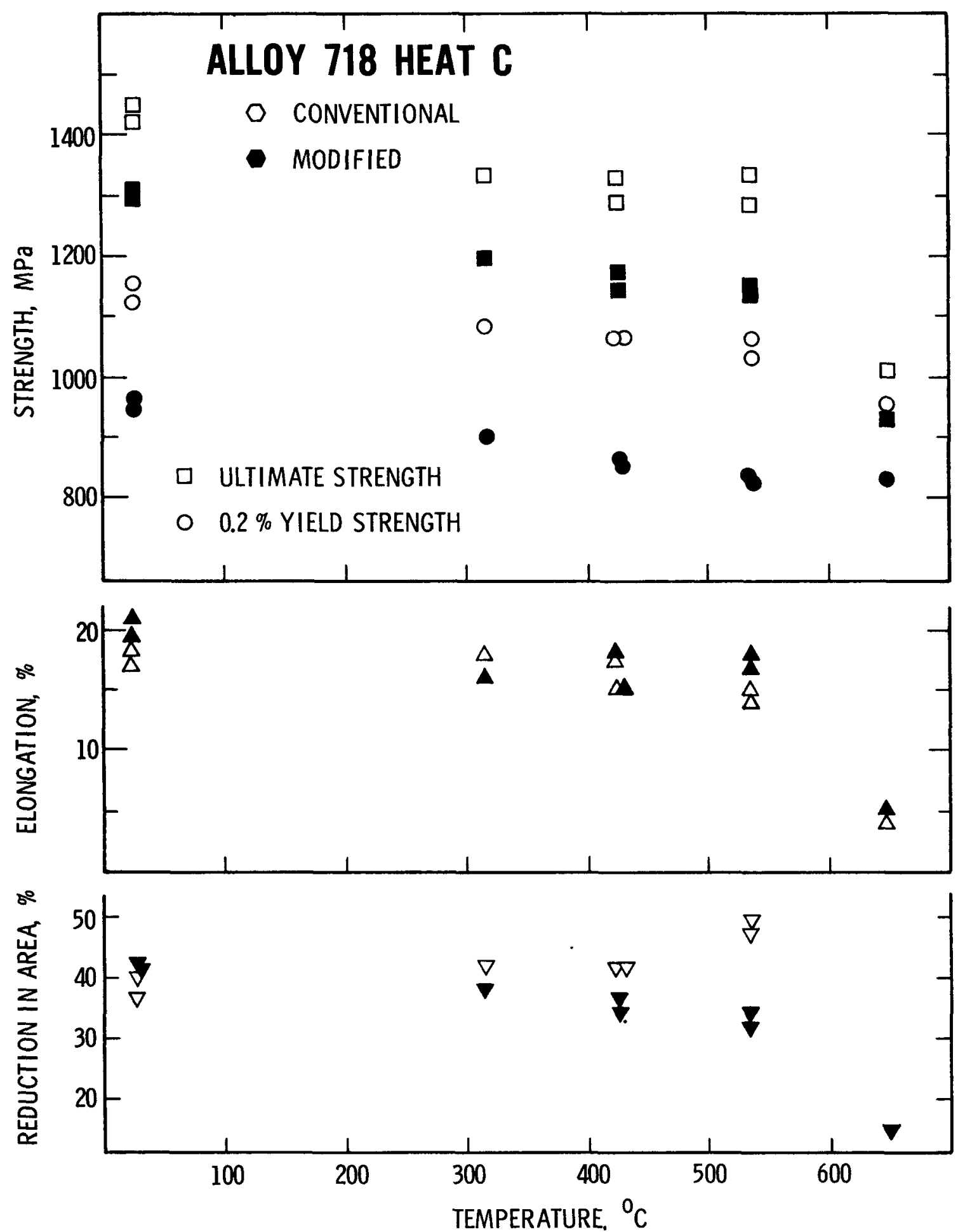

Figure 24. Effect of temperature on the tensile properties of precipitation heat treated Alloy 718 (Heat C). 
In contrast to the tensile behavior of Heats $A$ and $C$, the strength of Heat $B$ (Figure 23) was found to be independent of heat treatment over the test temperature range. Furthermore, Table VIII reveals that this behavior occurred because the strength of the "conventionally" treated Heat B was substantially lower than that reported for Heats $A$ and $C$, whereas the strength of the "modified" treated Heat $B$ was found to be comparable to strength levels exhibited by the other two heats in the "modified" condition. These phenomena are believed to be associated with variations in the microstructure resulting from the two heating treatments. For example, microstructures for the three heats of Alloy 718 given the "modified" treatment were found to be essentially the same, thereby accounting for the lack of a heat-to-heat variation in mechanical properties for the "modified" material. By contrast, the microstructure of "conventionally" treated Heat $B$ was somewhat different from that observed in Heats $A$ and $C$. The most important differences were the presence of Widmanstätten $\delta$ phase banding (as shown in Figures 10a and 11a) throughout Heat $B$ and a larger grain size than in Heats $A$ and $C$. It should be noted that the hardness of the $\delta$ phase banded regions was significantly greater than the hardness of the surrounding matrix (Table IX; this behavior is discussed in more detail below). However, this nonuniform microstructure could result in a stress gradient or stress concentration around the banded zones, thereby causing an overall reduction in the observed strength levels. Consequently this non-uniform microstructure, consisting of high strength banded regions, coupled with the larger grain size is believed to be related to the reduction in strength observed in the "conventionally" treated Heat B.

As a final point, Figures 22-24 show that heat treatment had almost no effect on ductility. This observation is somewhat unexpected in light of the fracture toughness values for the "modified" treated Alloy 718, which were significantly greater than those for the "conventionally" treated material. (32-34) However, this increase in toughness was not reflected in tensile properties, thereby suggesting that factors controlling conventional mechanical properties do not necessarily control fracture toughness properties. 
TABLE IX

SUMMARY OF DIAMOND PYRAMID HARDNESS

VALUES FOR PRECIPITATION HEAT TREATED ALLOY 718

$\begin{array}{ccccc}\text { Heat } & \begin{array}{c}\text { Heat } \\ \text { Treatment }\end{array} & \begin{array}{c}\text { Microstructural } \\ \text { Feature }\end{array} & \begin{array}{c}\text { DPH } \\ \text { Range }\end{array} & \begin{array}{c}\text { DPH } \\ \text { Average }\end{array} \\ & \text { "Conventional" } & \text { Matrix } & 463-493 & 483 \\ \text { A } & \text { "Conventional" } & \text { Light Etching Region } & 463-483 & 473 \\ & \text { "Modified" } & \text { Matrix } & 426-473 & 448 \\ \text { B } & \text { "Conventional" } & \text { Matrix } & 418-463 & 441 \\ \text { B } & \text { "Conventional" } & \text { Phase Banding } & 493-552 & 512 \\ \text { B } & \text { "Modified" } & \text { Matrix } & 394-401 & 399 \\ & & & & \\ \text { C } & \text { "Conventional" } & \text { Matrix } & 444-453 & 450 \\ \text { C } & \text { "Modified" } & \text { Matrix } & 418-444 & 432\end{array}$


The mechanical response of selected microstructural features within the Alloy 718 base metal was characterized by room temperature micro-hardness testing. Table IX shows that the micro-hardness values for the matrix and the light-etching regions (Figure $2 a$ ) of "conventionally" treated Heat $A$ were essentially the same (483 versus 473 ). This behavior was expected since the overall morphology of the primary strengthening $r$ "platelets was essentially the same within both the elongated regions and the surrounding matrix (recall Figure 4c). On the other hand, the banded regions of "conventionally". treated Heat $B$ were found to be considerably harder than the matrix. This behavior is believed to be associated with increased $\delta$ precipitation within the banded regions. It was mentioned earlier that excessive $\delta$ could reduce the strength of Alloy 718 by consuming a significant amount of $\mathrm{Nb}$ thereby reducing the concentration of $\gamma^{\prime \prime}$. However, in this heat of Alloy 718, transmission electron microscopy results indicated that the $\delta$ particles formed without consuming the primary strengthening $\gamma$ " precipitates, since essentially no $\gamma$ " denuding was observed around the $\delta$ plates. Therefore, the combination of $\delta$ particles in addition to the $\gamma^{\prime \prime}$ platelets resulted in a hardening of the banded regions in comparison to the surrounding matrix where only $\gamma$ " precipitates were observed.

In general, comparison of the DPH results for the three heats of Alloy 718 (Table IX) indicates that the micro-hardness of the "conventionally" treated material was slightly greater than the micro-hardness of the "modified" material. This overall response is consistent with the tensile results reported previously. 
-

- 


\section{RESULTS AND DISCUSSION - ALLOY 718 WELDMENTS}

\subsection{MICROSTRUCTURE OF ALLOY 718 WELDMENTS}

The microstructure of the "as-welded" Alloy 718 weld zone, shown in Figure $25 \mathrm{a}$, reveals a typical dendritic structure. Higher magnification of this region (Figure 25b) illustrates the presence of a white phase in the interdendritic regions identified by its shape and color as Laves phase. Formation of this TCP phase occurs during the solidification process in microsegregated regions enriched in $\mathrm{Nb}$ content. Furthermore, it has been suggested that this Laves phase is responsible for the low ductility and toughness properties exhibited by Alloy 718 weldments and castings. $(1,16,35)$

The typical microstructure of "conventionally" heat treated Alloy 718 weld, shown in Figure 26 , once agian reveals a dendritic micromorphology with a significant amount of blocky Laves phase in the interdendritic regions. The inability of the "conventional" $954^{\circ} \mathrm{C}$ postweld solution anneal to homogenize the dendritic structure of the weld zone was expected; in previous investigations, temperatures in excess of $1038^{\circ} \mathrm{C}$ were required to dissolve the Laves phase. $(16,18,20,21)$ Needle-like $\delta$ precipitates surrounded the $\mathrm{Nb}$ rich Laves phase during the $954^{\circ}$ solution anneal, as indicated in Figure 26b. In fact, in some regions (such as Figure 27), the Laves phase completely transformed into or thorhombic $\delta$ platelets. This nucleation of $\mathrm{Ni}_{3} \mathrm{Nb}$ needles from the Laves phase is also consistent with previous observations in Alloy 718 castings, whereby the Nb-rich TCP phase acted as a source for $\delta$ precipitation. $(1,35,36)$ Unfortunately, the Laves phase and $\delta$ precipitates contribute little to the strength of the precipitation heat treated Alloy 718 weldments while they tend to act as localized crack initiation sites (as shown in the subsequent discussion).

The "modified" heat treatment with a $1093^{\circ} \mathrm{C}$ solution anneal reduced the amount of Laves phase present in the Alloy 718 weld microstructure (Figure 28), which is consistent with observations made at INEL. $(20,21)$ The 


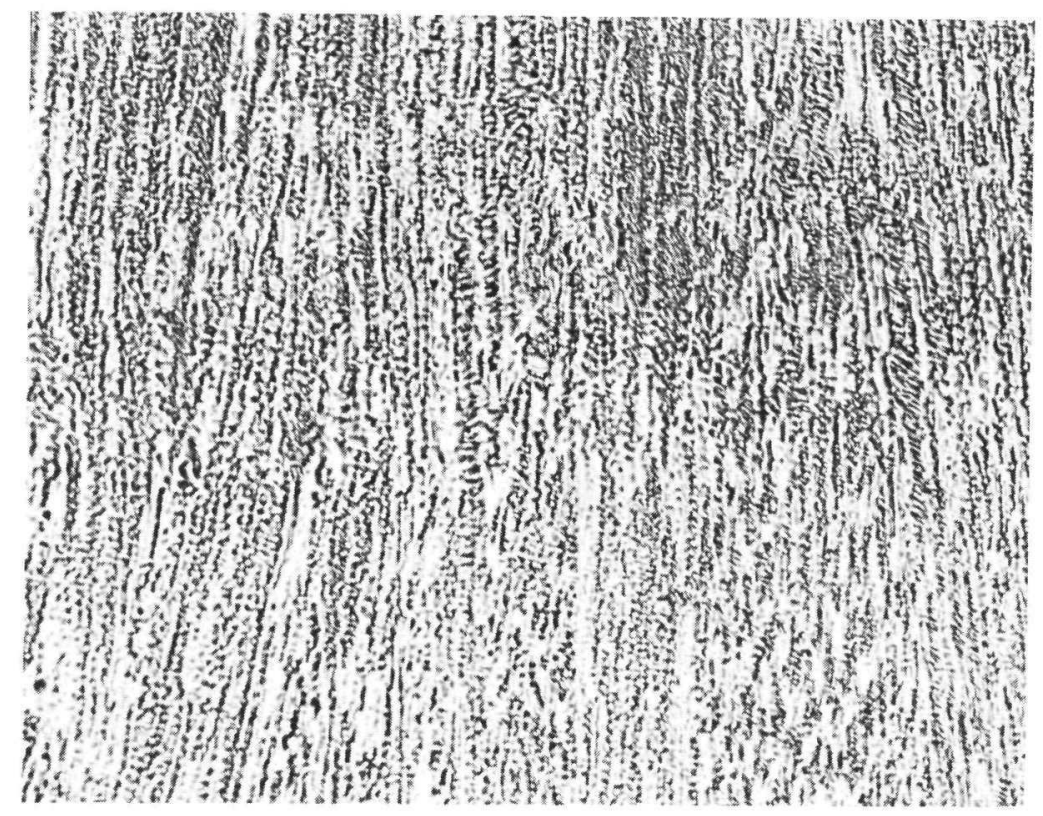

(a)

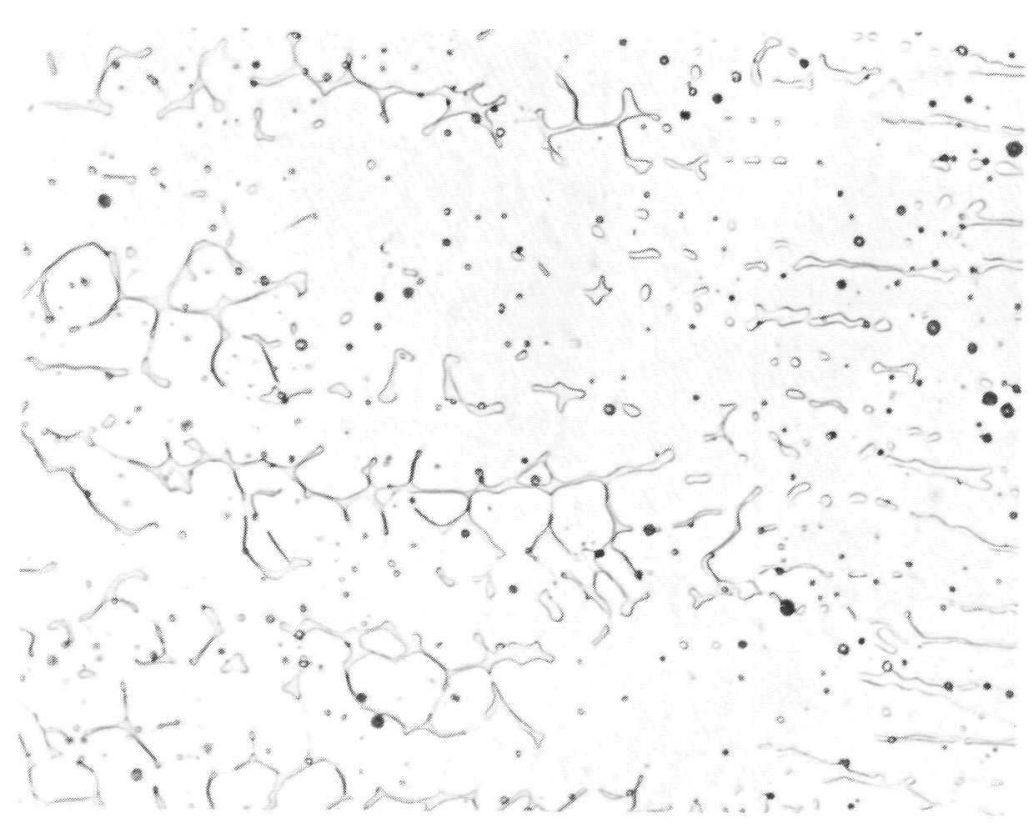

(b)

Figure 25. Microstructure of the "as-welded" A1Ioy 718 GTA weldment.

(a) Low magnification illustrating the typical dendritic structure of the weld zone. (100X)

(b) High magnification revealing the presence of blocky Laves phase in the interdendritic regions. (750X) 


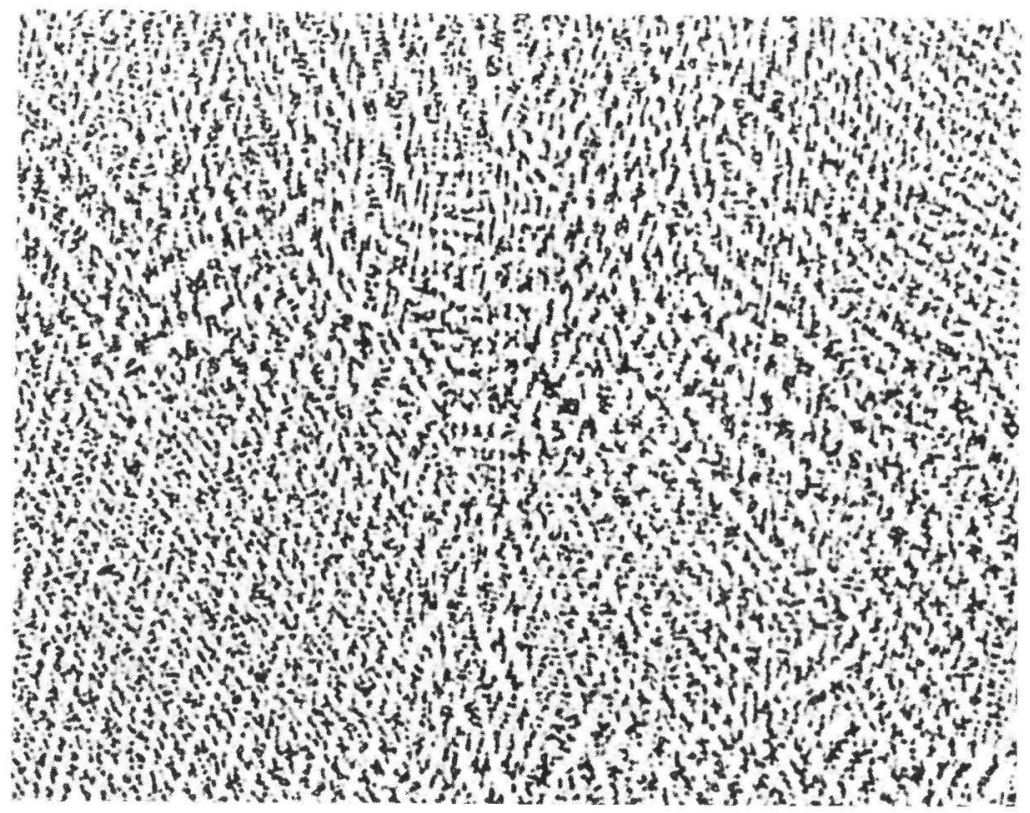

(a)

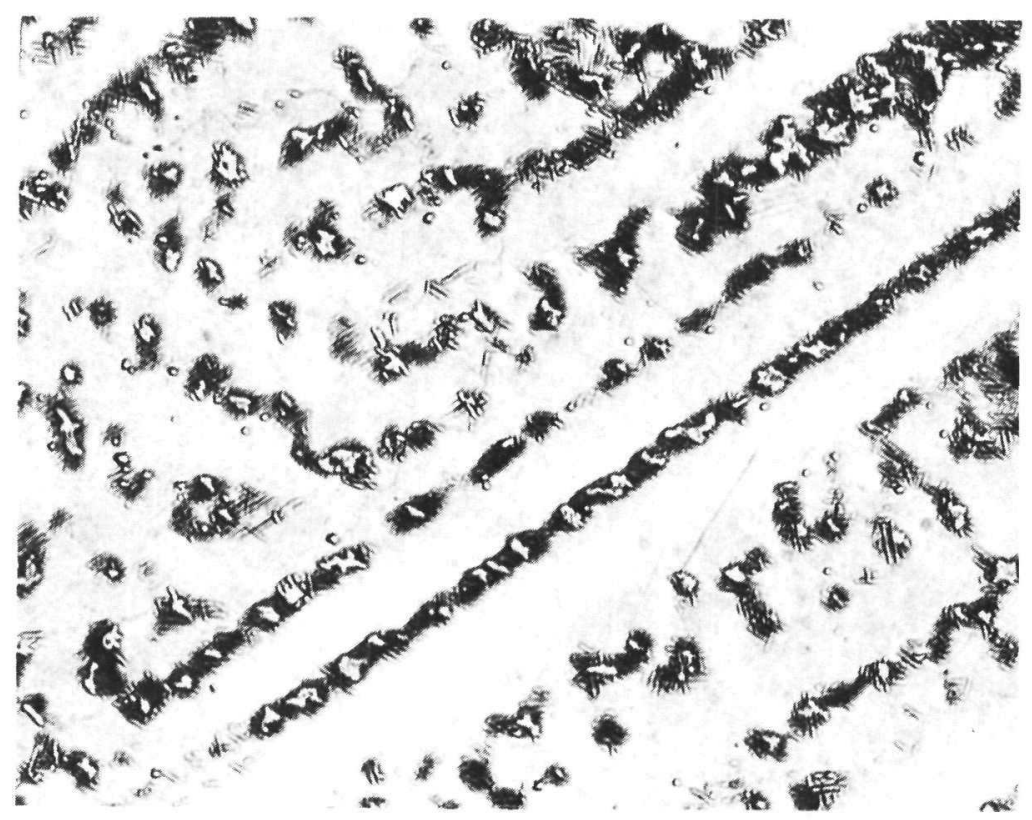

(b)

Figure 26. Microstructure of the "conventionally" treated Alloy 718 GTA weldment.

(a) Typical dendritic structure of the weld zone. (100x)

(b) Higher magnification of the dendritic structure

illustrating a significant amount of Laves phase surrounded by needle-like $\delta$ precipitates. (750X) 


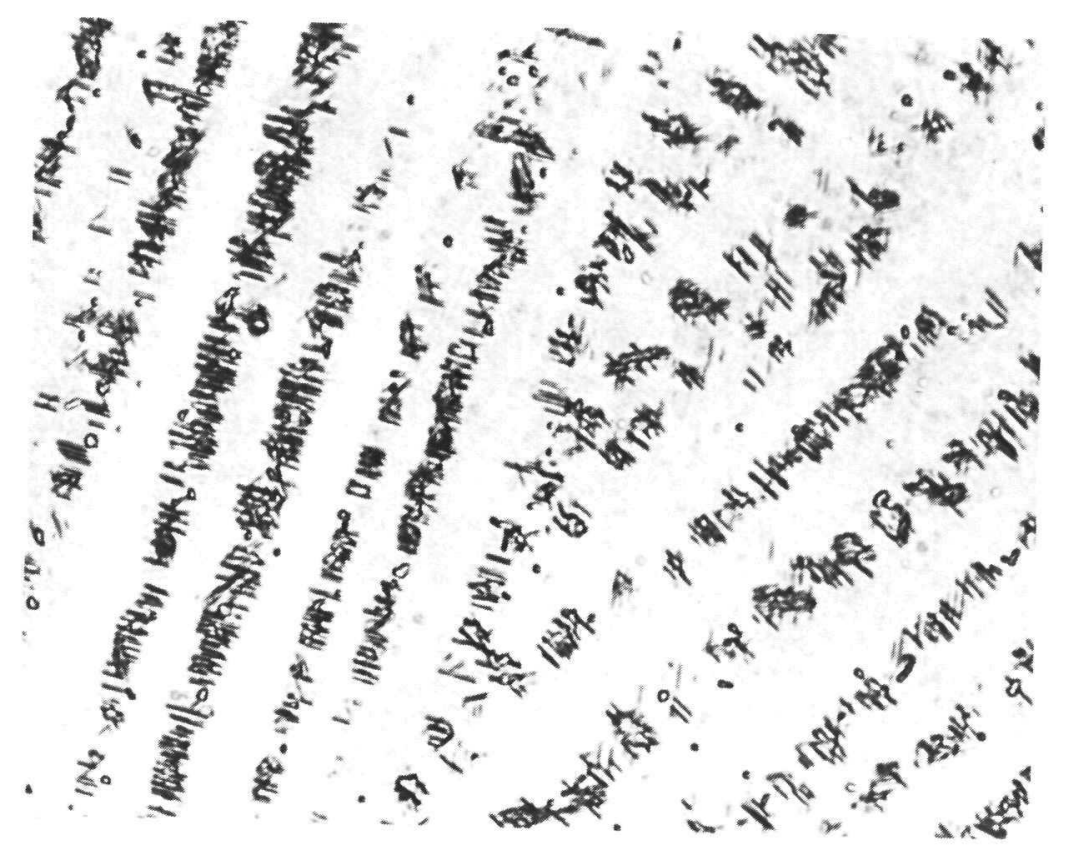

Figure 27. Micrograph of the "conventionally" heat treated Alloy 718 weld zone revealing that the Laves phase had completely transformed into $\delta$ needles. (750x) 


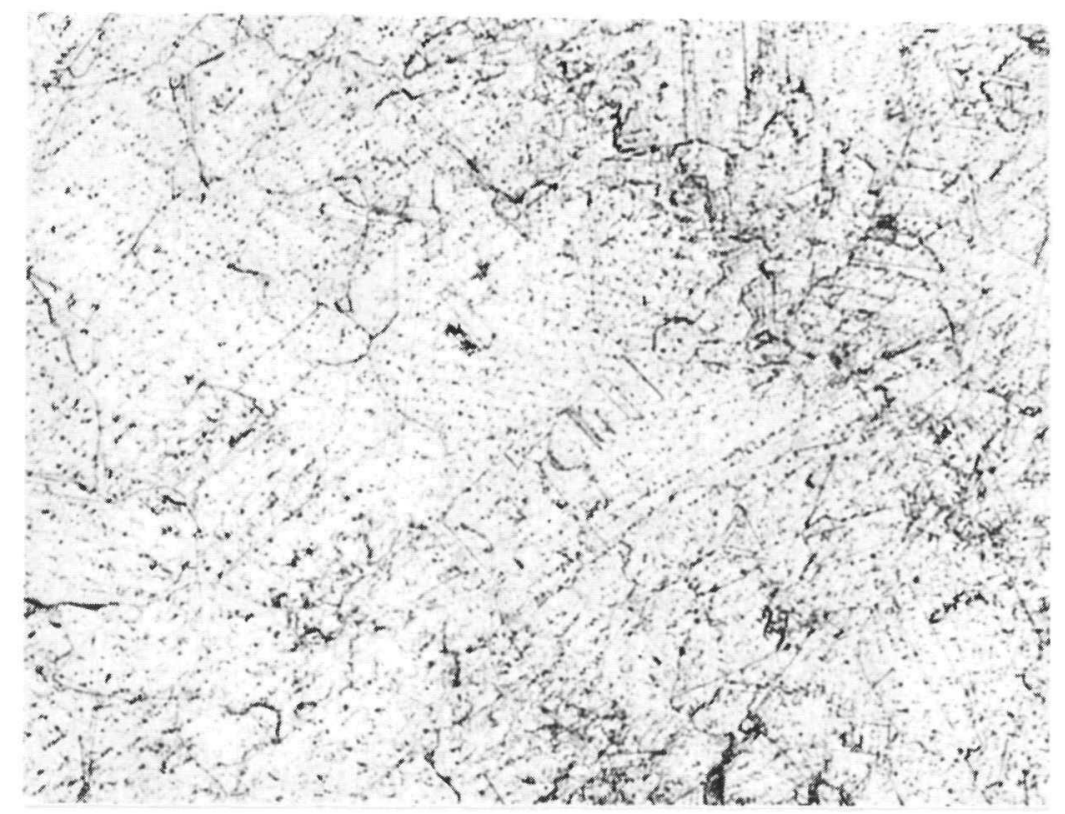

(a)

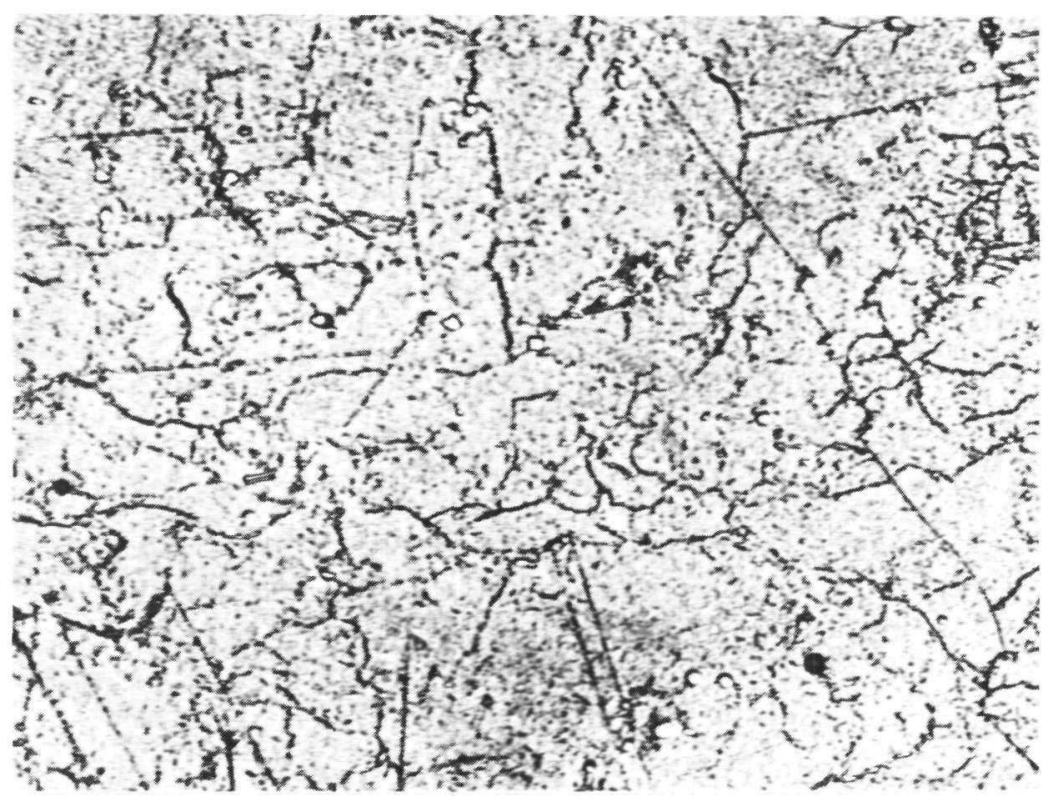

(b)

Figure 28. Microstructure of the "modified" treated Alloy 718 GTA weldment.

(a) Typical microstructure revealing that only traces of the original dendritic structure remain in the weld zone. (100x)

(b) Higher magnification of the "modified" weld zone revealing a reduction in the amount of Laves phase present. (750X) 
higher temperature anneal apparently resulted in partial dissolution of the Laves phase, since only traces remained with in the weld zone following the "modified" treatment.

\subsection{MECHANICAL PROPERTIES OF ALLOY 718 WELDMENTS}

Room temperature and elevated temperature tensile property data for "aswelded" and precipitation heat treated Alloy 718 GTA welds are tabulated in Table X. Figures 29-32 compare the tensile behavior of the GTA welds with the average tensile response of the Alloy 718 base metal (represented by the broken lines). In general, the tensile properties of the GTA welds reported herein were in very good agreement with those reported previously for both heat treated and "as-welded" Alloy 718 GTA welds $(21,28,30,31,37)$. The overall trends in the tensile behavior of the welds are discussed below.

The $0.2 \%$ offset yield strength values of the precipitation heat treated welds (Figure 29) are relatively insensitive to heat treatment and temperature, decreasing from approximately $1050 \mathrm{MPa}$ at room temperature to 930 MPa at $649^{\circ} \mathrm{C}$. Furthermore, the yield strength of the age hardened welds was found to be equal to or greater than the average yield strength of the base metal given the "modified" treatment, but somewhat lower than the average strength of the "conventionally" aged base metal. As expected, the strength of the "as-welded" GTA weld was approximately half that of the aged material. In contrast to the tensile response of the heat treated weldments, however, the yield strength of the "as-welded" GTA welds increased slightly at the higher temperatures after reaching a minimum at $316^{\circ} \mathrm{C}$.

The room temperature and elevated temperature ultimate strength levels for the age hardened Ailoy 718 GTA welds, illustrated in Figure 30, were found to be in relatively good agreement with those of the heat treated Alloy 718 base metal (represented by the broken lines also shown in Figure 30 ). Furthermore, the ultimate strength of the welds, like that of the base metal, was found to decrease markedly under elevated temperature conditions, 
TABLE $X$

SUMMARY OF MECHANICAL PROPERTIES

ALLOY 718 WELDMENTS

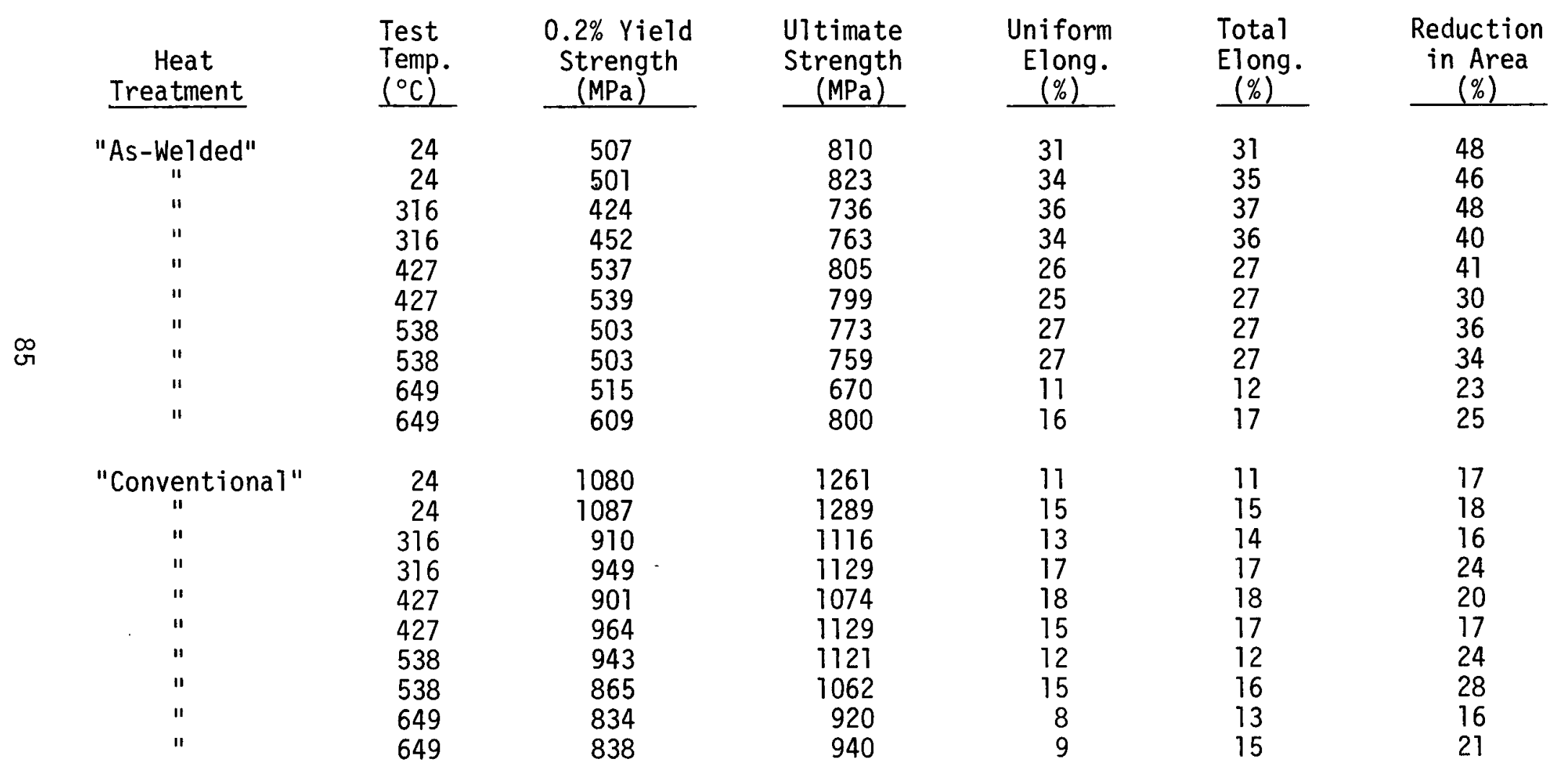


TABLE $\times$ (Continued)

\begin{tabular}{|c|c|c|c|c|c|c|}
\hline $\begin{array}{c}\text { Heat } \\
\text { Treatment }\end{array}$ & $\begin{array}{l}\text { Test } \\
\text { Temp. } \\
\left({ }^{\circ} \mathrm{C}\right)\end{array}$ & $\begin{array}{c}0.2 \% \text { Yield } \\
\text { Strength } \\
(\mathrm{MPa})\end{array}$ & $\begin{array}{l}\text { Ultimate } \\
\text { Strength } \\
\text { (MPa) } \\
\end{array}$ & $\begin{array}{l}\text { Uniform } \\
\text { Elong. } \\
(\%)\end{array}$ & $\begin{array}{l}\text { Total } \\
\text { Elong. } \\
(\%) \\
\end{array}$ & $\begin{array}{c}\text { Reduction } \\
\text { in Area } \\
(\%)\end{array}$ \\
\hline $\begin{array}{c}\text { "Modified" } \\
\text { " } \\
" \\
" \\
" \\
" \\
" \\
" \\
" \\
"\end{array}$ & $\begin{array}{r}24 \\
24 \\
316 \\
316 \\
427 \\
427 \\
538 \\
538 \\
649 \\
649\end{array}$ & $\begin{array}{r}1057 \\
1037 \\
958 \\
974 \\
936 \\
976 \\
916 \\
887 \\
866 \\
914\end{array}$ & $\begin{array}{r}1331 \\
1328 \\
1233 \\
1242 \\
1233 \\
1238 \\
1198 \\
1142 \\
935 \\
969\end{array}$ & $\begin{array}{r}17 \\
16 \\
15 \\
14 \\
15 \\
14 \\
16 \\
14 \\
6 \\
5\end{array}$ & $\begin{array}{r}19 \\
17 \\
17 \\
15 \\
17 \\
16 \\
18 \\
15 \\
9 \\
9\end{array}$ & $\begin{array}{l}37 \\
33 \\
33 \\
28 \\
40 \\
35 \\
42 \\
28 \\
16 \\
16\end{array}$ \\
\hline
\end{tabular}




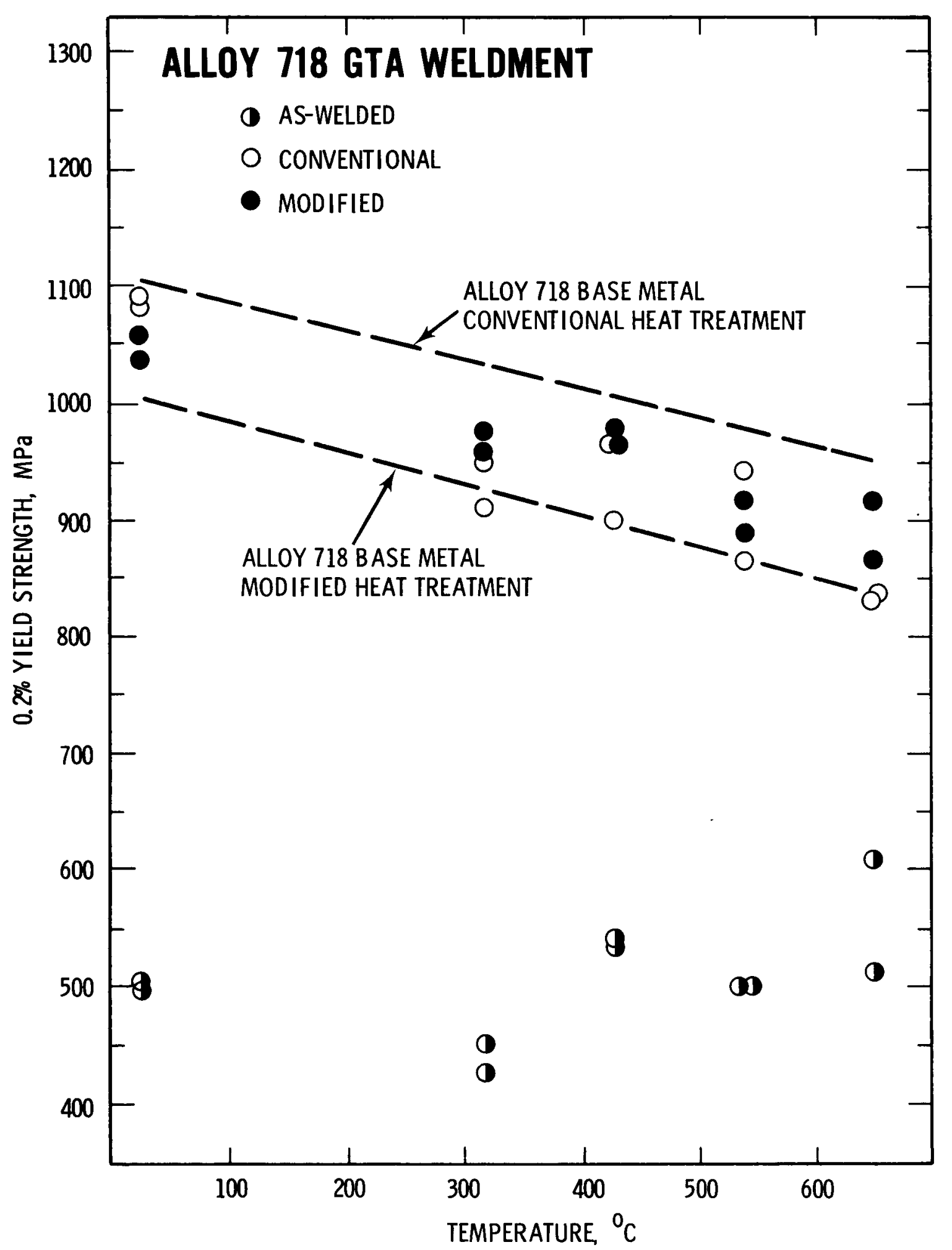

Figure 29. Effect of temperature on the yield strength of Alloy 718 GTA weldments. 


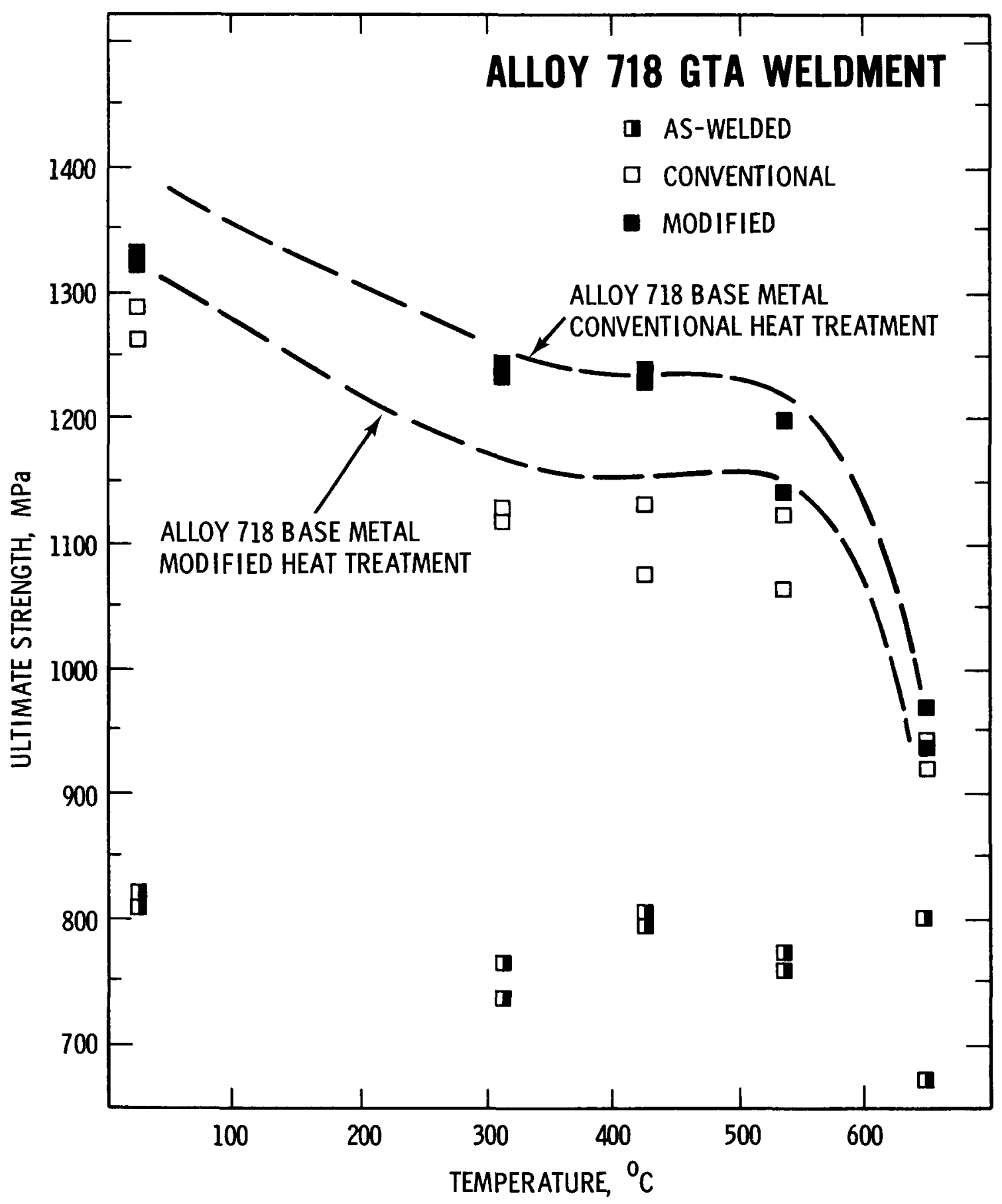

Figure 30. Effect of temperature on the ultimate strength of Alloy 718 GTA weldments. 
especially above $538^{\circ} \mathrm{C}$. In contrast to the base metal tensile response, however, the ultimate strength of the "conventionally" aged weld was consistently lower than that of the "modified" treated welds. Recall that the strength of the "conventional" Alloy 718 base metal was generally superior to that of the "modified" base metal, whereas the opposite trend was observed in the aged weldments. Figure 30 also reveals that the ultimate strength of the "as-welded" GTA weldments was relatively insensitive to temperature over the test temperature $r$ ange.

The observation that the yield and ultimate strength levels of the "aswel ded" material were relatively insensitive to temperature was in direct contrast to the trends exhibited by the precipitation heat treated weldments, especially at the highest test temperature $\left(649^{\circ} \mathrm{C}\right)$ where a marked reduction in strength was observed. This behavior is bel ieved to be associated with age hardening that occurred in the "as-welded" material prior to and during the $649^{\circ} \mathrm{C}$ tensile tests (Table XI). Apparently, the increase in strength that resulted from the age hardening offset the reduction in strength normally observed at the higher temperatures, thereby accounting for the strength of the "as-welded" Alloy 718 remaining relatively insensitive to temperature over the entire test temperature range.

The ductility response of the Alloy 718 welds is summarized in Figures 31 and 32 . Figure 31 shows that the uniform elongation of the "conventionally" treated welds was approximately equal to that of the "modified" welds. Furthermore, the elongations for the heat treated Alloy 718 welds (solid and open data points) and base metal (represented by the broken line on figure 31) were also found to be in very good agreement over the entire test temperature $r$ ange. Here again, the lack of an effect of heat treatment on the ductility response of the weldments is unexpected in light of numerous studies reporting that the impact toughness $(16,20,21)$ as well as the fracture toughness ${ }^{(38)}$ response of Alloy 718 welds were very sensitive to precipitation heat treatment. In fact, preliminary room temperature fracture roughness testing of the Alloy 718 welds studied during th is investigation indicates that the "conventionally" aged welds exhibited a 
TABLE XI

EFFECT OF AGING ON THE ROOM TEMPERATURE

HARDNESS OF AS-WELDED ALLOY 718 GTA WELDMENTS

\begin{tabular}{|l|rrrrrr|}
\hline $\begin{array}{l}\text { Aging } \\
\text { Temp. } \\
\left({ }^{\circ} \mathrm{C}\right)\end{array}$ & 0 & 1 & 3 & 10 & 30 & 100 \\
\hline & \multicolumn{5}{|c}{ ROCKWELL } & C HARDNESS \\
316 & 24 & - & 24 & 23 & 24 & - \\
427 & 24 & - & 25 & 22 & 24 & - \\
538 & 24 & - & 24 & 26 & 28 & 28 \\
649 & 24 & 30 & 35 & 37 & 40 & 42 \\
\hline
\end{tabular}

Hardness of "conventional" A1loy 718 GTA Weldment: $R_{C} 41$ Hardness of "modified" A11oy 718 GTA Weldment: $R_{c} 40$ 


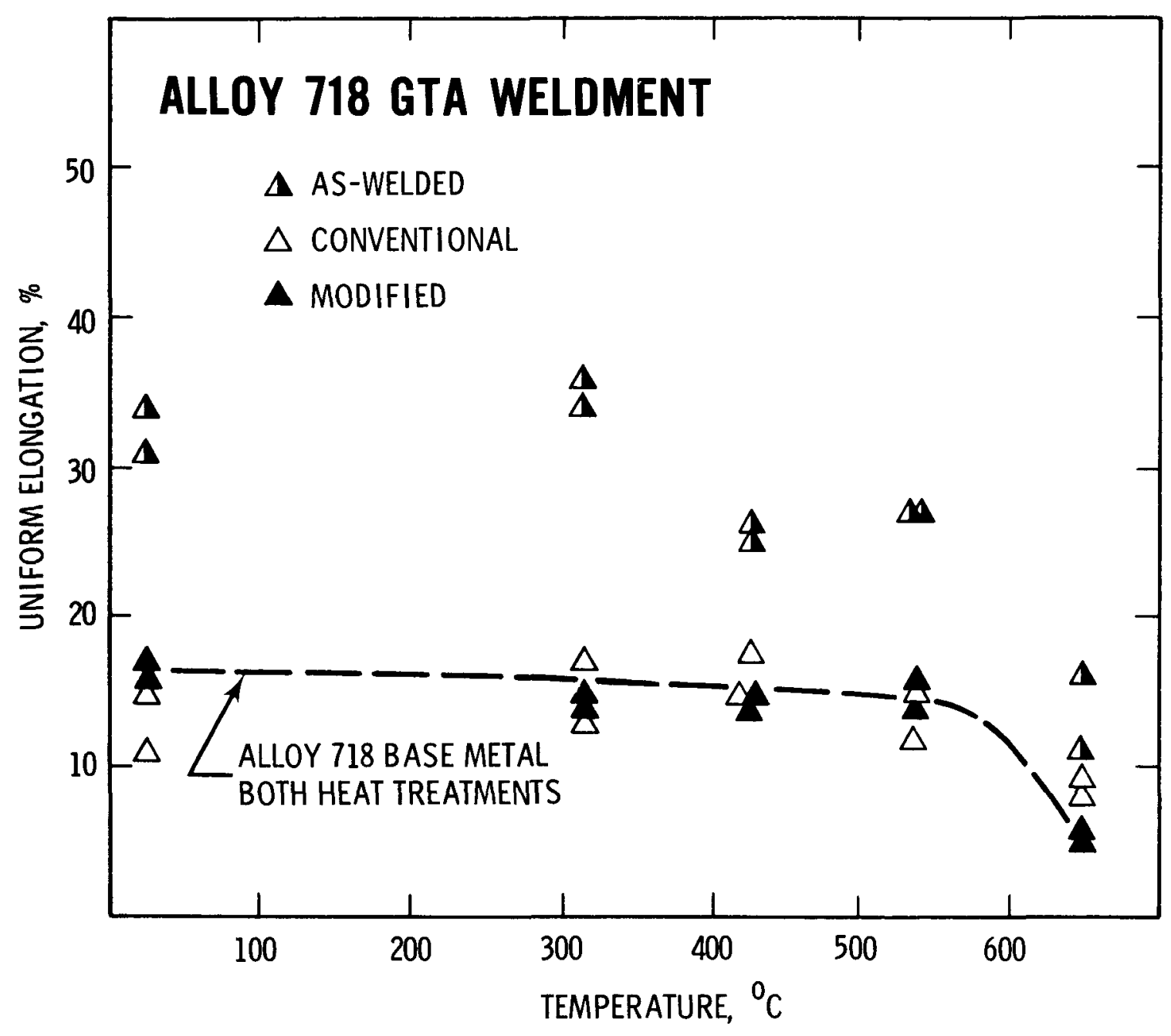

Figure 31. Effect of temperature on the uniform elongation of Alloy 718 GTA weldments. 


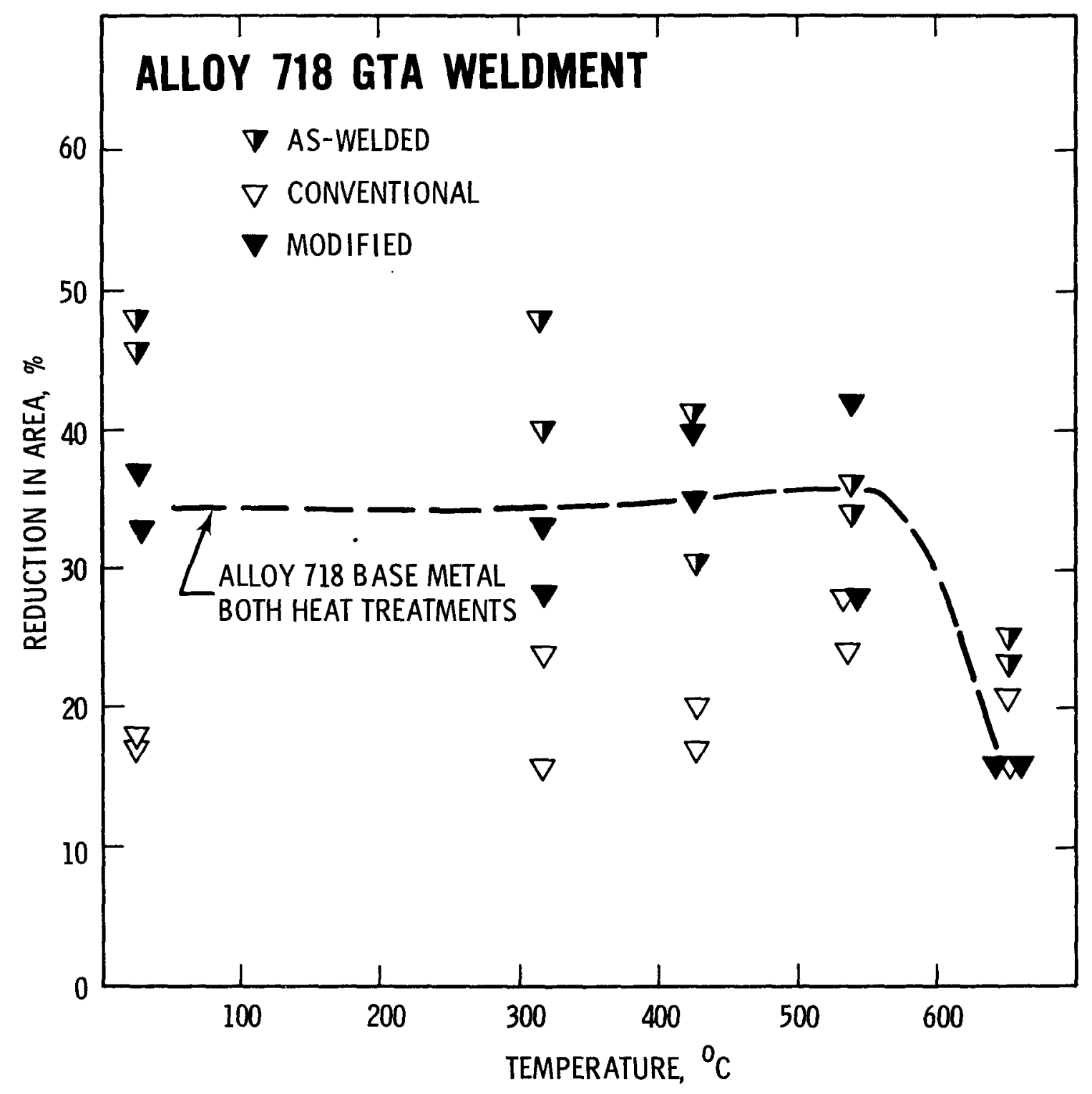

Figure 32. Effect of temperature on the reduction in area of Alloy 718 GTA weldments. 
"brittle" fracture response with $\mathrm{K}_{\text {Ic }}$ values of 60-70 $\mathrm{MPa} \sqrt{\mathrm{m}}$, whereas the "modified" aged welds exhibited a "ductile" fracture response with an equivalent $K_{\text {Ic }}$ value of approximately $160 \mathrm{MPa} \sqrt{\mathrm{m}}$. Nevertheless, this increased fracture toughness response was not reflected in the tensile ductilities, indicating once again that conventional mechanical properties cannot be used to predict fracture behavior.

The reduction-in-area parameter, on the other hand, appeared to be more sensitive to microstructural changes resulting from the two heat treatments. Figure 32 reveais that at room temperature and intermediate temperatures up to $427^{\circ} \mathrm{C}$, the reduction in area for the "conventional" welds was inferior to that of the "modified" welds, which is consistent with the overall fracture toughness response of the GTA weldments. However, in the higher temperature regime (above $538^{\circ} \mathrm{C}$ ), the reduction in area for the age hardened welds was again found to be independent of heat treatment.

The ductility of the "as-welded" Alloy 718 weldments (partially closed symbols in Figures 31 and 32 ) was found to be considerably greater than that of the precipitation strengthened Alloy 718 base metal and weldments at temperatures below $538^{\circ} \mathrm{C}$. However, under higher temperature conditions, ductlity values for the "as-welded" Alloy 718 rapidly approached the ductility levels of the precipitation heat treated material, which suggested that considerable hardening occurred prior to and during the elevated temperature tensile tests. To verify this hypothesis, the hardness of "aswelded" Alloy 718 GTA weldments aged at each test temperature for various periods of time was determined. Table XI shows that the hardness of the "as-welded" material aged at $649^{\circ} \mathrm{C}$ rapidly approached the hardness levels of the "conventional" and "modified" precipitation heat treated welds $\left(R_{C} 41\right.$ and 40 , respectively). This indicates that the drop in tensile ductility observed in the "as-welded" material at $649^{\circ} \mathrm{C}$ did, in fact, result from precipitation hardening prior to and during the tensile test. Table XI also reveals that essentially no precipitation hardening resulted from thermal aging at temperatures of $538^{\circ} \mathrm{C}$ and lower. 
To characterize the effect of Laves phase on the tensile response of Alloy 718 weldments, the metallographic fracture profiles from three room temperature tensile specimens were examined (see Figures 33-35). In the "as-welded" material (Figure 33), the Laves phase fractured throughout the gage length; however, the resulting small cracks subsequently arrested in the surrounding metal due to the $h i g h$ fracture res istance of the unaged nickel matrix. Hence, the ductile matrix of the unaged Alloy 718 welds appears to accommodate cracking of the Laves phase, thereby resulting in the high ductility levels observed in Figures 31 and 32 . In the highest test temperature regime $\left(649^{\circ} \mathrm{C}\right)$, however, recall that the elongation and reduction in area of the "as-welded" material decreased markedly. This behavior is believed to be associated with a reduction in the fracture res istance of the matrix due to substantial precipitation strengthening during the high temperature tensile tests.

In contrast to the behavior observed in the "as-welded" condition, failure of Laves phase in the "conventionally" aged weld was confined solely to the primary fracture region, as shown in Figure 34. In this case, the fracture resistance of the matrix was relatively low as a result of the precipitation heat treatment. Consequently, cracks that initiated in the "brittle" Laves phase immediately grew in to the 1 ow fracture resistant matrix. This caused the absence of fractured Laves particles away from the primary fracture region and the low ductility levels observed in the "conventionally" heat treated Alloy 718 welds.

A metallographic fracture profile for the "modified" age hardened weld, shown in Figure 35 , reveals a significant reduction in the amount of Laves phase present in the weld zone as a result of the high temperature solution anneal employed during the "modified" heat treatment. However, remnants of the original dendritic structure are still present in the "modified" microstructure (note the series of dark and light regions in Figure 35). It is interesting to note that in some regions (indicated by arrows) the crack apparently propagated along this prior dendritic structure. 


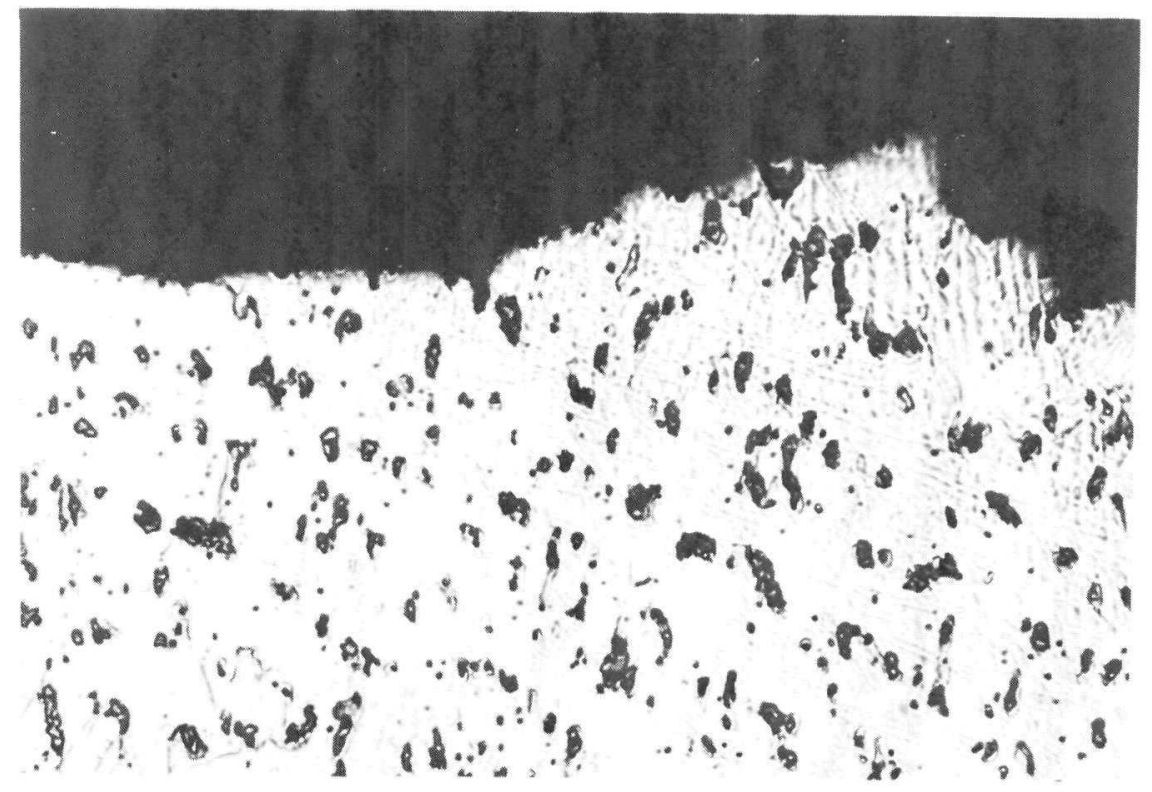

Figure 33. Typical metallographic fracture profile of the "as-welded" A1loy 718 GTA weldment. (400X) 


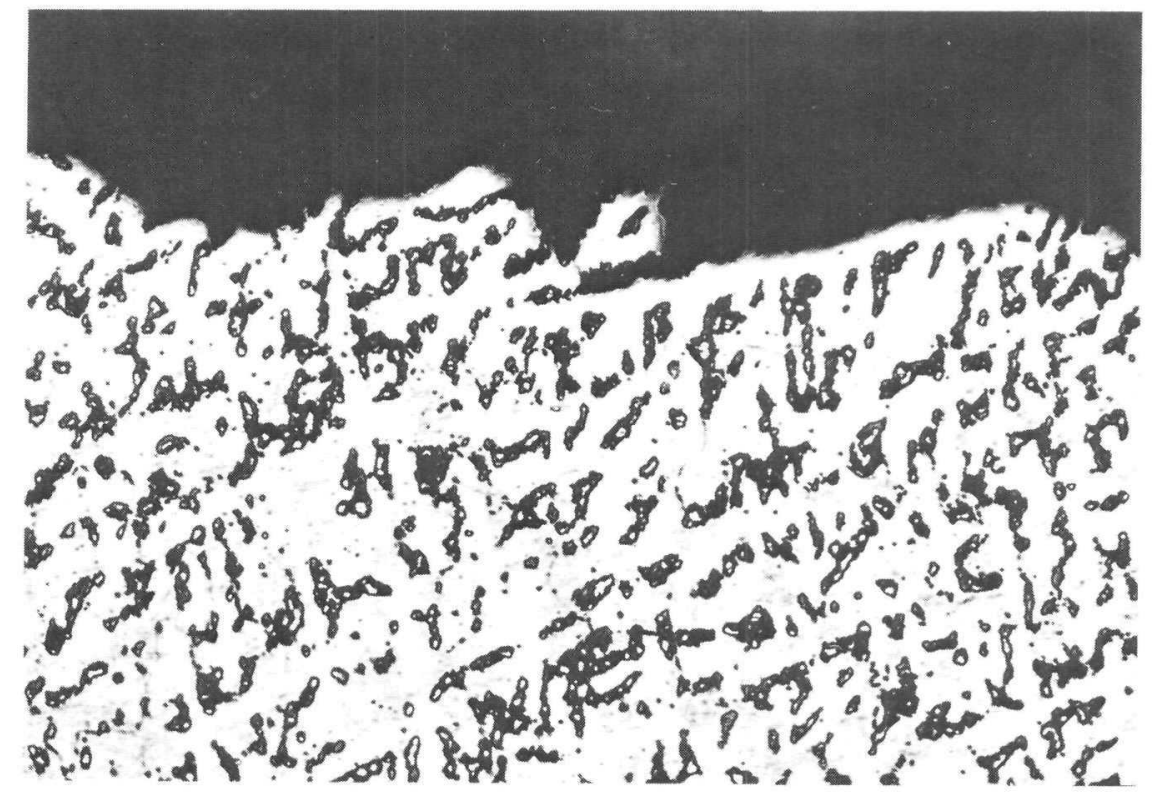

Figure 34. Typical metallographic fracture profile of the "conventionally" heat treated A1loy 718 GTA weldment. (300X) 


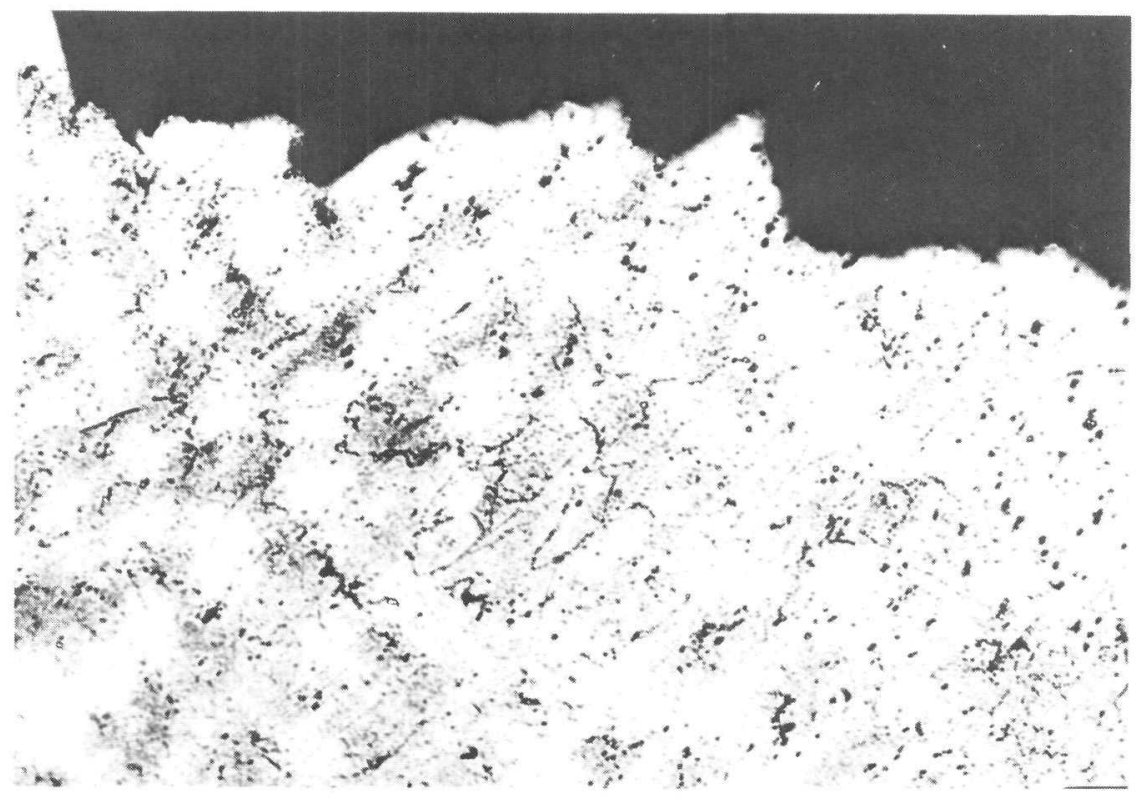

Figure 35. Typical metallographic fracture profile of the "modified" heat treated Alloy 718 GTA weldment. (300X) 
-

- 


\section{SUMMARY}

The effect of the "conventional" and "modified" precipitation heat treatment on the microstructure and mechanical properties of three heats of Alloy 718 base metal and an Alloy 718 GTA weldment was characterized. The results of

this investigation may be summarized as follows:

- The microstructure of Alloy 718 base metal was found to be dependent on heat treatment. The high temperature solution anneal employed during the "modified" treatment resulted in considerable grain growth and a more homogeneous microstructure in comparison to the "conventional" aging treatment. In addition, the "conventionally" aged Alloy 718 was found to exhibit a finer, more closely spaced $\gamma$ " platelet morphology.

- The "conventionally" heat treated Alloy 718 exhibited heat-to-heat variations in strength that were directly associated with variations in microstructure. Perhaps the most significant microstructural difference was the presence of $\delta$ phase banding in Heat $B$, which is believed to have adversely affected the room temperature and elevated temperature strength properties of this superalloy.

- In the "modified" condition, no heat-to-heat variations in tensile properties were observed. This behavior was believed to be associated with the more homogeneous microstructures resulting from the "modified" heat treatment.

- In general, the strength of the "conventionally" hardened Alloy 718 was superior to that of the "modified" superalloy. This increased strength in the conventionally treated material was caused by a finer grain size coupled with a finer $\gamma^{\prime \prime}$ precipitate morphology. 
- Heat treatment was found to have almost no effect on the ductility of Alloy 718. This finding was unexpected since fracture toughness values for Alloy 718 have been shown to be very dependent on precipitation heat treatment. It is concluded, therefore, that factors controlling conventional tensile properties do not necessarily control fracture toughness properties.

- The precipitation morphology of the Alloy 718 weldments was found to be very dependent on heat treatment. In the "as-welded" condition, Laves phase was observed in the interdendritic regions. The "conventional" $954^{\circ} \mathrm{C}$ postweld solution treatment was unable to dissolve th is blocky TCP phase; hence, Laves particles were still present in the "conventionally" treated welds. By contrast, the higher temperature anneal $\left(1093^{\circ} \mathrm{C}\right)$ employed in the "modified" treatment significantly reduced the amount of Laves phase present in the weld zone.

- The strength and ductility of the precipitation strengthened Alloy 718 welds were relatively insensitive to heat treatment. Dissolution of Laves phase from the weld zone during the "modified" treatment appears to have had essentially no effect on the weld's tensile response, whereas it did result in a significant increase in fracture toughness. These findings again suggest that fracture toughness behavior cannot be predicted by tensile properties alone.

- In the "as-welded" condition, the Alloy 718 weldments exhibited lower strength levels and higher ductilities than the heat treated weldments. Apparently, the high fracture resistance of the unaged weld matrix tended to arrest cracks that initiated in the Laves phase, thereby resulting in the high ductility levels. 


\section{$\underline{\text { REFERENCES }}$}

1. Eiselstein, H. L., "Metallurgy of Columbium-Hardened Nickel-ChroniumIron Alloy," Advances in the Technology of Stainless Steel and Related Alloys, ASTM STP No. 369, pp 62-77, 1965.

2. Paulonis, D. F., Oblak, S. M. and Duvall, D. S., "Precipitation in Nicke1-Base A1loy 718," Transactions Quarter7y, American Society for Metals, Vol. 62, pp. 611-622, 1969.

3. Cozar, R. and Pineau, A., "Morphology of $\gamma^{\prime}$ and $\gamma^{\prime}$ Precipitates in Nickel-Base Inconel 718 Type Alloys," Metallurgical Transactiorıs, Vol. 4, pp. 47-59, 1973.

4. Barber, J. F., Ross, E. W., and Rodavich, J. F., "Long Time Stability of Inconel 718," Journal of Metals, Vol. 22, pp. 31-41, 1970.

5. Kotval, P. S., "Identification of the Strengthening Phase in Inconel Alloy 718," Transactions AIME, Vol. 242, pp. 1746-1765, 1968.

6. Raymond, E. L., "Effect of Grain Boundary Denudation of Gamma Prime on Notch-Rupture Ductility of Inconel Nickel-Chronium Alloys X-750 and 718," Transactions AIME, Vol. 239, pp. 1415-1422, 1967.

7. Oblak, S. M., Paulonis, D. F., and Duvall, D. S., "Coherency Strengthening in $\mathrm{Ni}$ Base Alloys Hardened by $\mathrm{DO}_{22} \gamma$ " Precipitates," Metallurgical Transactions, Vol. 5, pp. 143-153, 1974.

8. Hall, R. C., "The Metallurgy of Alloy 718," Journal of Basic Engineering, Transactions of the ASME, Voi. 89, pp. 511-516, 1967.

9 Rizzo, R. J. and Buzzane11, J. D., "Effect of Chemistry Variations on the Structural Stability of Alloy 718," Journal of Metals, Vol. 21, pp. $24-33,1969$.

10. Boesch, W. J. and Canada, H. B., "Precipitation Reactions and Stability of $\mathrm{Ni}{ }_{3} \mathrm{Cb}$ in Inconel 718," Journal of Metals, Vol 21, pp. 34-38, 1969.

11. Merrick, H. F., "Effect of Heat Treatment on the Structure and Poperties of Extruded P/M A1loy 718," Metallurgical Transactions, Vol. $7 A$, pp. 505-514, 1976.

12. Cremisio, R. S., Butler, H. M. and Radavich, J. F., "The Effect of Thermomechanical History on the Stability of Alloy 718 , "Journal of Metals, Vo1. 21, pp. 55-61, 1969.

13. Prager, M. and Shira, C. S., "Welding of Precipitation-Hardening NickelBase Alloys," Welding Research Counci1, Bulletin No. 128, 1968. 
14. Lashko, N. F., et al., "Formation of Cracks in the Heat Affected Zone of Joints in a High Strength Nickel-Chromium Alloy During Aging," Automatic Welding, No. 9, pp. 1-5, 1969.

15. Duval1, D. S. and Owczarski, W. A., "Studies of Postweld Heat-Treatment Cracking in Nickel-Base Alloys," Welding Research Supplement, Vol. 48, pp. 10s-22s, 1969 .

16. Gordine, J., "Some Problems in Welding Inconel 718," Welding Research Supplement, Vol. 50, pp 480s-484s, 1971.

17. Morrison, T. J., Shira, C. S., and Weisenberg, L. A., "The Influence of Minor Elements on Alloy 718 Weld Microfissuring, "Effects of Minor

Elements on the Weldability of High-Nickel Alloys, Welding Research Council, pp. 47-67, 1969 .

18. Graber, M. J., Brinkman, C. R., and Hobbins, R. R., Metallurgical Evaluation of Welding and Heat Treating Procedures for the Incone 718 PBF In-Pile Tube, Report ANCR-1087, Aeorojet Nuclear Company, Idaho Falts, 1975.

19. Smolik, G. R., Analysis of Failure Which Occurred During Heat Treatments of the Inconel 718 PBF Acoustic Filter, Report ANCR-1178, Aerojet Nuclear Compnay, Idaho FalTs, 1974.

20. Smolik, G. R. and Reuter, W. G., Heat Treatment Investigations for Welded Inconel 718 Pressure Vessels for the Power Burst Facility, Report ANCR-1227, Aerojet Nuclear Company, Idaho Fa11s, 1975.

21. Reuter, W. G., Design Data for the 1/4-in. Thick Alloy 718 In-Pile Tube, Report TREE-NUREG-1087. EG\&G Idaho, Inc., Idaho Fa17s, 1977.

22. "Microhardness of Materials," ASTM Specification E384-73, Annual Book of ASTM Standards, Part 11, pp. 443-463, American Society for Testing Materials, Philadelphia, PA, 1977.

23. Hillert, M., "On the Theory of Normal and Abnormal Grain Growth," Acta Metallurgica, Vol. 13, pp. 237-327, 1965.

24. Petrovic, J. J. and Ebert, L. J., "Abnormal Grain Growth in TD-Nickel," Metallurgical Transactions, Vol. 3, pp. 1131-1136, 1973.

25. Menon, M. N., and Gurney, F. J., "Microstructural Investigation of the Growth of Large Grains in Prealloyed Powder Extrusions of a Nickel Base Superalloy," Metallurgical Transactions, Vol. 7A, pp. 731-743, 1976.

26. Leverant, G. R., and Sullivan, C. P., "The Low-Cycle Fatigue of TDNickel at $1800^{\circ} \mathrm{F}, "$ Transaction AIME, Vol. 245, pp. 2035-2039, 1969. 
27. Brinkman, C. R. and Korth, G. E., "Strain Fatigue and Tensile Behavior of Inconel 718 from Room Temperature to $650^{\circ} \mathrm{C}$, "Journal of Testing and Evaluation, Vol. 2, pp. 249-259, 1974.

28. Korth, G. E. and Smolik, G. R., Status Report of Physical and Mechanical Test Data of Alloy 718, Report TREE-1254, EG\&G Idaho, Inc., Idaho Falls, 1978.

29. 1975 Aerospace Structural Metals Handbook, Mechanical Properties Data Center, Belfour Stulen, Inc., AFML-TR-68-115, Vol. 4, Code 4103, pp. 1-72, Syracuse University Press, 1974.

30. Ward, A. L., Steichen, J. M., and Knecht, R. L., "Irradiation and Thermal Effects on the Tensile Properties of Inconel 718," Irradiation Effects on the Microstructure and Properties of Metals, ASTM STP 611, American Society for Testing and Meterials, pp. 156-170, 1976.

31. INCONEL ALLOY 718, Huntington Alloy Products Division, The International Nickel Comapny, Inc, Huntington, West Virginia, 1973.

32. Mills, W. J., and Knecht, R. L., The Effect of Heat Treatment on the Fracture Toughness Response of Inconel 718 at $75^{\circ} \mathrm{F}$ and $800^{\circ} \mathrm{F}$, Report ORNL-5237, pp. 248-263, Oak Ridge National Laboratory, 1976.

33. Mills, W. J., and Knecht, R. L., The JIc Fracture Toughness Behavior of A1 loy 718 at Elevated Temperatures, Report ORNL-5380, pp. 160-164, Oak Ridge National Laboratory, 1978.

34. Mills, W. J., and Knecht, R. L., A Survey of Heat-to-Heat Variations in the Fracture Toughness Response of Alloy 718, Report ORNL-5416, 0ak Ridge National Laboratory, 1978.

35. DeVries, R. P. and Mumau, G. R., "Importance of a Relationship Between Dendrite Formation and Solidification in Highly Alloyed Materials," Journal of Metals, Vol. 20, No. 11, pp. 33-36.

36. Barker, J. F., "A Superalloy for Medium Temperatures," Metal Progress, Vol. 81, pp. 72-76, 1962.

37. Mayor, R. A., "Selected Mechanical Properties of Inconel 718 and 706 Weldments," Welding Research Supplement, Vol. 55, pp. 269s-275s, 1976.

38. James, L. A., "Fatigue-Crack Growth in Inconel 718 Weldments at Elevated Temperatures," Welding Research Supplement, Vol. 57, pp. 17s-23s, 1978. 


\begin{abstract}
APPENDIX I
IDENTIFICATION OF ELEMENTS CONTAINED IN

THE LARGE MC-TYPE INCLUSIONS FOUND IN ALLOY 718
\end{abstract}

The large MC-type inclusions observed in the precipitation heat treated Alloy 718 were examined by electron microprobe analysis. Metallographic specimens were prepared by using standard metallographic techniques and a Tucker's etch (Etchant 3 in Table $V$ ) in order to reveal the general microstructure of the Alloy 718. Scanning electron micrographs of the overall microstructure were obtained with secondary electrons. To identify the elements contained within the inclusion, a wavelength dispersive $X$-ray spectrometer was used to analyze $X$-ray wavelengths emitted from the specimen. An elemental distribution micrograph was then obtained from the intensity of the characteristic $X$-rays emitted by each of the following elements: carbon, niobium, titanium, nickel, iron, chromium, molybdenum, and silicon. Comparison of these elemental distribution profiles provided qualitative identification of the second phase microconstituents.

Scanning electron micrographs and elemental distribution micrographs for "conventional" and "modified" precipitation treated Heat $A$ and "conventionally" precipitation treated Heat $C$ are illustrated in Figures $A-1, A-2$ and $A-3$, respectively. These figures reveal that the large inclusions observed in Alloy 718 possessed high carbon, niobium, and titanium contents, while essentially no evidence of nickel, iron, chromium, molybdenum, and silicon (the molybdenum and silicon elemental distributions are not reported herein) was detected within the large particles. Therefore, the coarse inclusions found in Alloy 718 were identified by wavelength dispersive $X$-ray analyses as niobium-titanium rich $\mathrm{MC}$-type carbides, $(\mathrm{Nb}, \mathrm{Ti}) \mathrm{C}$. 


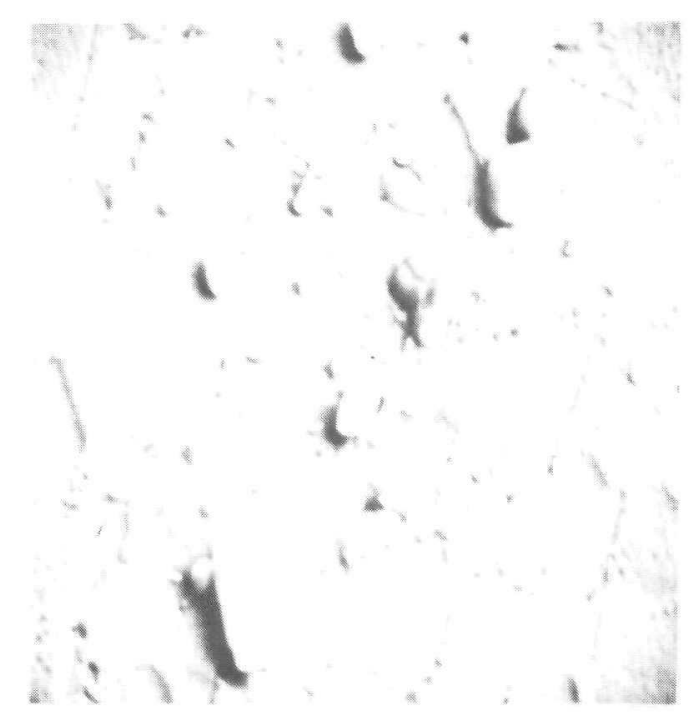

(a)

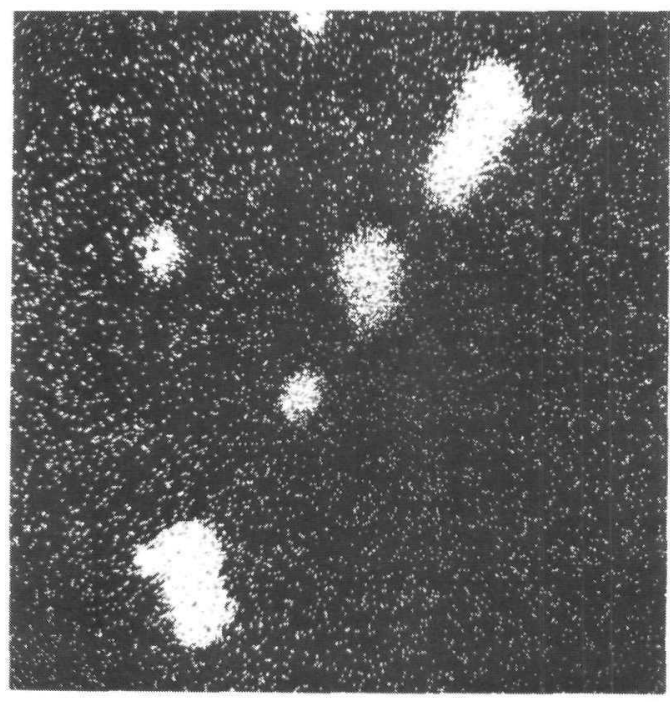

(c)

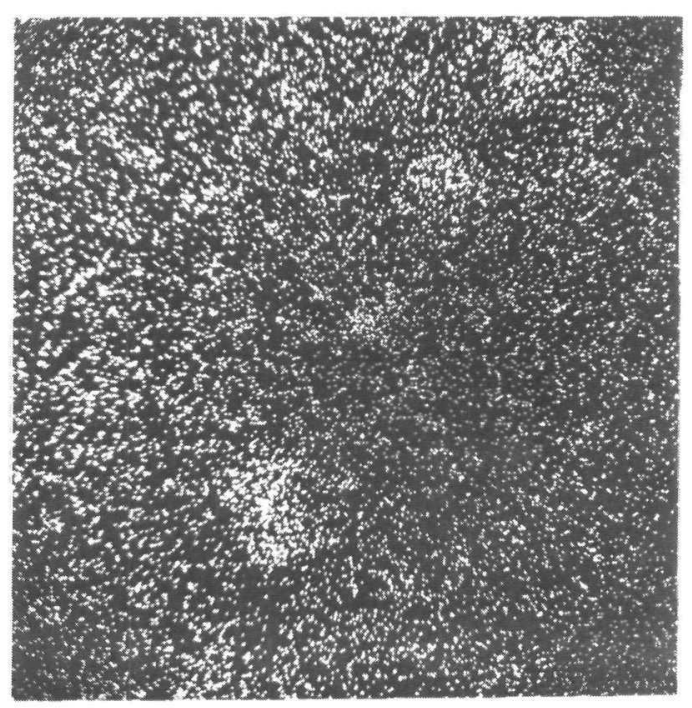

(b)

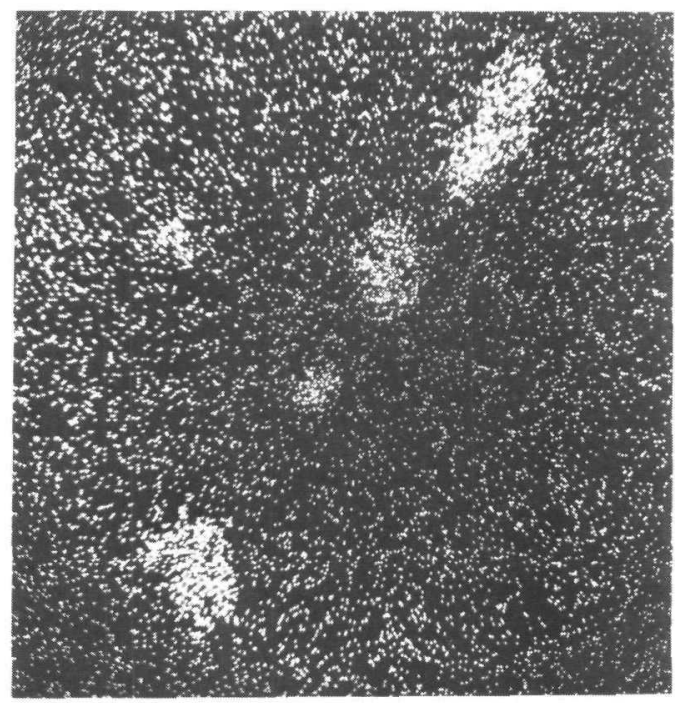

(d)

Figure A-1 "Conventiona17y" precipitation treated Heat A.

(a) Scanning electron micrograph revealing coarse carbide particles.

(b) Elemental distribution micrograph obtained from the carbon $K_{\alpha}$ X-rays.

(c) Elemental distribution micrograph obtained from the niobium $L \alpha$-rays.

(d) Elemental distribution micrograph obtained from the titanium $K_{\alpha} X$-rays. 


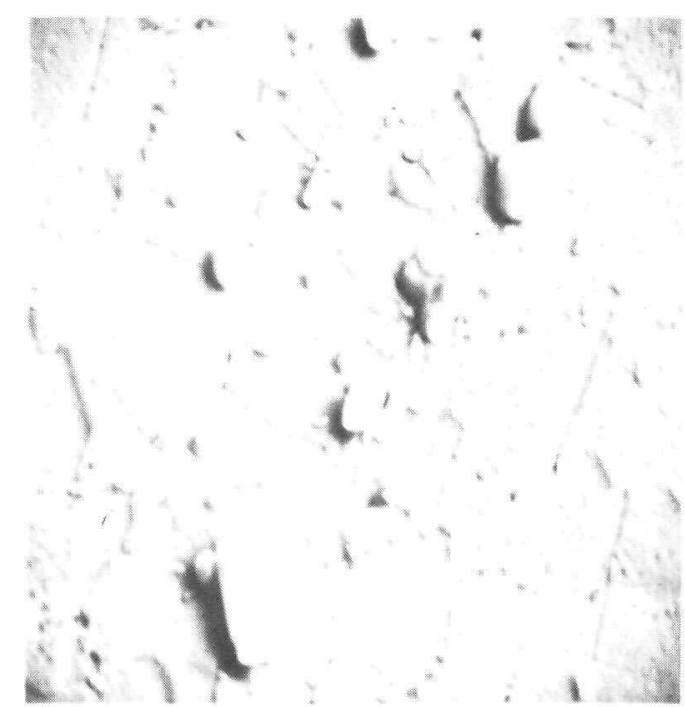

(e)

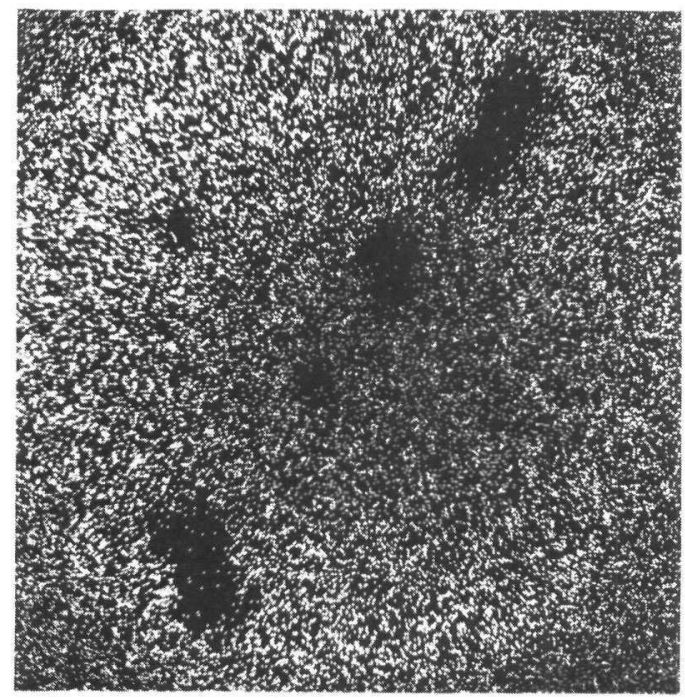

(g)

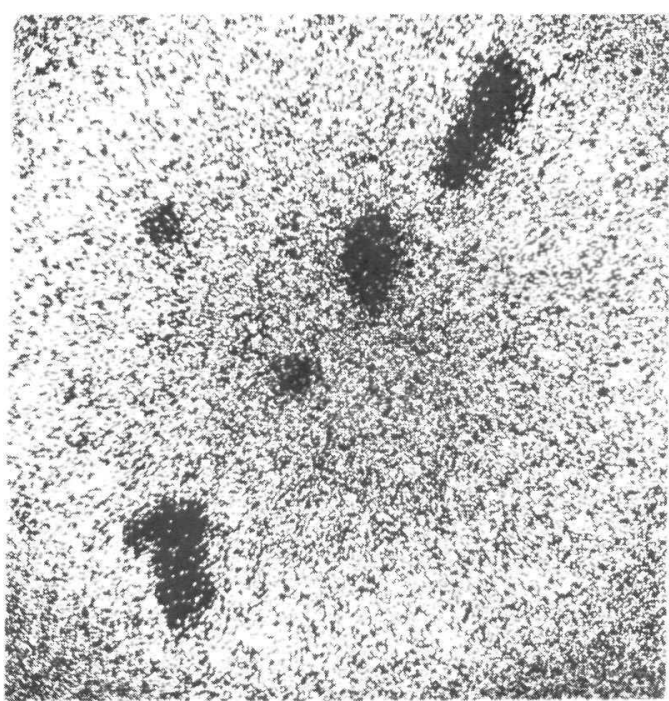

( $f$ )

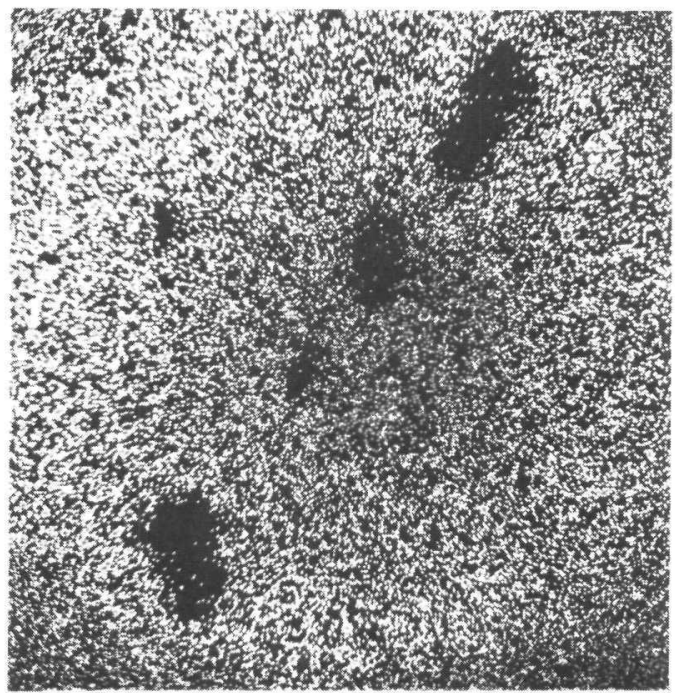

(h)

Figure A-1 (cont'd) "Conventionally" precipitation treated Heat A.

(e) Scanning electron micrograph revealing coarse carbide particles. (Same as Figure A-1 a.)

(f) Elemental distribution micrograph obtained from the nickel $K_{\alpha} X$-rays.

(g) Elemental distribution micrograph obtained from the iron $K_{\alpha} X$-rays.

(h) Elemental distribution micrograph obtained from the chromium $K_{\alpha} \mathrm{X}$-rays. 


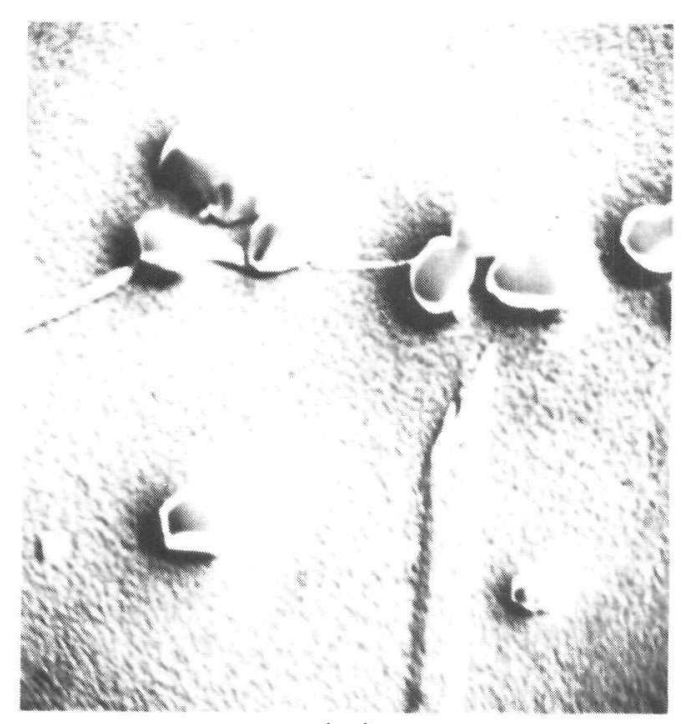

(a)

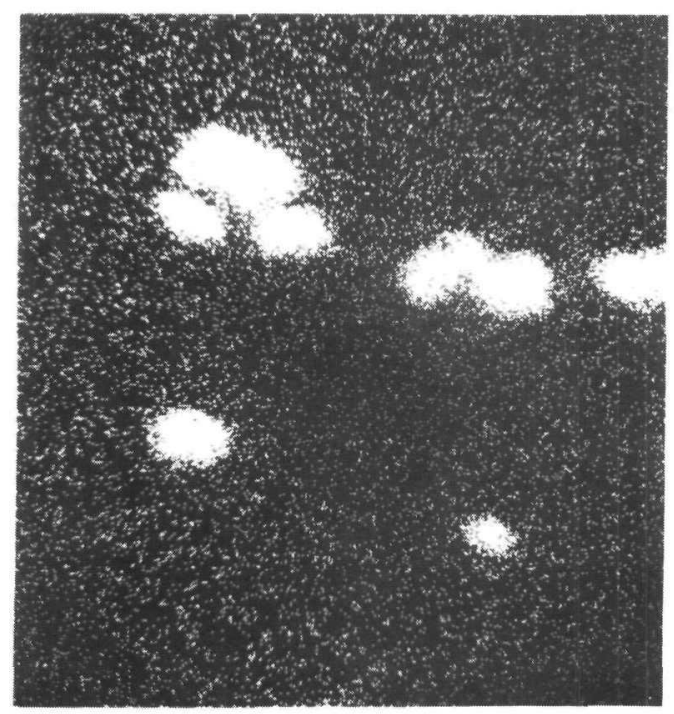

(c)

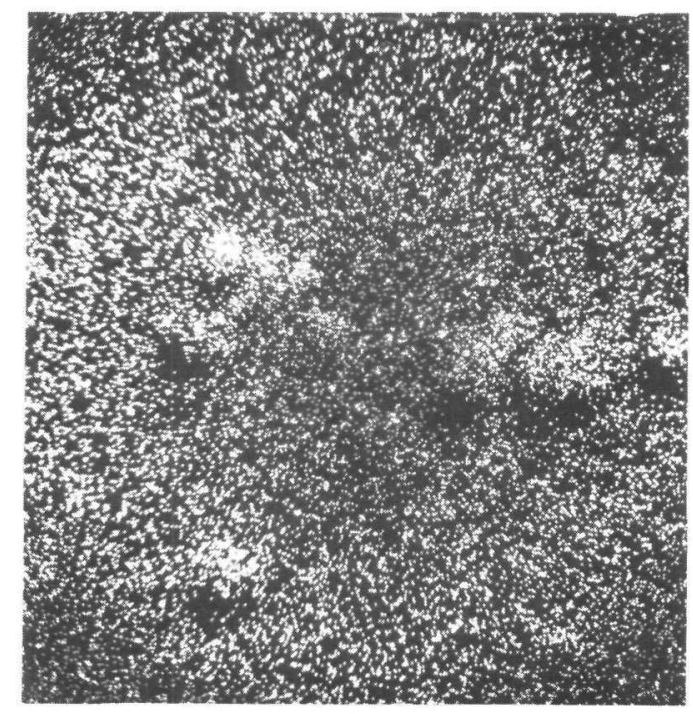

(b)

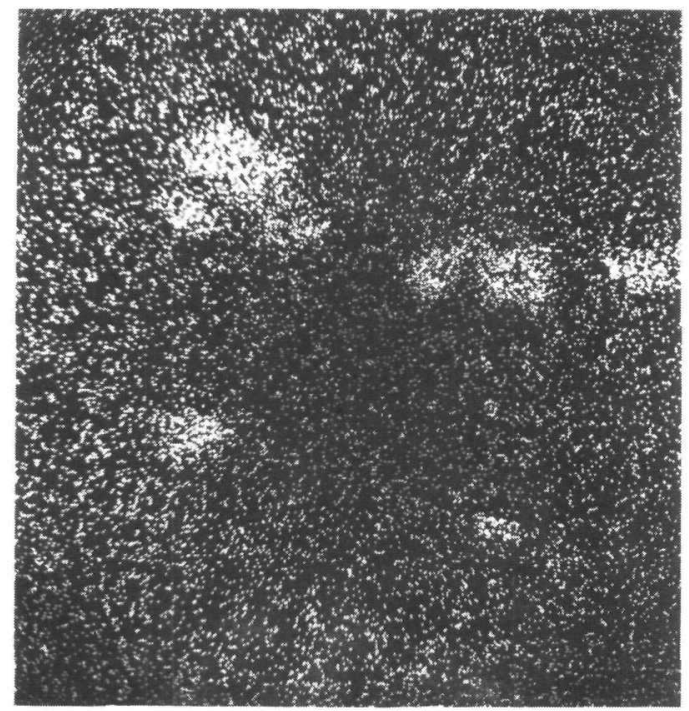

(d)

Figure A-2 "Modified" precipitation treated Heat A.

(a) Scanning electron micrograph revealing coarse carbide particles.

(b) Elemental distribution micrograph obtained from the carbon $\mathrm{K} \alpha \mathrm{X}$-rays.

(c) Elemental distribution micrograph obtained from the niobium $L \alpha X$-rays.

(d) Elemental distribution micrograph obtained from the titanium $K_{\alpha} \mathrm{X}$-rays. 


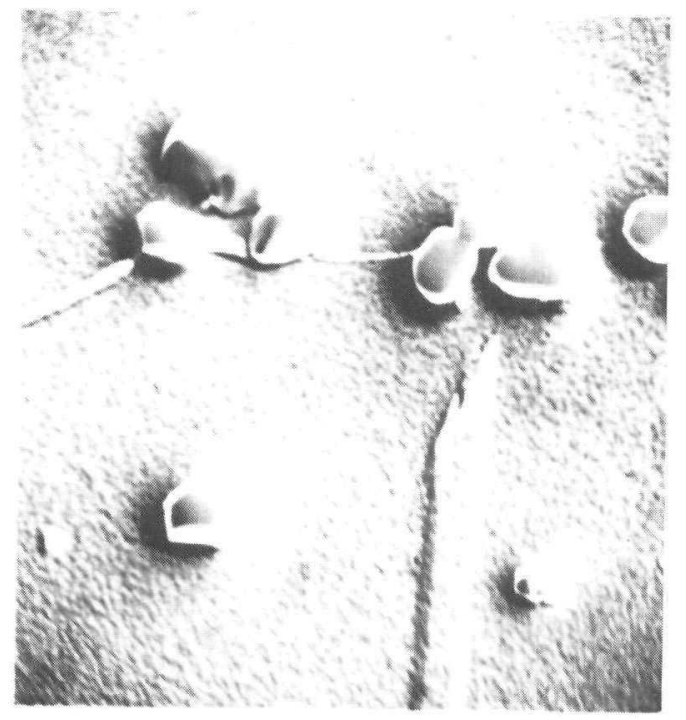

(e)

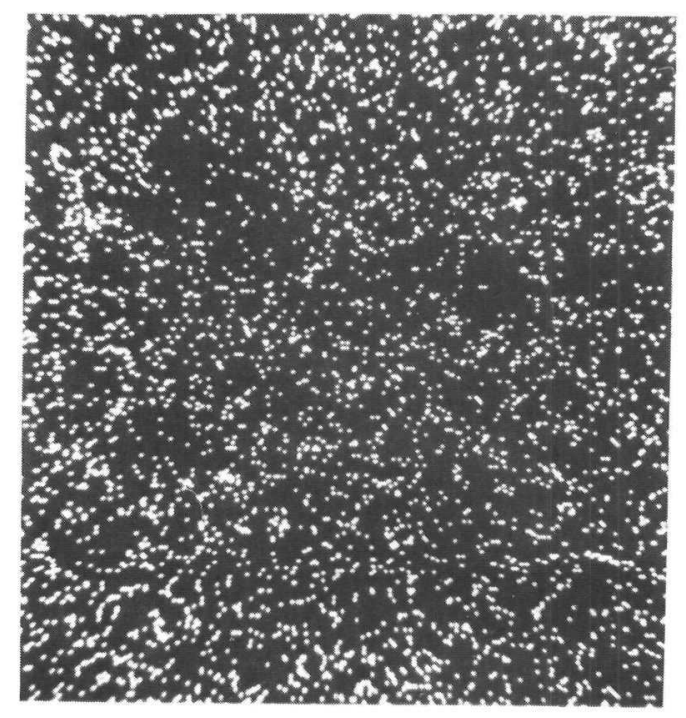

(g)

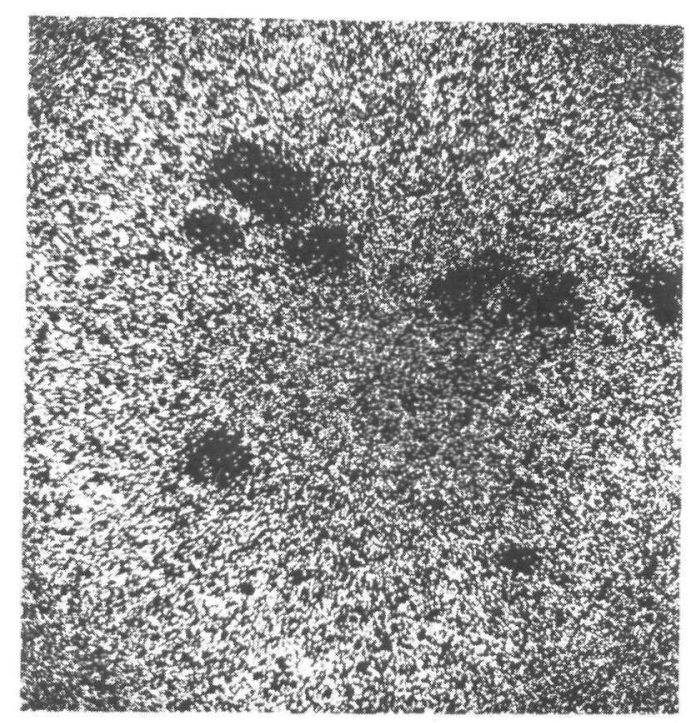

( f)

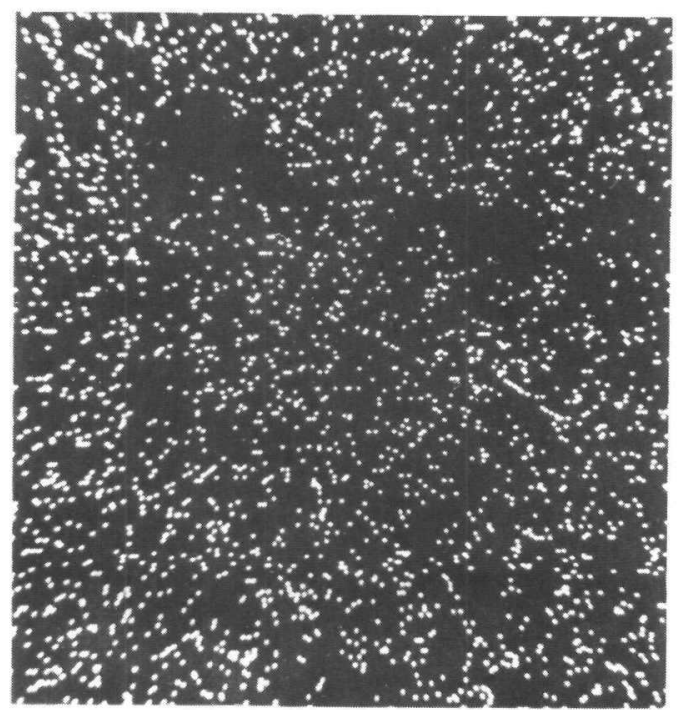

(h)

Figure A-2 (cont'd) "Modified" precipitation treated Heat A.

(e) Scanning electron micrograph revealing coarse carbide particles. (Same as Figure A-2 a.)

(f) Elemental distribution micrograph obtained from the nickel $K_{\alpha} X$-rays.

(g) Elemental distribution micrograph obtained from the iron $K \alpha$ X-rays.

(h) Elemental distribution micrograph obtained from the chromium $\mathrm{K} \alpha \mathrm{X}$-rays. 


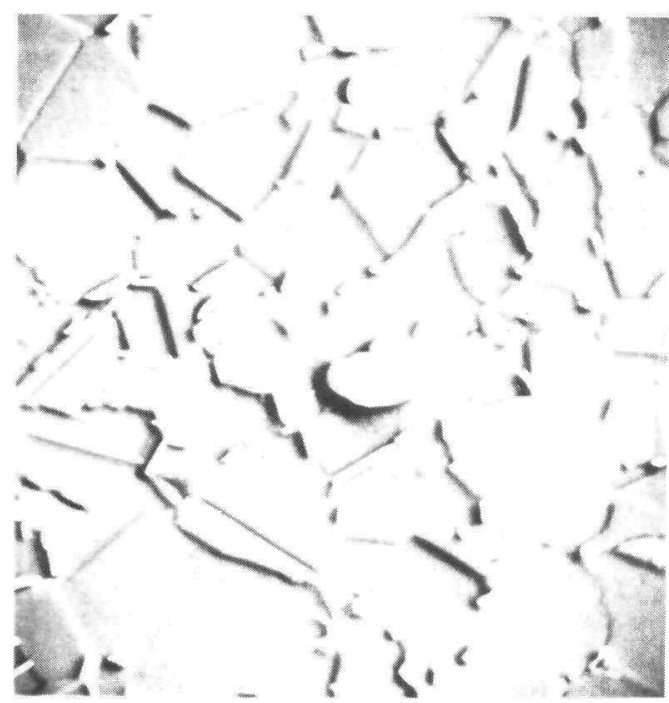

(a)

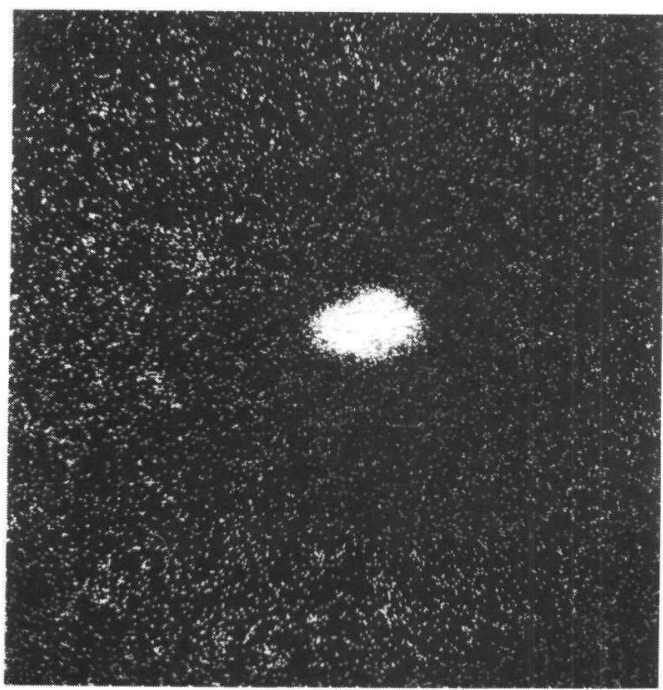

(c)

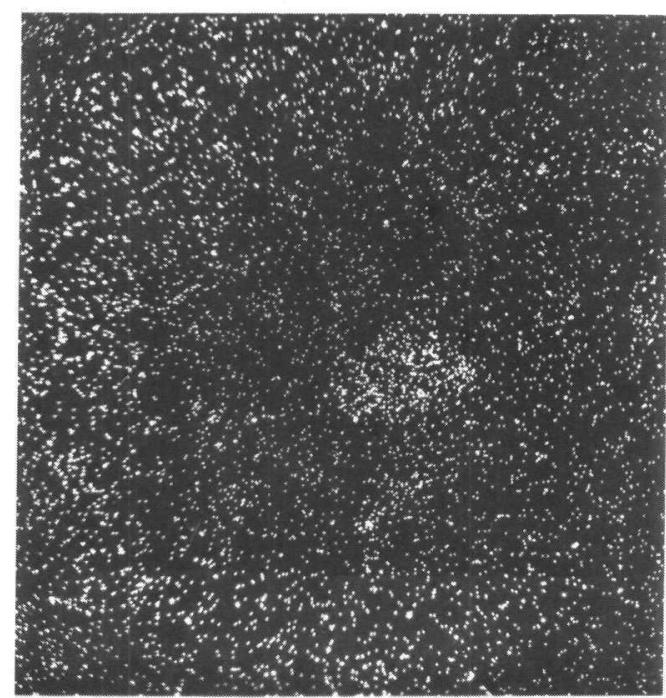

(b)

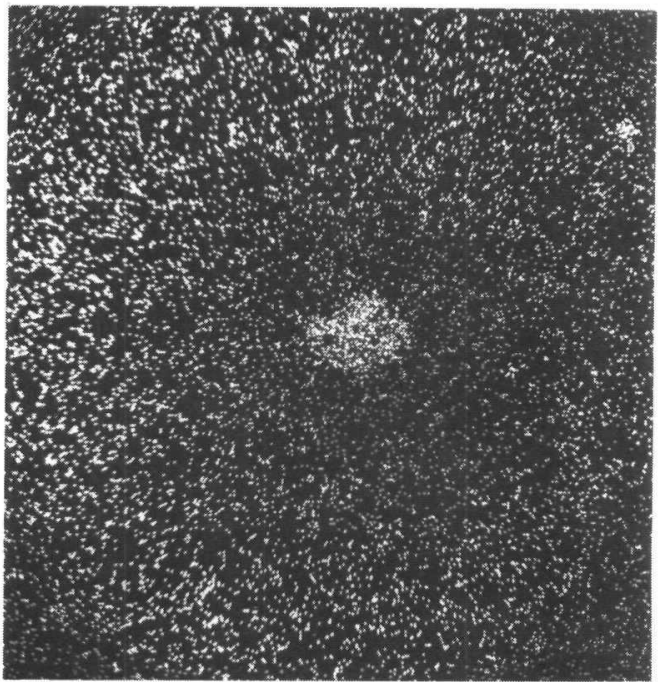

(d)

Figure A-3 "Conventiona11y" precipitation treated Heat C.

(a) Scanning electron micrograph revealing a coarse carbide particle.

(b) Elemental distribution micrograph obtained from the carbon $K_{\alpha} X$-rays.

(c) Elemental distribution micrograph obtained from the niobium $L_{\alpha} X$-rays.

(d) Elemental distribution micrograph obtained from the titanium $K_{\alpha} X$-rays. 


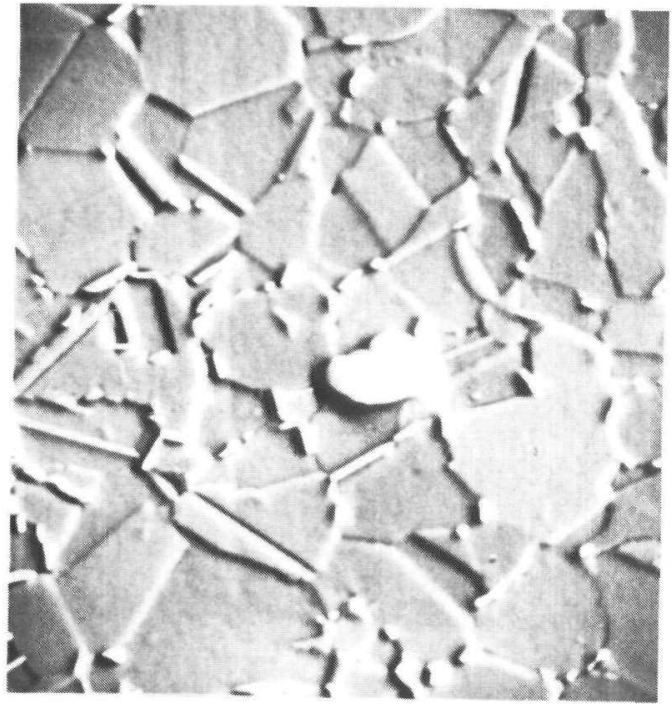

(e)

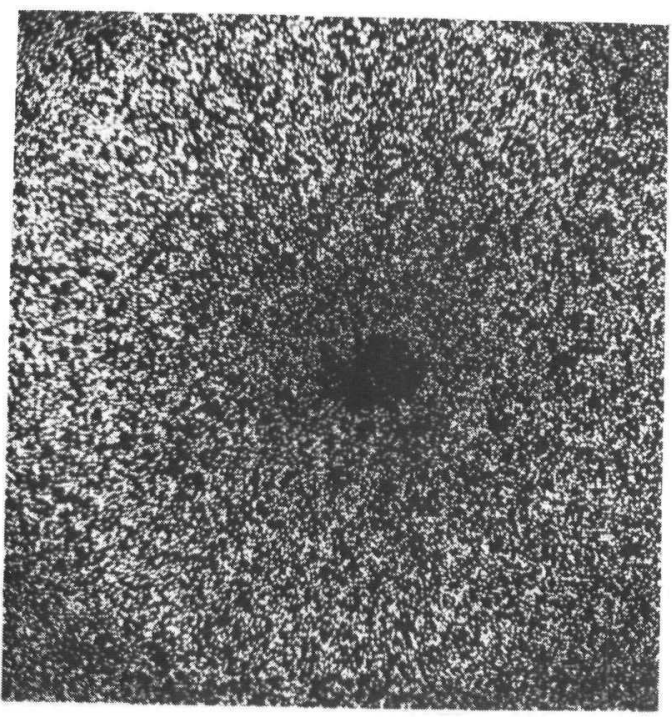

(g)

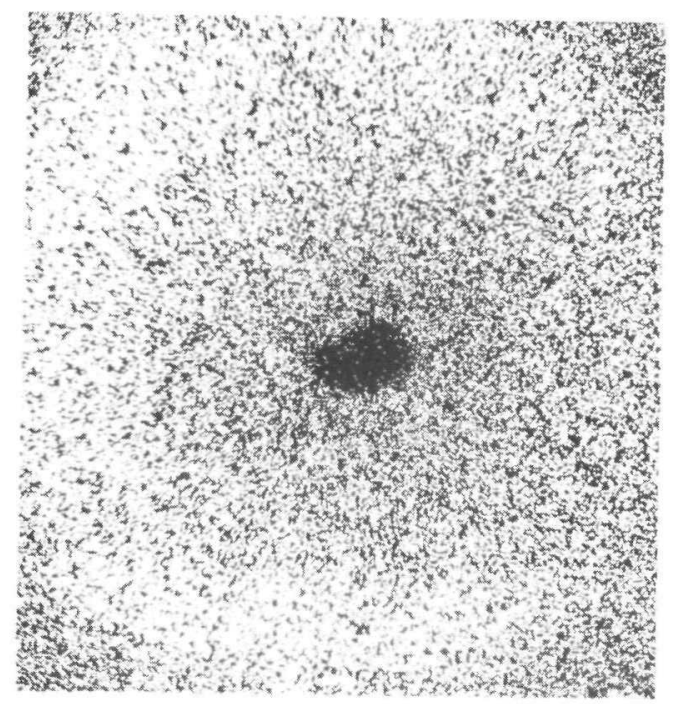

(f)

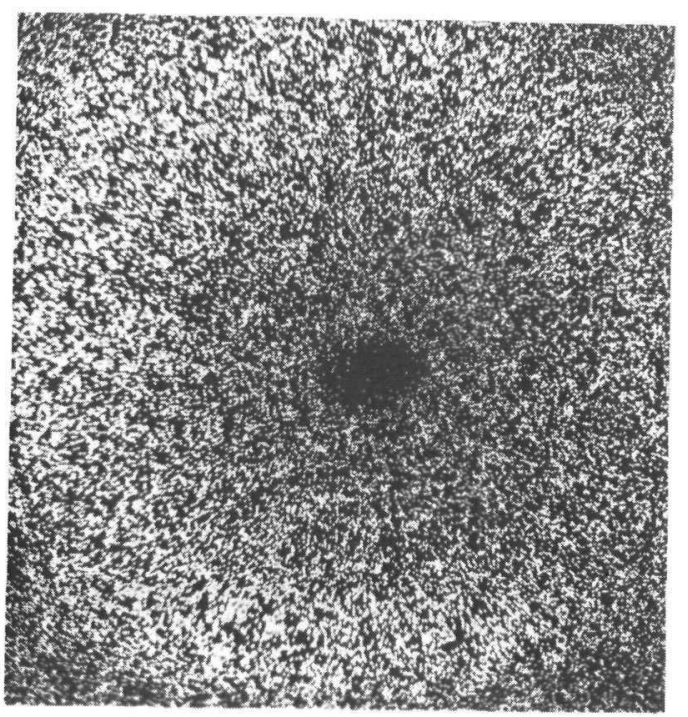

(h)

Figure A-3 (cont'd) "Conventionally" precipitation treated Heat C.

(e) Scanning electron micrograph revealing a coarse carbide particle. (Same as Figure A-3 a.)

(f) Elemental distribution micrograph obtained from the nickel $\mathrm{Ka} X$-rays.

(g) Elemental distribution micrograph obtained from the iron $\mathrm{Ka}$ X-rays.

(h) Elemental distribution micrograph obtained from the chromium $\mathrm{K} \alpha \mathrm{X}$-rays. 
HEDL-TME 78-54

UC-79 b, h

\section{DISTRIBUTION}

UC-79 Basic (206)

UC-79b (25)

UC-79h (31)

DOE/RRT-HQ (3)

Director of Program Division

E. E. Hoffman

A. Van Echo

DOE/FFTFPO (5)

Director

DOE/RL

Chief Patent Attorney

HEDL (51)

$\begin{array}{ll}\text { R. G. Bentley } & \text { W/A-40 } \\ \text { T. K. Bierlein } & \text { W/A-50 } \\ \text { L. D. Blackburn } & \text { W/A-40 } \\ \text { H. R. Brager } & \text { W/A-57 } \\ \text { K. W. Carlson } & \text { W/A-40 } \\ \text { B. A. Chin } & \text { W/A-58 } \\ \text { T. T. Claudson } & \text { W/C-16 } \\ \text { D. J. Criswell } & \text { W/A-40 } \\ \text { A. L. Dittmer } & \text { W/A-40 } \\ \text { E. A. Evans } & \text { W/JAD } \\ \text { R. L. Fish } & \text { W/A-40 } \\ \text { F. A. Garner } & \text { W/A-57 } \\ \text { D. S. Gelles } & \text { W/A-57 } \\ \text { E. R. Gilbert } & \text { W/A-58 } \\ \text { G. L. Guthrie } & \text { W/C-39 } \\ \text { J. J. Holmes } & \text { W/A-58 } \\ \text { W. L. Hu } & \text { W/A-53 } \\ \text { F. F. Huang } & \text { W/A-53 } \\ \text { C. W. Hunter } & \text { W/A-53 } \\ \text { J. A. James } & \text { W/A-40 }\end{array}$

M. D. Jones

$W / A-40$

R. L. Knecht

W/A-40

G. C. Massie

$W / A-40$

B. Mastel

M. N. Menon

W/A-60

$W / A-40$

D. Mervyn

W. J. Mills (2)

R. E. Nygren

W/A-58

$W / A-40$

$W / A-58$

E. K. Opperman

$W / A-58$

M. M. Paxton

$W / A-58$

J. L. Straalsund

$W / A-58$

W. D. Themar

$W / A-40$

L. E. Thomas

$W / A-57$

A. L. Ward

J. A. Williams

G. L. Wire

$W / A-40$

W/A-40

$W / A-53$

W.J.S. Yang

H. H. Yoshikawa

Central Records and Files (10)

W/A-57

$W / A-62$

Publications Services (2)

$W / C-110$

$W / C-115$ 